\title{
Development of a Graphical User Interface Presenting Turbulent Airflow Over A Flight-Deck For Improved Situational Awareness For Helicopter Pilots in Challenging Wind Conditions
}

\author{
By \\ Diane Hould
}

\begin{abstract}
A thesis submitted to
The Faculty of Graduate Studies and Research

In partial fulfilment of

The degree requirements of

Masters of Applied Science

Ottawa-Carleton Institute for

Human Computer Interaction

Human Computer Interaction

Carleton University

Ottawa, Ontario, Canada
\end{abstract}


June 2015

Copyright (C)

2015 - Diane Hould 
The undersigned recommend to

The Faculty of Graduate Studies and Research

Acceptance of the Thesis

\title{
Development of a Graphical User Interface Presenting Turbulent Airflow Over A Flight-Deck For Improved Situational Awareness For Helicopter Pilots in Problematic Wind Conditions
}

\author{
Submitted by Diane Hould \\ In partial fulfilment of the requirements for the degree of \\ Masters of Applied Science
}

Professor Anthony Whitehead, Thesis Supervisor

Anthony Whitehead, Chair, Human Computer Interaction

Carleton University

2015

iii 


\section{Abstract}

The intent of this study is to provide the helicopter operators a presentation of the airflow over the flight deck prior to the approach Phase Of Flight (POF). This capability has the potential to influence the decision making associated with the approach.

Turbulent airflow visualization designs were created focusing on user centered design principles and usability heuristics. The designs were presented to experienced helicopter pilots and subjectively evaluated by the same pilots.

Based on the evaluation results, a dynamic three dimensional (3D) design was selected for development of a Shear-Stress Transport (SST) turbulence model using the Simplifed Frigate Shape 2 (SFS11) geometry. The three dimensional model was created and is used for further testing in a simulator where quantitative results are obtained.

The findings show that not only interest exists within the helicopter pilot community for a capability to have identified where hazardous airflow is located over the flight deck but a more in-depth awareness of what the airflow is doing is desired. 
This page intentionally left blank 


\section{Acknowledgements}

This study is the work of the author, Diane Hould.

"Without change there is no innovation, creativity or incentive for improvement.

Those who initiate change will have a better opportunity to manage the change that is inevitable"

C. William Pollard 1828-1893 


\section{Table of Contents}

Abstract $\quad$ iv

Acknowledgements $\quad$ vi

Table of Contents vii

List of Tables $\quad$ xi

List of Figures $\quad$ xii

Nomenclature $\quad$ xiv

1 Introduction $\quad 1.16$

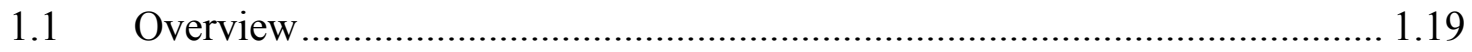

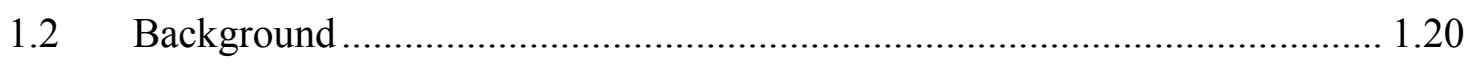

1.2.1 Helicopter Search and Rescue (SAR) Operations .............................. 1.20

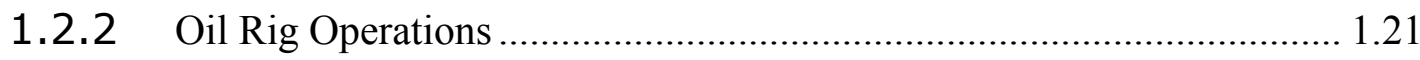

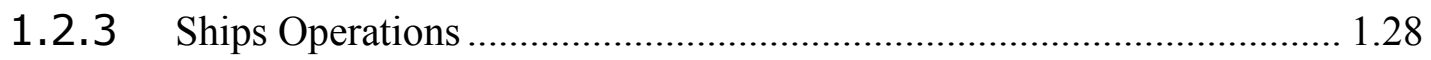

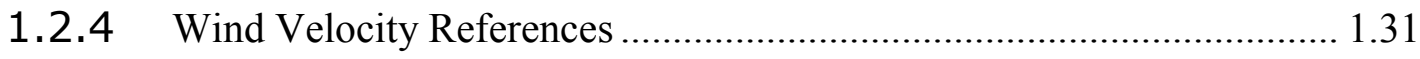

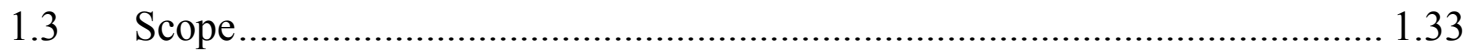

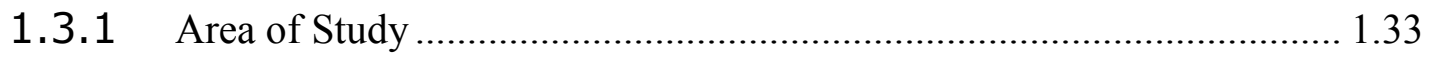

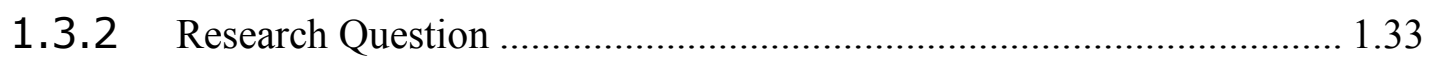

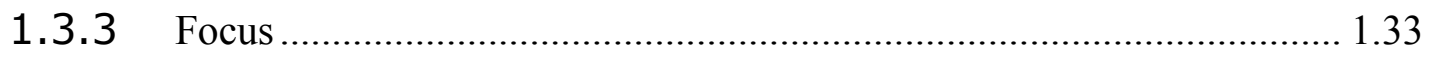

$2 \quad$ Literature Review Summary $\quad$ 2-35

2.1 What is in Place Today .......................................................................... 2-35

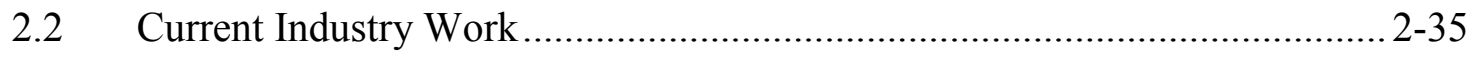


$4 \quad$ System Analysis $\quad \mathbf{4 - 4 0}$

4.1 Current Procedures............................................................................. 4-40

4.2 Operational Requirements ................................................................ 4-42

4.3 Critical Location for Turbulence Requirements ............................................ 4-43

4.4 Turbulence Requirements ....................................................................... 4-45

4.5 Turbulence Type Requirements ................................................................ 4 -45

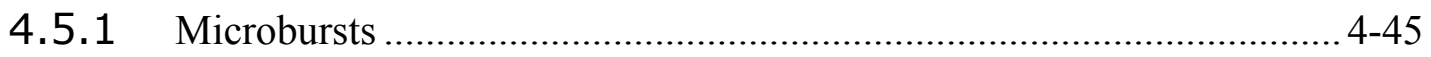

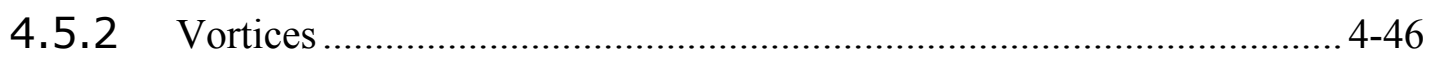

4.5.3 Low Level Windshear....................................................................... 4-47

4.6 High Relative Wind Requirements ....................................................... 4-47

4.7 Turbulence Display Requirements Summary ……………............................ 4-47

5 Design $\quad 5-49$

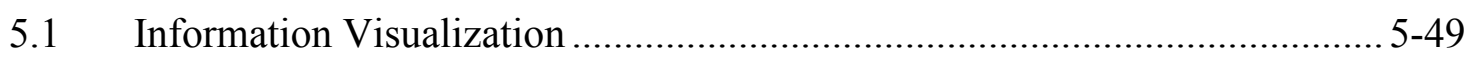

5.1.1 Design A - Aragon ..................................................................... 5-50

5.1.2 Design B - Industry Direction ...................................................... 5-50

5.1.3 Design C and D - Traditional Airflow …………………………...... 5-50

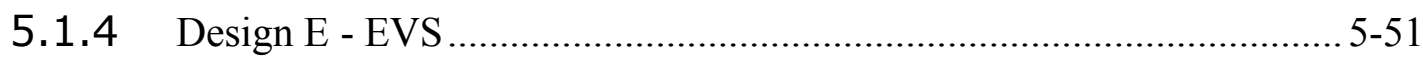

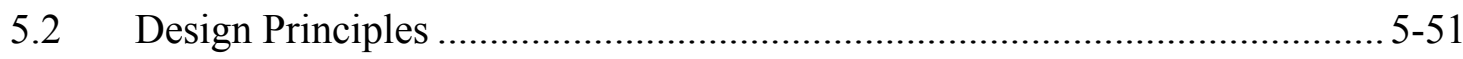

5.2.1 Design Principle: Autonomy .......................................................... 5-52

5.2.2 Design Principle: Consistency …………………………………..... 5-52

5.2.3 Design Principle: Explorable Interfaces …………………………..... 5-53

5.2.4 Design Principle: Metaphors............................................................ 5-53

5.3 Usability Heuristics......................................................................... 5-53

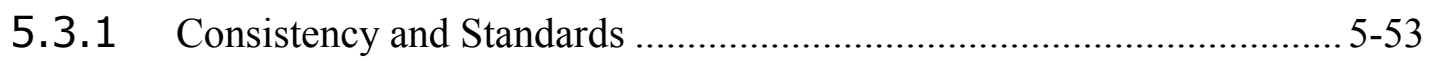

5.3.2 Recognition Rather Than Recall ..................................................... 5-54

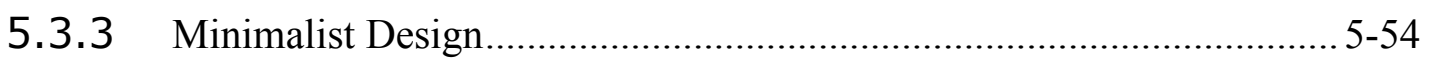




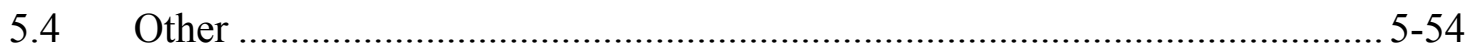

5.4.1 Confidence and Perceived Reliability.................................................. 5-54

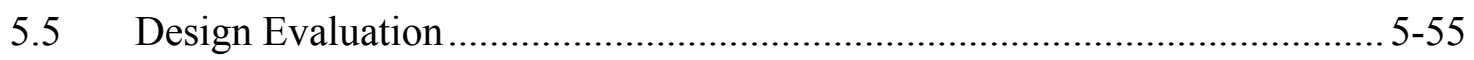

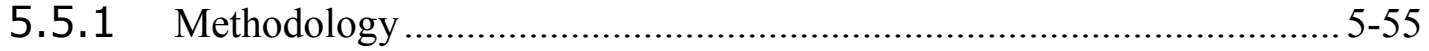

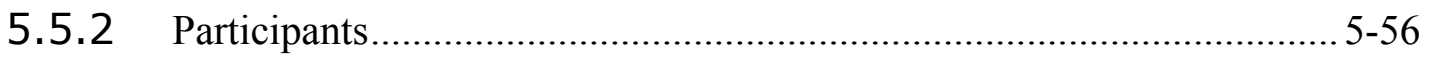

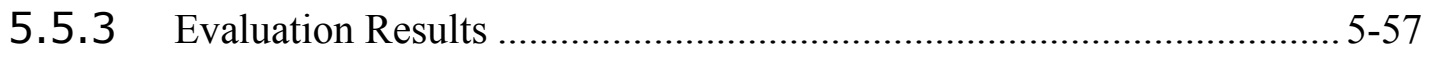

6 Verification 6-67

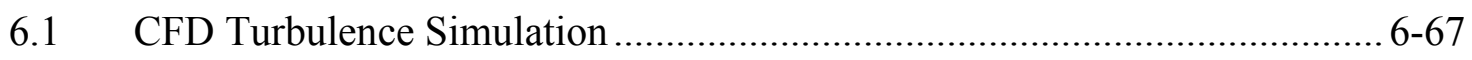

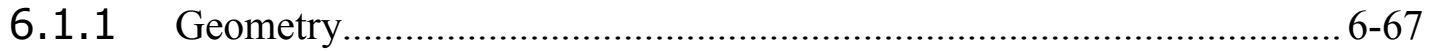

6.1.2 Boundary/Initial Conditions.............................................................. 6-70

6.1.3 Turbulence Model........................................................................... 6-70

6.1.4 Turbulence Model Results ................................................................ 6-73

6.2 Turbulence Visualization Model Evaluation ................................................ 6-76

$\begin{array}{lll}7 & \text { Conclusion and Continued Work } & \text { 7-77 }\end{array}$

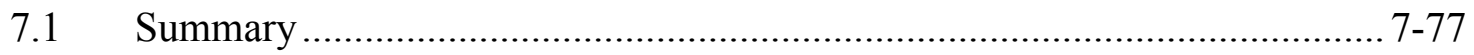

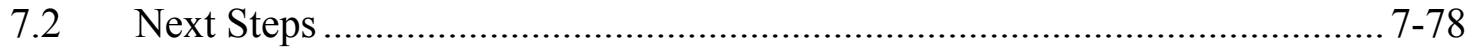

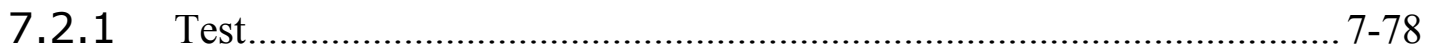

7.2.1 Evaluate Performance .................................................................. 7-80

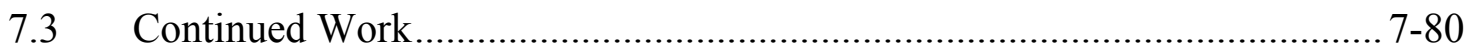

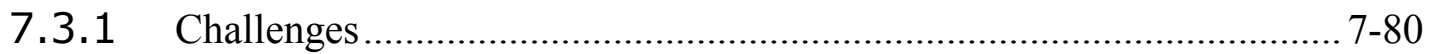

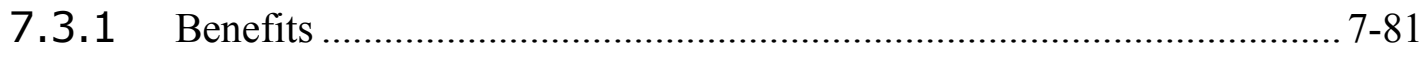

8 References $\quad 8-83$

Appendix A - Turbulence Visualization Evaluation $\quad$ A.0

A. Design Principles and Usability Heuristic Evaluation Instructions A.3

$\begin{array}{lll}\text { B. Part I Demographics } & \text { A.4 }\end{array}$

$\begin{array}{ll}\text { C. Part II - Information Requirements A.5 } & \text { A }\end{array}$ 
C.1. Information Required / Relative Wind - Speed Component ......................... A.6

C.2. Information Required / Relative Wind - Azimuth ....................................... A.7

C.3. Information Required / SHOPS ............................................................. A.8

C.4. Information Required / True Wind ......................................................... A.9

$\begin{array}{lll}\text { D. Part III - Design } & \text { A.10 }\end{array}$

D.1. Design A (Red areas indicating hazardous airflow) ................................... A.11

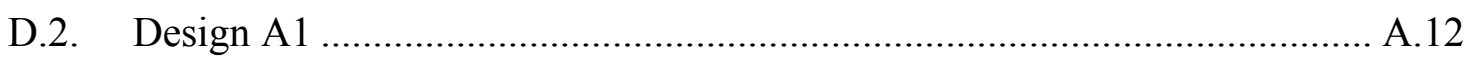

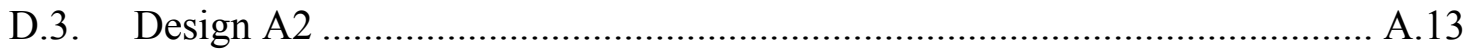

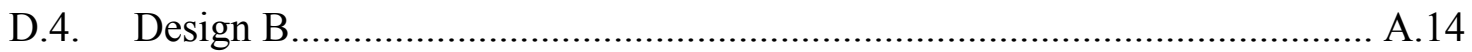

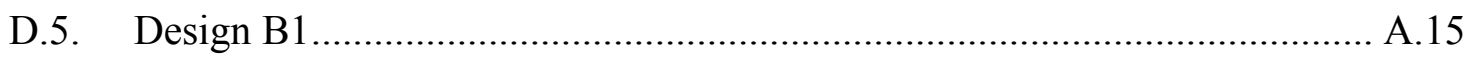

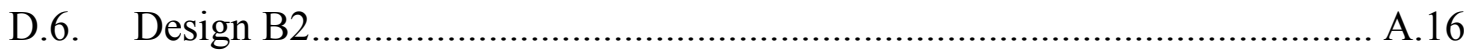

D.7. Design C (Red velocity vectors indicating hazardous airflow area and direction) A. 17

D.8. Design C1 (Velocity vectors of airflow over simplified oil rig).................. A.18

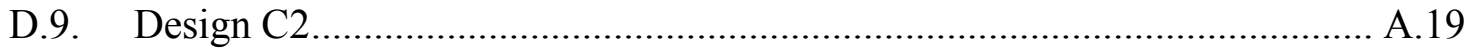

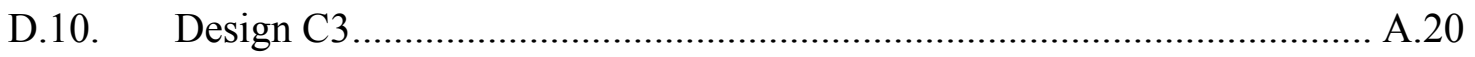

D.11. Design D (Other e.g. Hazard Types) ...................................................... A. 21

$\begin{array}{lll}\text { E. Part IV - Perspective } & \text { A.22 }\end{array}$

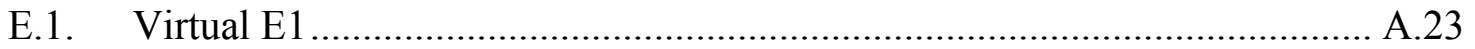

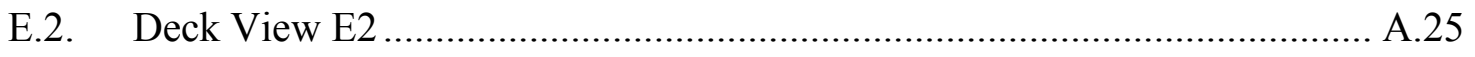

$\begin{array}{lll}\text { F. Part V - General } & \text { A.27 }\end{array}$

$\begin{array}{lll}\text { G. Part VI - Art Critics } & \text { A.29 }\end{array}$

Appendix B - Ground School Flight Deck Turbulence Visualization $\quad$ B.0 


\section{List of Tables}

Table 1.1: Table of Visual Wind Velocity References (Offshore and Onshore) ........... 1.32

Table 4.1: Summary Table of Display of Turbulent Airflow Requirements................ 4-48

Table 5.1: Design Evaluation Participant Profiles table............................................ 5-57

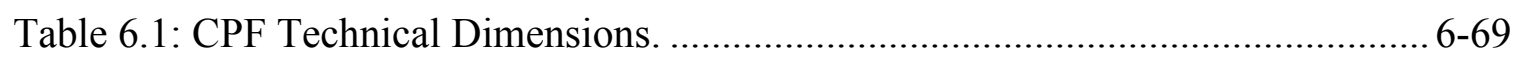

Table 6.2: Boundary/Initial Conditions. ................................................................. 6-70

Table 6.3: Table of Mesh Statistics for SFS 11 3D Model.......................................... 6-71 


\section{List of Figures}

Figure 1-1: Commercial Aircraft Accidents Over Time Graph...................................... 1.17

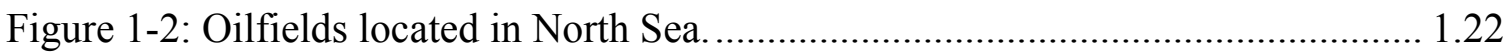

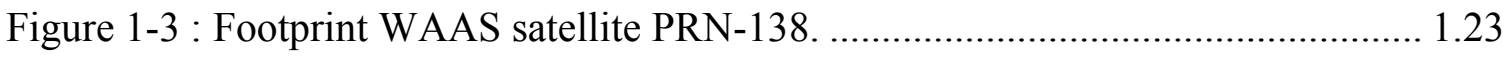

Figure 1-4: Offshore Oil Rig Visible Environment Effect .......................................... 1.24

Figure 1-5 Oil Rig Helideck With and Without Air Gap........................................... 1.26

Figure 1-6 Turbulence Around Helideck from Oil Rig Structure and Exhaust Gases . 1.28

Figure 1-7 Wave Motion Directions ......................................................................... 1.30

Figure 1-8 Wave Motion influence Versus Helideck Location .................................... 1.30

Figure 2-1 Prototype Images of Wake Turbulence and the Corresponding Wake Height

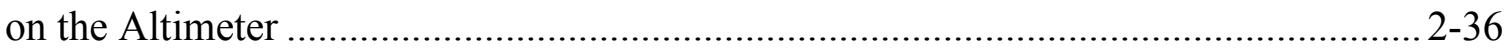

Figure 2-2 Honeywell Aerospace Display of Turbulence Detection on the Weather Radar

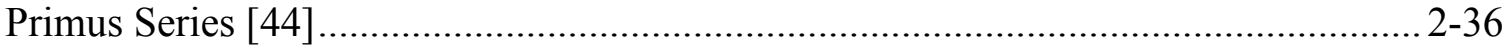

Figure 2-3 Rockwell Collins Display of Turbulence Detection on the Weather Radar [45]

Figure 2-4 DRDC Flight Deck Motion System Display for the LSO........................... 2-38

Figure 4-1 Helicopter Relative Wind Operational Envelope Example ........................... 4-41

Figure 4-2 Helicopter Approach Path to Ship (Pilot Flying) .......................................... 4-44

Figure 4-3 Turbulence Critical Area on Frigate ....................................................... 4-44

Figure 5-1 Preferred Technology versus Number of Participants ................................. 5-62

Figure 5-2 Preferred Design versus Number of Participants ........................................ 5-63

Figure 5-3 Usefulness of Knowledge of Turbulence Type versus Number of Participants

Figure 5-4 Usability of Information versus Number of Participants ............................ 5-66

Figure 6-1 3-Dimensional Model of the Canadian Patrol Frigate (CPF) [57] .............. 6-68

Figure 6-2 Simplified Frigate Shape (SFS2) Geometry …………………………..... 6-69 
Figure 6-3 Simplified Frigate Shape (SFS2) Mesh.................................................. 6-71

Figure 6-4 Simplified Frigate Shape (SFS2) within Domain Area ............................. 6-72

Figure 6-5 Simplified Frigate Shape (SFS2) - Airflow ................................................ 6-73

Figure 6-6 Static view of Turbulence Model at $55 \mathrm{KTs}\left(0^{\circ}\right.$ Green) - CFD (ANSYS CFX) 6-74

Figure 6-7 Static view of Turbulence Model at $50 \mathrm{KTs}\left(0^{\circ}\right.$ Green $)$ - SolidWorks ...... 6-74

Figure 6-8 Static view of TacView $\odot$ Display Presenting Turbulence Information ..... 6-76

Figure 7-1 TacView $^{\mathcal{O}}$ Within Test Environment [17].............................................. 7-79

Figure D-1: Design A....................................................................................... A.11

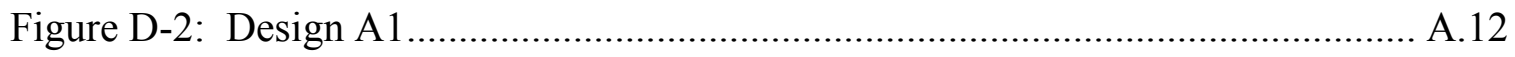

Figure D-3: Design A2 ……………………………….................................... A.13

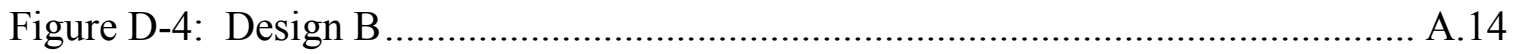

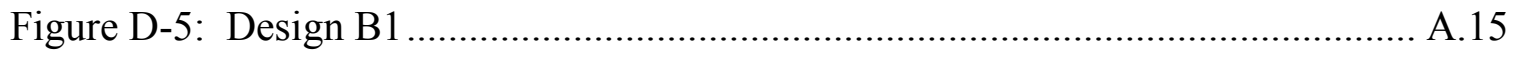

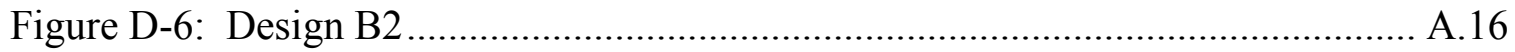

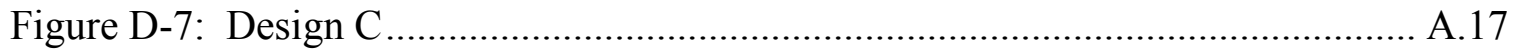

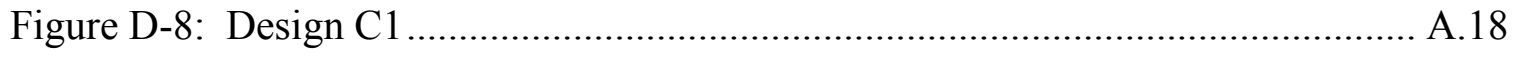

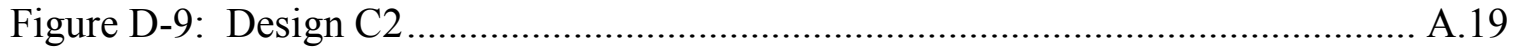

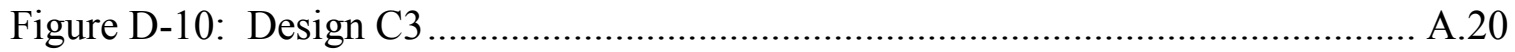

Figure E-1: Design E1 (actual size) ................................................................ A.23

Figure E-2: Design E2 (actual size) ................................................................... A.25 


\section{Nomenclature}

\begin{tabular}{ll} 
ACRONYM & \\
3D & Three Dimensional \\
AC & Advisory Circular \\
ATC & Air Traffic Control \\
CAA & Civil Aviation Authority \\
CFD & Computational Fluid Dynamics \\
CONOPS & Concept of Operations \\
CPF & Canadian Patrol Frigate \\
CPU & Computer Processing Unit \\
DRDC & Defence Research and Development Canada \\
EFB & Electronic Flight Bag \\
EVS & Enhanced Vision System \\
FAA & Federal Aviation Administration \\
FDMS & Flight Deck Motion Study \\
FLIR & Forward Looking Infrared Radiometre \\
FMS & Flight Management System \\
GUI & Graphical User Interface \\
HUD & Heads Up Display \\
ICAO & International Civil Aviation Organization \\
IR & InfraRed \\
KM & Kilometre \\
KT & Knots \\
LCD & Liquid Crystal Display \\
LSO & Landing Safety Officer \\
NASA & National Aeronautics Space Administration \\
NATO & North Atlantic Treaty Organization \\
NM & Nautical Mile \\
MAP & Missed Approach Procedure \\
PFD & Primary Flight Display \\
POF & Phase of Flight \\
SAR & Search and Rescue \\
SFS2 & Simplified Frigate Shape 2 \\
SHOL & Ship Helicopter Operating Limits \\
SHOP & Ship Helicopter Operating Procedures \\
SOP & Standard Operating Procedure \\
SST & Shear Stress Transport \\
& \\
& \\
\hline
\end{tabular}


SVS Synthetic Vision System

TCCA Transport Canada Civil Aviation

TM Technical Memo

TSO Technical Standard Order

WAAS Wide Area Augmentation System 


\section{Introduction}

Within the aviation industry the operator is required to understand the system in order to be able to diagnose the system. This is particularly true when the demand to recover from abnormal system conditions is required. Systems such as those seen in the mobile communications industry, the user does not need to know the system in order to address abnormal system conditions. Failure of systems in the mobile communication industry does not contribute to a catastrophic condition resulting in incidents or accidents as within the aviation industry.

The front cover of the September 5th, 2011 issue of Maclean's magazine has the words, “Can your pilot really fly your plane?". The article makes the statement, "Fifty big crashes in five years have the industry asking if jets have become too complicated to handle in an emergency" [42].

An initial investigation was performed to determine how the number 50 compares with the overall number of accidents over the last five (5) decades [52]. The results showed that we are having fewer commercial accidents. In fact, it appears as if we are in a downward trend for aircraft accidents. Figure 1-1 shows the number of commercial accidents on a downward trend however, the total quantity of flights influence on this data would need to be known to determine and confirm the legitimacy of this claim. A 
key factor on the total number of flights could be the impact that the incidents of $9 / 11^{1}$ had on the commercial air travel industry.

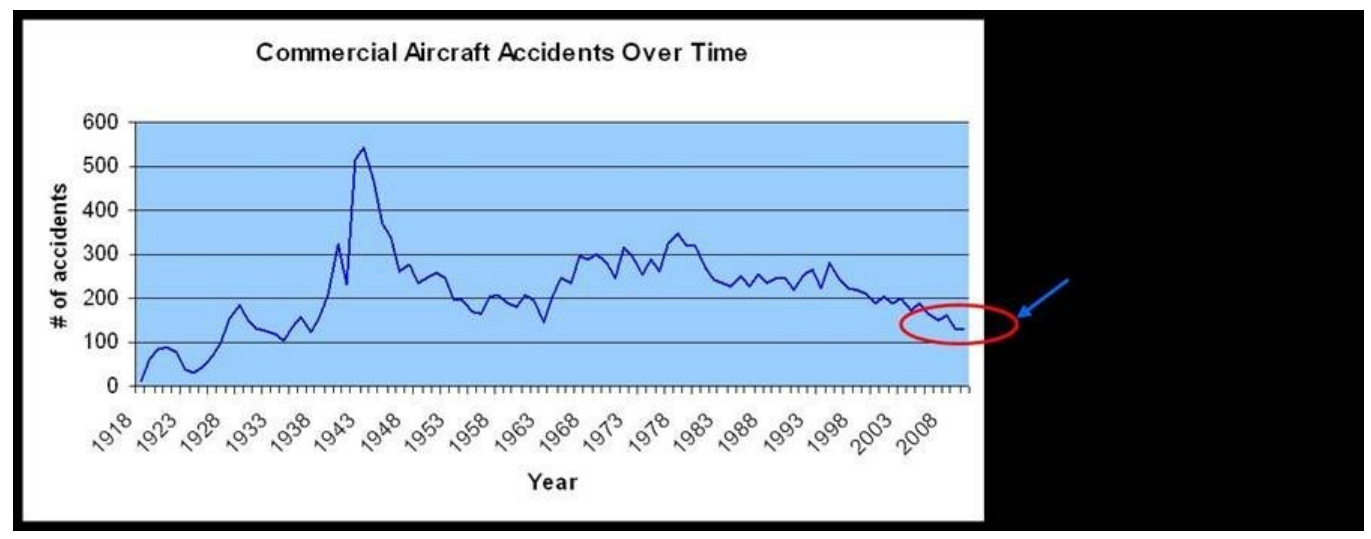

Figure 1-1: Commercial Aircraft Accidents Over Time Graph.

The data also shows that $67 \%$ of the crashes is attributed to pilot error as primary cause and over $50 \%$ of the crashes occur during the critical phases of flight (within ten kilometre $(10 \mathrm{~km})$ of an aerodrome). This data supports Macleans claim of can pilots really fly the plane?

Macleans article states that the feedback the operators are conveying is that they (the operators) have lost control of the airplane. The operators are presented data but do not understand what the system is doing. Further to that point the article states that Boeing determined that loss of control is the single most common cause of fatal aircraft

1 September 2011, referred to as 9/11 is referring to the four hijacked aircraft attacks on US soil including the twin towers of the World Trade Centre in New York city that had an aftermath of reduced commercial air travel within the US and abroad. 
accidents. This number is said to be double the next largest cause of controlled flight into terrain. A key aspect of this study is to map the system information of the real world environment and presenting it in a readily comprehensible format for operator use. 


\subsection{Overview}

Helicopters are versatile and agile aircraft when compared to their fixed-wing counterparts. The rotary wing configuration allows for increased maneuverability in the vertical plane, an advantage over the fixed wing aircraft in confined spaces. By design the wind screen viewing area is larger and the ability of the helicopter to perform a controlled rotation about the centre axis results in the helicopter having greater visibility relative to the fixed wing aircraft. As a result of these capabilities helicopters can perform a diverse set of tasks that include emergency response, search and rescue, tactical missions and transport to name a few. It is because of the helicopter's versatility that allows helicopters to perform operations in environmental conditions and areas that are challenging. The environment challenges are disturbances that influence operator management of flight operations from natural occurrences. Natural occurrences concern weather effects due to wind and water. These two (2) forces of nature can create treacherous conditions that are not suitable for continuing helicopter operations.

The airflow around obstacles and structures creates a turbulence that can be fatal to helicopter operations. These turbulent areas are unpredictable and in most cases not visible to the human eye. An operator can scan the environment for signs of turbulent effects on vegetation or flags for example, however, in poor visibility conditions or where vegetation is not apparent, a helicopter operator may not be able to determine the turbulent hazardous areas, nor the magnitude of the hazard.

Statistical data showed that one third (1/3) of the incidents and accidents associated with approach and landing between 1984 and 1997 had wind conditions as a contributing 
factor $[13]^{2}$. It was determined that operator awareness is a key factor in windshear (sudden change in wind speed and direction) avoidance [14]. This unpredictable airflow became such a concern to industry and regulatory bodies (Government organizations such as Transport Canada Civil Aviation (TCCA) and Federal Aviation Administration (FAA) verifying and monitoring compliance to standards and regulations) because of the growing increase in accidents and incidents where turbulent air was a factor. Industry has since developed a windshear detection and alerting system and the Federal Aviation Administration (FAA) mandated [6] [13] that all commercial fixed wing aircraft are equipped with a functional forward looking windshear detection and alerting system. The FAA has also incorporated ground based windshear detection systems at aerodromes. Windshear is defined as the abrupt change in wind speed and/or wind direction. To date there is no equivalent FAA mandate for helicopter operations.

\subsection{Background}

\subsubsection{Helicopter Search and Rescue (SAR) Operations}

SAR helicopter operators are subject to unpredictable airflow conditions when performing operations. It is unpredictable because the destination of the site for the rescue cannot be predicted until there is a demand for a rescue. In these situations the resulting airflow, particularly in and around mountain cliffs, cause areas of hazardous turbulence. In some cases the resulting conditions are extreme that the operations are aborted. These conditions require an experienced helicopter operator and the incremental

\footnotetext{
${ }^{2}$ Helicopter accidents were not considered and excluded from the study.
} 
approach method is used to approach the landing area. Ideally if the operator had a visual representation of the turbulent areas in and around the mountain cliff, avoidance would be incorporated.

\subsubsection{Oil Rig Operations}

Helicopters, during the departure and approach phase of flight fly fixed wing procedures where in some cases favorable considerations are made for the helicopters or they fly helicopter only procedures know as COPTER procedures. Companies such as Jeppesen publish approach and departure procedures in accordance with the standards defined by ICAO (International Civil Aviation Organization). These certified procedures are usually packed into a Navigation database that accompanies all aircraft as a requirement for certificate of airworthiness [53]. The purpose of having these procedures already defined, loaded and available is to reduce operator workload during the critical and demanding phases of flight.

The scope of this paper is limited to approach procedures only. The standards and recommended practices that form the land based approach model that is used as a basis for the development of approach procedures is to provide the operator an approach environment that is obstacle free with a fixed destination. These standards and recommended practices are not directly transferable to offshore approaches because offshore operations are typically in an obstacle rich environment with a moving destination. In short, offshore helicopter approaches based on the land based approach model are challenging when considering certification by regulating bodies for use.

In addition to the limitations of the land based approach model, there are other limitations that although not further explored in this paper are worth mentioning. A typical offshore approach procedure is the approach procedure for offshore oil rigs. One 
of the difficulties in developing offshore approaches for oil rigs is where the offshore oil rig is located. A significant quantity of oil rigs are located north of the $58^{\circ}$ latitude. Figure 1-2 shows the distribution of oilfields located in the North Sea [54]. Satellite availability in this region is low because the angle of elevation is low, limiting the available alternatives for the development of improved instrument precision approach procedures.

Figure 1-3 shows Wide Area Augmentation System (WAAS) availability distribution, as the latitude moves north the availability decreases ${ }^{3}$ [56]. For drilling operations off of the coast of Grand Banks, Newfoundland, only one satellite is visible and that is the PRN-138. As seen in Figure 1-3 the availability of this satellite reception at the $13^{\circ}$ elevation is low, not enough to meet the required integrity for offshore operations.

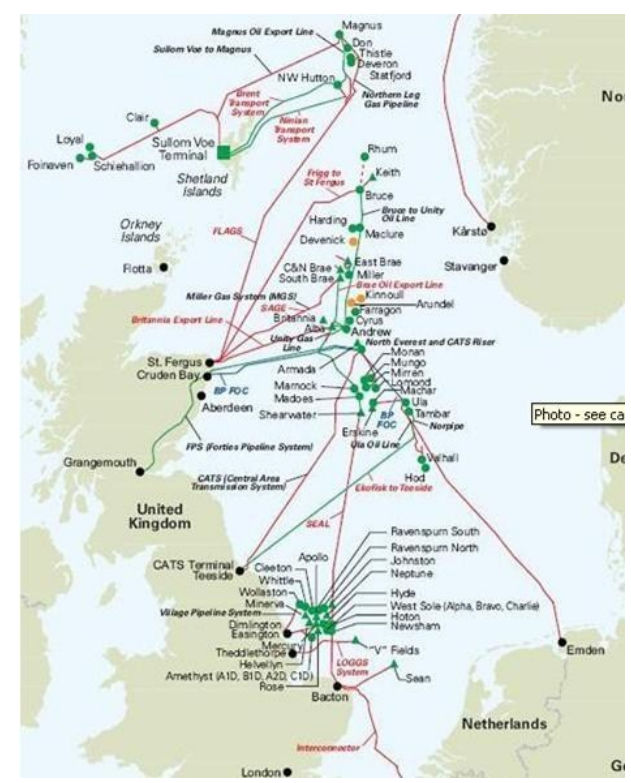

Figure 1-2: Oilfields located in North Sea.

3 TELESAT/107W visible at about 13 elevation (south west direction). 


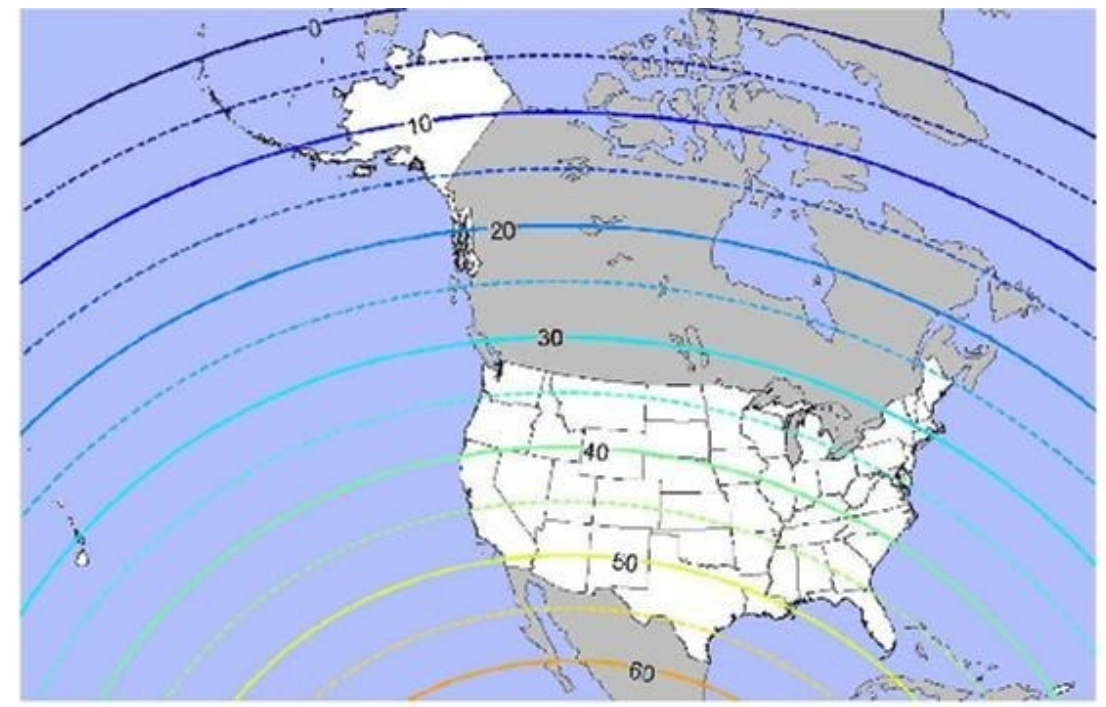

Figure 1-3 : Footprint WAAS satellite PRN-138.

Another limitation worth mentioning for offshore approaches is the airspace category the offshore oil rigs reside. Typically the offshore oil rigs are located in uncontrolled airspace relative to the controlled airspace surrounding land based airports. Uncontrolled airspace has additional restrictions on operations, in the form of limitations. The uncontrolled airspace does not have the Air Traffic Control (ATC) support as in controlled airspace where traffic and clearance is provided.

Offshore oil rig helidecks are exposed and sensitive to aerodynamic effects and wave motion effects, both of these effects contribute to the airflow hazards over the helicopter flight path resulting in missed or failed approaches. Figure 1-4 shows a typical environmental condition the offshore oil rigs are subjected to [50]. The visibility requirements may be met however, the high wind conditions could prevent success of an approach. Further investigation would be required to determine what the correlation between high winds and unsuccessful flights. 


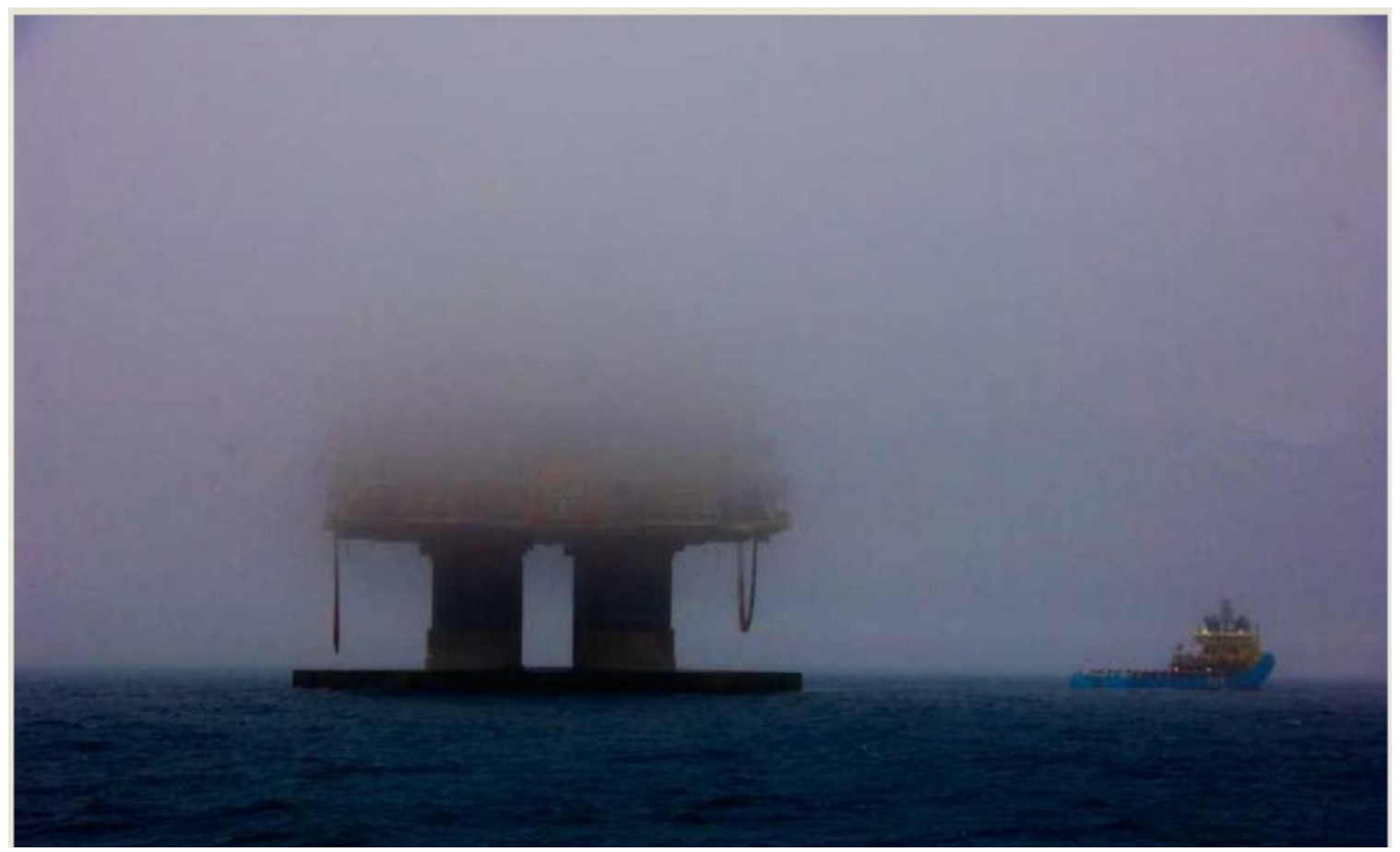

Figure 1-4: Offshore Oil Rig Visible Environment Effect

\subsubsection{Aerodynamic Effects}

Sensitive helicopter airflow hazards near the oil rigs and vessels are in the form of vortices, downdrafts, low level wind shear, microbursts (in some areas) and turbulence resulting from structures and vegetation within the vicinity. The aerodynamic effects of these helicopter airflow hazards are apparent to a degree on all oil platform types. Aerodynamic effects include turbulence caused by the airflow around the oil rig structure and a non-streamlined oil platform.

A fully clad drilling derrick will generate a significant wake. When the wind direction is such that the helideck is downwind of the drilling derrick, the helicopter may be subject 
to additional operational limits as a result of the obstruction because of turbulence from the oil rig structure. A rule of thumb for the helideck design to ensure dissipation of wake over the helideck is to incorporate a significant distance from the helideck to the clad derrick of a factor of ten (10) linear widths of the clad derrick. Designers consider the installation of the helideck such that the occurrence of the operation limit enforced is in the rare wind direction. The clearance distance can be reduced to a factor of five (5) linear widths for an unclad derrick.

Turbulence over an offshore helideck is contributed by the airflow around the oil rig's structures superstructure (features that sit proud of the structure and further disturb the airflow such as drills and exhaust stacks). Close proximity to exhaust stacks and drilling derricks that sit proud of the helideck will result in turbulence and a downdraft effect when these structures are upwind of the helideck. The design rule of thumb is the same as for the cladded derrick, the linear distance is a minimum of ten (10) linear widths of the obstruction. If these structures are trussed (allowing air flow), the distance can be reduced to five (5) linear widths. Wind tunnel tests on the oil rig will verify these values or suggest modifications.

A direct approach with a $030^{\circ}$ wind direction will produce downdrafts on the inboard and outboard of the helideck edge. A feature inherent to the helideck design. Figure 1-5 shows the oil rig helideck design with an air gap and the increase in turbulence over the helideck without the air gap, an air gap too large will have the same turbulence effect 
along the surface of the helideck as no air gap. Where feasible, helidecks are designed with an ideal air gap to reduce downdraft effects.

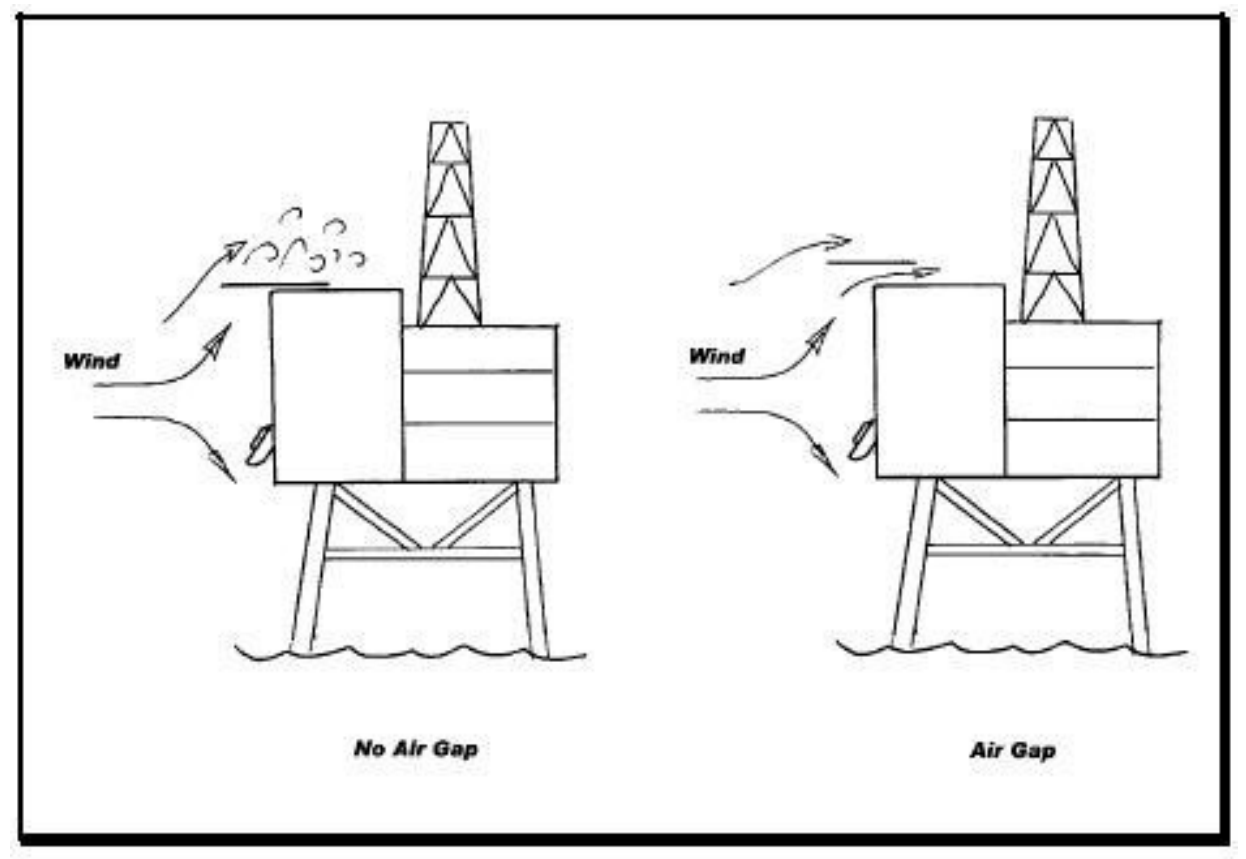

Figure 1-5 Oil Rig Helideck With and Without Air Gap

Turbulence caused by the airflow effects around vegetation such as large mountain ranges can contribute to the turbulence over the offshore helideck. Offshore fixed oil rigs are to be strategically located outside the range of influence of the mountain ranges when feasible and mobile oil rig vessels will be subject to operating restrictions when within range of the mountain range effects. However, obstacle coverage can influence the wind speeds within the area of the helideck.

Turbulence caused by the thermal effects of the exhaust gases and flares will contribute to the turbulence over the helideck. Thermal effects are included in this discussion because from the operator's perspective, the handling and management of the 
helicopter subjected to the thermal effects is the same as if it was subjected to the turbulence caused by the oil rig structures.

Hot exhaust gases (Figure 1-6) within the vicinity of the helicopter will raise the ambient temperature of the air resulting in less lift when the helideck is downwind of the hot gases plume effect. The exhaust forming the hot gas plume is of temperature in the $400^{\circ} \mathrm{C}$ range but can reach temperatures of $500^{\circ} \mathrm{C}$. Flaring restrictions incurred in 1985 (Oil and Gas Conservation Act) for energy conservation dictate that flaring is for use in the event of an emergency only. Because turbulent airflows over the oil platforms increases operator workload and thus becomes the biggest safety risk for helicopter oil platform approaches, the minimization of the influences affecting the turbulent airflow is considered in helideck design. Design considerations for the effect of hot gas plumes is available in distance from heat source to helideck in units of temperature. Ensuring a helideck is located sufficiently away from the hot gas exhaust plume demands a significant amount of real estate, the same effect can be achieved by implementing stacks high enough to not impact the airflow of the helicopter approach however, 


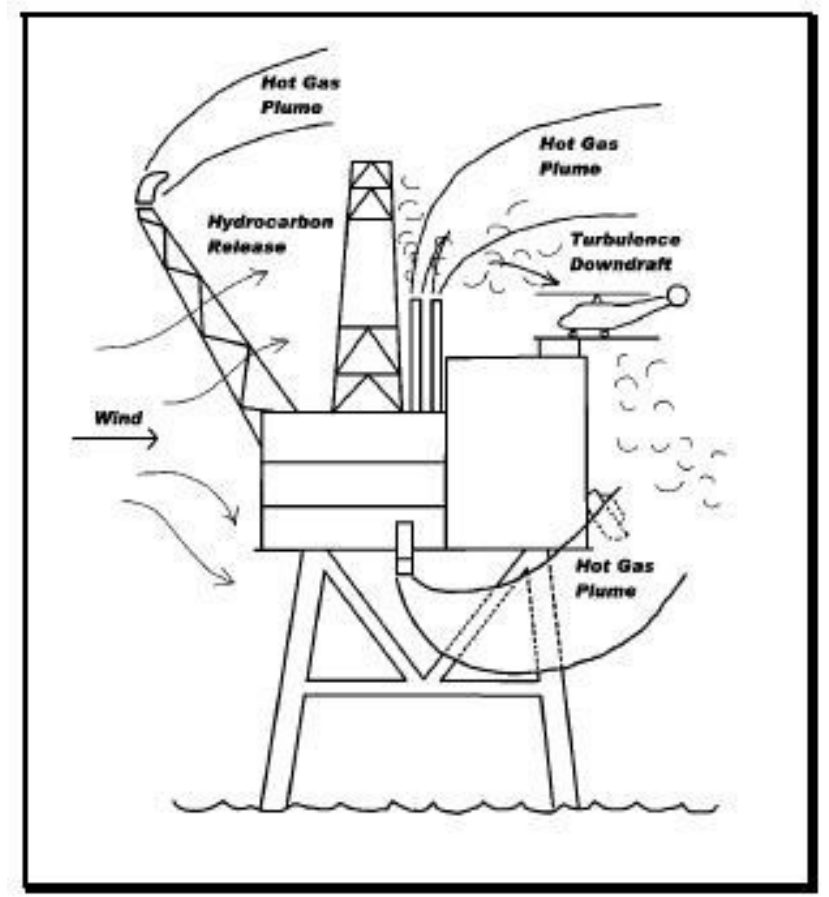

Figure 1-6 Turbulence Around Helideck from Oil Rig Structure and Exhaust Gases structures higher than the helideck compromises visibility. In turn, too high a helideck could place helideck in clouds and compromise visibility.

\subsubsection{Ships Operations}

Wave motion effects affect the movable oil platform and some fixed oil platform types. They are the result of the motion of the water body on the oil rig. The motions that impact offshore helicopter approaches are pitch, roll and heave and motion limits exist for the above motion components.

The semi-submersible fixed oil platforms are subject to angular motions of pitch and roll (surge and sway) and are affected by wave motions. Figure 1-8 shows the 
directions of wave motion (sway, surge and heave) effects on a moving vessel. The oil rig generates vortices because of it's size and it's movement (wave motion effect), the semisubmersible in the pitch and roll axis and the moving oil rig vessels in all three (3) axes. Semi-submersibles are equipped with viscous dampers to minimize the motion of the oil platform based on the wave magnitude.

Motion limits are criterion enforced for allowing offshore helicopter approaches. These motion limits are defined as maximum heave, pitch and roll motions. The wave motions coupled with the high wind speeds have caused sinking of oil rigs in the Northern shores of Canada [16]. Figure 1-8 shows the helideck location and the influence of the wave motion type relative to the helideck locations. The motion of the vessel is not equal all around. Locating the helideck to a location on the moving oil platform will subject the helideck to lesser downtime with respect to wave motion, this more prominent on the smaller vessels. Considerations are made for bow mounted helidecks to account for the restricted visual cues to the operator. The influence of the wave motions is dependent on the size and type of vessel.

The Ship Helicopter Operating Limits (SHOL) are established for the vessel and helicopter types during flight trials for defining the allowable conditions based on wind speeds and direction. Some oil rig vessels will have more than one (1) helideck to optimize the number of successful approaches by ensuring each helideck (by placement of the helidecks) are not subject to the same operating limits. 


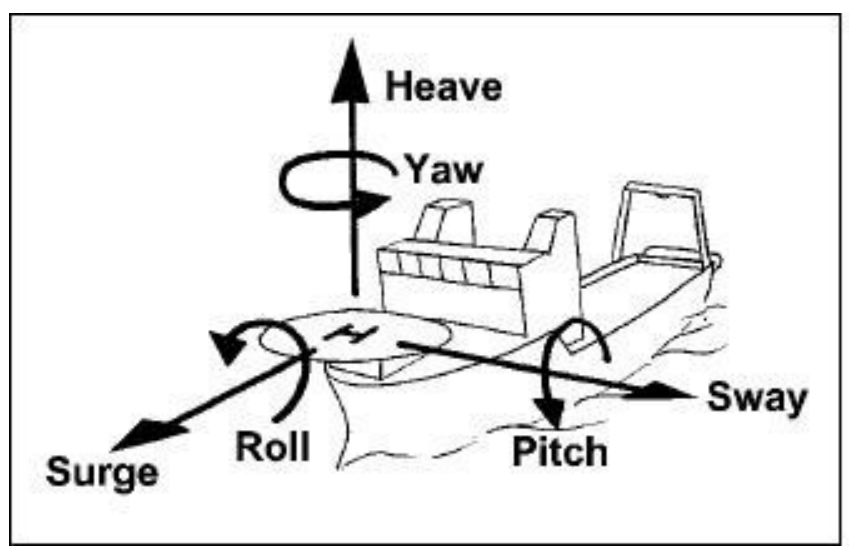

Figure 1-7 Wave Motion Directions

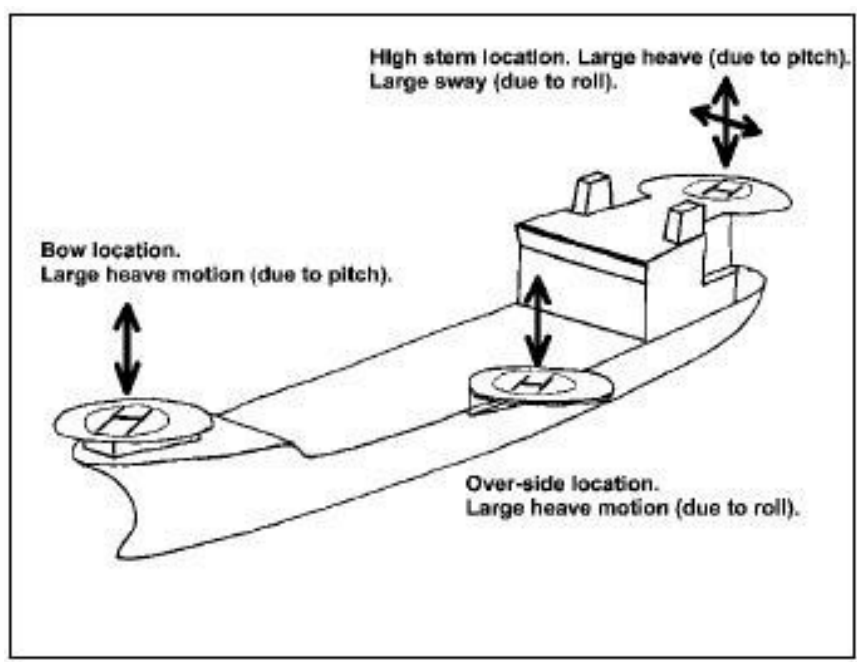

Figure 1-8 Wave Motion influence Versus Helideck Location 


\subsubsection{Wind Velocity References}

The prevailing wind condition is the dominant consideration when assessing the impact of winds on the offshore helideck operations. The more severe the winds the more subject the offshore operation is to effects of turbulence. The more severe the winds the more subject the offshore operation is to reduced visibility. High gusty winds can produce white water spray causing visibility to be reduced.

Combinations of wind speed and direction will impact the severity of the wind on the offshore operations. Limitations for mobile offshore oil platforms differ from that of the semi-submersibles and jack-ups because of the positive capability to maneuver and allow an into wind approach and the negative influence of the vessel being subject to heave limits above in addition to the limitations of the roll and pitch. Table 1.1 shows the used by industry [55] in transmissions and references to estimating wind velocity. 
Table 1.1: Table of Visual Wind Velocity References (Offshore and Onshore)

\begin{tabular}{|c|c|c|c|}
\hline \multirow{2}{*}{$\begin{array}{l}\text { Wind } \\
\text { (Knots) }\end{array}$} & \multirow{2}{*}{$\begin{array}{l}\text { Wind } \\
\text { Classification }\end{array}$} & \multicolumn{2}{|c|}{$\begin{array}{l}\text { Appearance of Wind Effects } \\
\text { Shipboard Landings }\end{array}$} \\
\hline & & On the Water & On Land \\
\hline$<1$ & Calm & Sea surface smooth and mirror-like & Calm, smoke rises vertically \\
\hline $1-3$ & Light Air & Sealy ripples, no foam crests & $\begin{array}{l}\text { Smoke drift indicates wind direction, wind } \\
\text { vanes are still }\end{array}$ \\
\hline $4-6$ & Light Breeze & Small wavelets, crests glassy, no breaking & $\begin{array}{l}\text { Wind felt on face, leaves rustle, vanes begin } \\
\text { to move }\end{array}$ \\
\hline $7-10$ & Gentle Breeze & Large wavelets, crests begin to break, scattered whitecaps & $\begin{array}{l}\text { Leaves and small twigs constantly moving, } \\
\text { light flags extended }\end{array}$ \\
\hline $11-16$ & Moderate Breeze & Small waves 1-4 ft, becoming longer, numerous whitecaps & $\begin{array}{l}\text { Dust, leaves and loose paper lifted, small tree } \\
\text { branches move }\end{array}$ \\
\hline $17-21$ & Fresh Breeze & $\begin{array}{l}\text { Moderate waves } 4-8 \mathrm{ft} \text {. taking longer form, many } \\
\text { whitecaps, some spray }\end{array}$ & Small trees in leaf begin to sway \\
\hline $22-27$ & Strong Breeze & Larger waves 8-13 ft., whitecaps common, more spray & $\begin{array}{l}\text { Larger tree branches moving, whistling in } \\
\text { wires }\end{array}$ \\
\hline $28-33$ & Near Gale & $\begin{array}{l}\text { Sea beaps up, waves 13-20 ft., white foam streaks off } \\
\text { breakers }\end{array}$ & $\begin{array}{l}\text { Whole trees moving, resistance felt walking } \\
\text { against wind }\end{array}$ \\
\hline $34-40$ & Gale & $\begin{array}{l}\text { Moderately high (13-20 ft.) waves of greater length, edges } \\
\text { of crests begin to break into spindrift, foam blown in streaks }\end{array}$ & $\begin{array}{l}\text { Whole trees in motion, resistance felt } \\
\text { walking against the wind }\end{array}$ \\
\hline $41-47$ & Strong Gale & $\begin{array}{l}\text { High waves ( } 20 \mathrm{ft} \text {.) sea begins to roll, dense streaks of } \\
\text { foam, spray may reduce visibility }\end{array}$ & $\begin{array}{l}\text { Slight structural damage occurs, slate blows } \\
\text { off roofs }\end{array}$ \\
\hline $48-55$ & Storm & $\begin{array}{l}\text { Very hifh waves ( } 20-30 \mathrm{ft} \text {.) with over-hanging crests, sea } \\
\text { white with densely blows foam, heavy rolling, lowered } \\
\text { visibility }\end{array}$ & $\begin{array}{l}\text { Seldom experienced on land, trees broken or } \\
\text { uprooted, "considerable structural damage" }\end{array}$ \\
\hline $56-63$ & Violent Storm & $\begin{array}{l}\text { Exceptionally high ( } 30-45 \mathrm{ft} .) \text { waves, foam patches cover } \\
\text { sea, visibility more reduced }\end{array}$ & \\
\hline $64+$ & Hurricane & $\begin{array}{l}\text { Air filled with foam, waves over } 45 \mathrm{ft} \text {., sea completely } \\
\text { white with driving spray, visibility greatly reduced }\end{array}$ & \\
\hline
\end{tabular}




\subsection{Scope}

\subsubsection{Area of Study}

The overall objective is to contribute to the Information Visualization area of study. The contribution is the enhancement of situational awareness within environments where the user interface is the secondary task and the not the primary focus. This is relevant in environments such as operating automobiles, flying aircraft, emergency response as examples of only some of the areas where the user interface is not the primary focus.

\subsubsection{Research Question}

The research question is, what is the most effective way to present turbulence to a helicopter pilot on a secondary display within the cockpit, to be used (referred to) prior to the approach phase of flight? Secondary display within the cockpit is referring to a display that is not in the operator's primary field of view.

\subsubsection{Focus}

Although all helicopter operations listed in section 1.2 are subject to hazardous turbulence during operations, the focus for this paper is testing on helicopter operators performing a landing on a moving ship. This investigation will address relative wind speed and relative wind direction influence on the airflow over the flight deck of a ship as presented to the helicopter operator. 
There are on-going studies for ship motion including investigations for a Flight deck Motion system [15] for the Landing Safety Officer (LSO) when guiding the helicopter in high sea conditions.

The ship motion and the influence on the operations performed by the LSO are not considered within the scope of this investigation. The influence of the main rotor wash is not considered within the scope of this investigation. 


\section{Literature Review Summary}

This chapter provides a summary of what has been done in the past, what industry is doing now and what research is in progress with respect to hazardous airflow turbulence.

\subsection{What is in Place Today}

Landing a helicopter on a platform is an operational challenge, the challenge increases when the landing platform is moving. These challenges are being mitigated by experienced pilots through repeated approaches to the ship in defined conditions developing a safe flight envelope for approach and take-off for that ship and aircraft type. To increase the challenge even further, landing a helicopter on a moving platform with wind effects that are not visible to the naked eye. This condition known as low level windshear was the result regulatory bodies mandating low level wind shear detection on aircraft.

\subsection{Current Industry Work}

The FAA NextGen initiative has resulted in an innovative industry response. Corporations such as Honeywell and Rockwell Collins are developing user interfaces to allow the operator to visualize the airspace. Figure 2-1 shows a visualization of another 
aircraft's air wake as seen from within the cockpit [43]. This visualization was flight tested and presented at the 2011 Advances In Visual Computing seventh $\left(7^{\text {th }}\right)$ International Symposium and the stated results indicating that the real time display of wake turbulence will provide a more accurate wake avoidance.

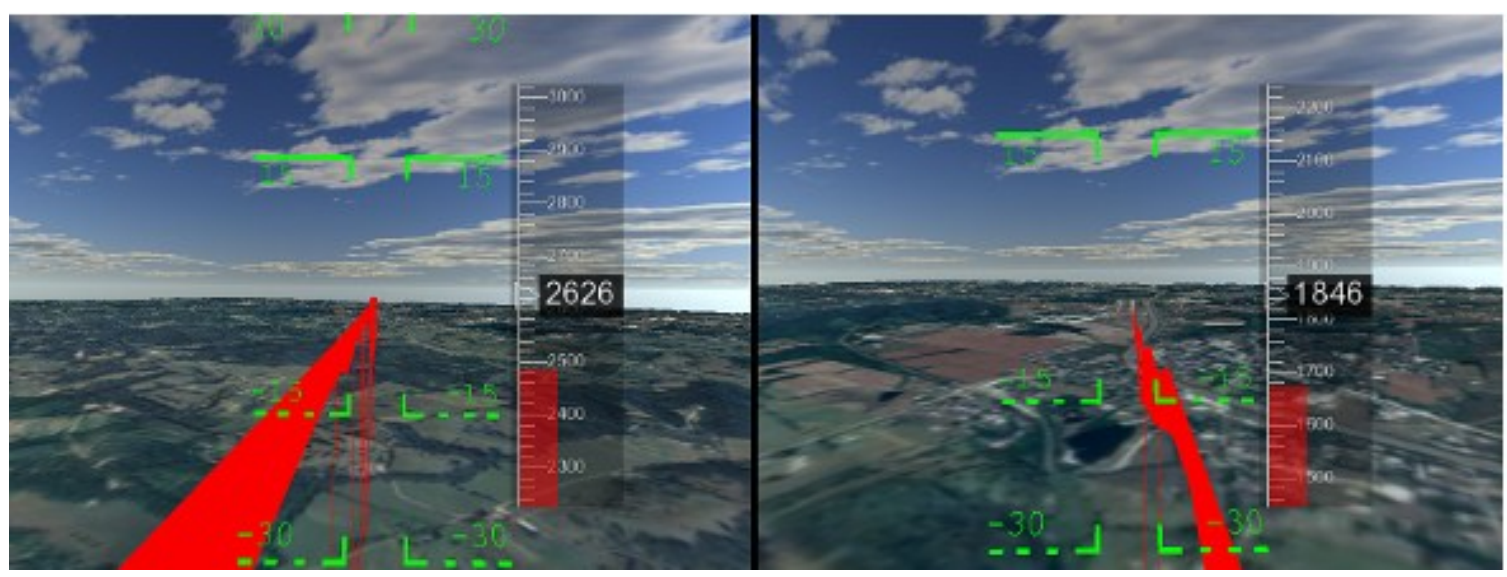

Figure 2-1 Prototype Images of Wake Turbulence and the Corresponding Wake Height on the Altimeter

Figure 2-2 and Figure 2-3 show the colour depiction of turbulence detection system display of turbulence.

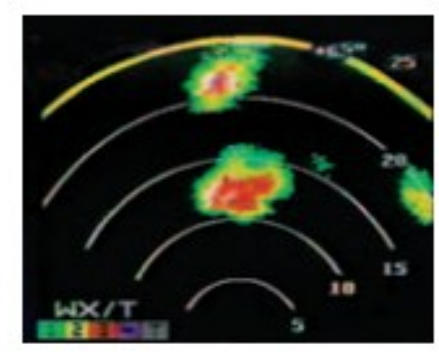

Figure 2-2 Honeywell Aerospace Display of Turbulence Detection on the Weather Radar Primus Series [44] 


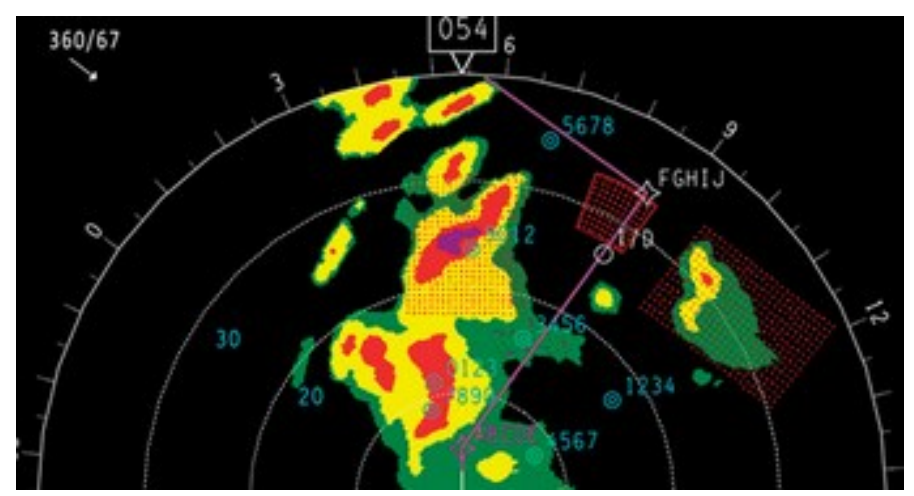

Figure 2-3 Rockwell Collins Display of Turbulence Detection on the Weather Radar [45]

\subsection{Current Research}

Research is addressing all aspects of the turbulent airflow challenges. Forward Looking Infrared Radiometer (FLIR), a leader in thermal imaging is investigating the feasibility of using infrared cameras to aid in the visualization of airflow [46]. The initial findings are positive and continued work is being pursued.

Defence Research and Development Canada (DRDC) [47] is developing the Flight Deck Motion System that will measure, predict and display the ship motions with the intent to provide the operator a safer more accurate approach. The intent of this tool is to aid the LSO, this display would be located on the ship. 


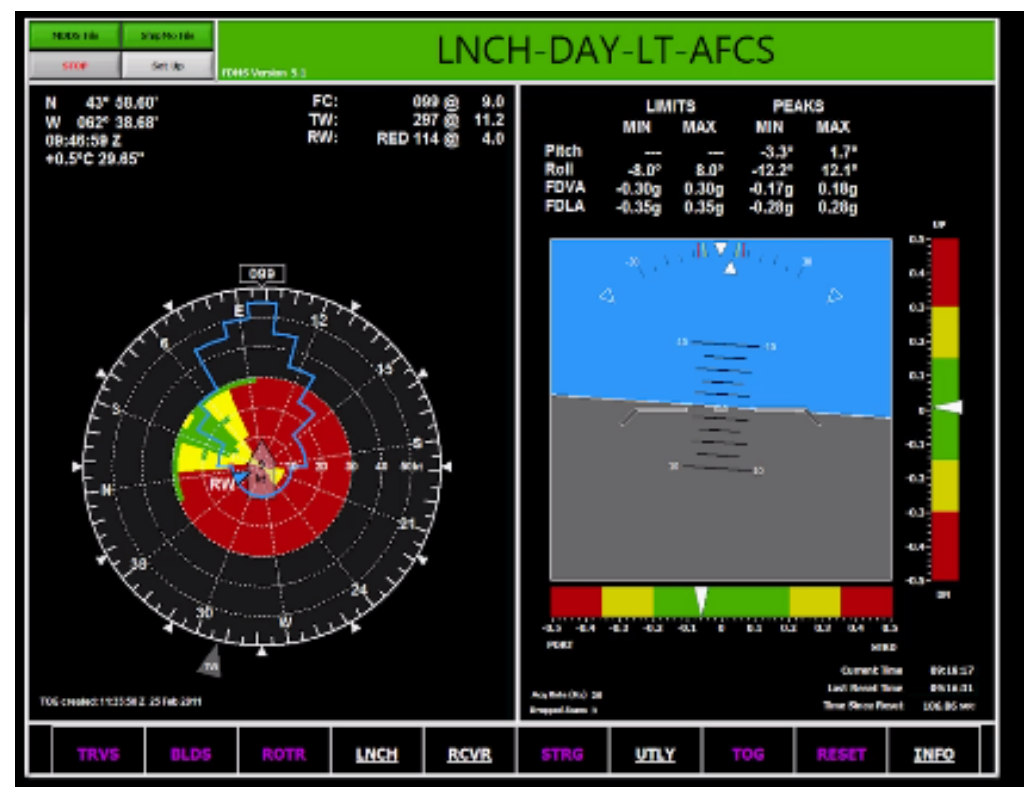

Figure 2-4 DRDC Flight Deck Motion System Display for the LSO

Figure 2-4 horizontal and vertical scales indicate green indicating to the LSO that the ship motion is within limits. 


\section{CONOPS}

The Concept Of Operations (CONOPS) is to provide helicopter operators turbulence visualization of the landing area on a cockpit display based on the wind speed and direction for the selected flying course.

The information provided to the operator would widen the allowable wind envelope for landing operations because of the more precise data available compared to the current operations of erring on the side of caution (applying worse case scenarios) with respect to wind conditions becoming a factor. 


\section{System Analysis}

This chapter discusses the investigation of relevant background in the existing procedures. Based on the investigation the requirements for the data to be presented, as a minimum, on the Graphical user Interface (GUI) is derived. These are the resulting requirements for the turbulence visualization solution.

\subsection{Current Procedures}

There are several tasks that an operator currently performs in order to understand the turbulence hazards over the landing area. Currently the operator learns to pick up visual cues from the surrounding area. The landing zone is scanned for clues about the state of the wind over the landing area. This can become challenging in operations in the water because of the lack of vegetation.

In ship and aircraft related operations, flight trials are performed to create a Ship Helicopter Operating Limits (SHOL) wind envelope for the defined ship and helicopter type and configuration. Flight operations are defined by the relative wind. Refer to Figure 4-1 for the SHOL for the Sea King helicopter on a Canadian Patrol Frigate (CPF). The chart shows the relative wind direction (angle) in degrees $\left(^{\circ}\right)$ and the wind speed (radius) in knots $(\mathrm{KT})$. The area shaded defines the acceptable combinations for the relative wind speed and wind direction. The reason why it is not symmetrical is because 
the tail rotor is located on the starboard side and is not partially sheltered by the tail boom as it is on the port side. From the diagram, it is possible for an approach to occur with waves up to 30 feet. Outside the wind envelope is deemed unacceptable relative wind conditions for approach. These restrictions are respected, the ship will alter it's course to allow for a relative wind condition that would permit helicopter operations within the SHOLs defined.

Convention defines relative wind from the port side as red and from the starboard side as green.

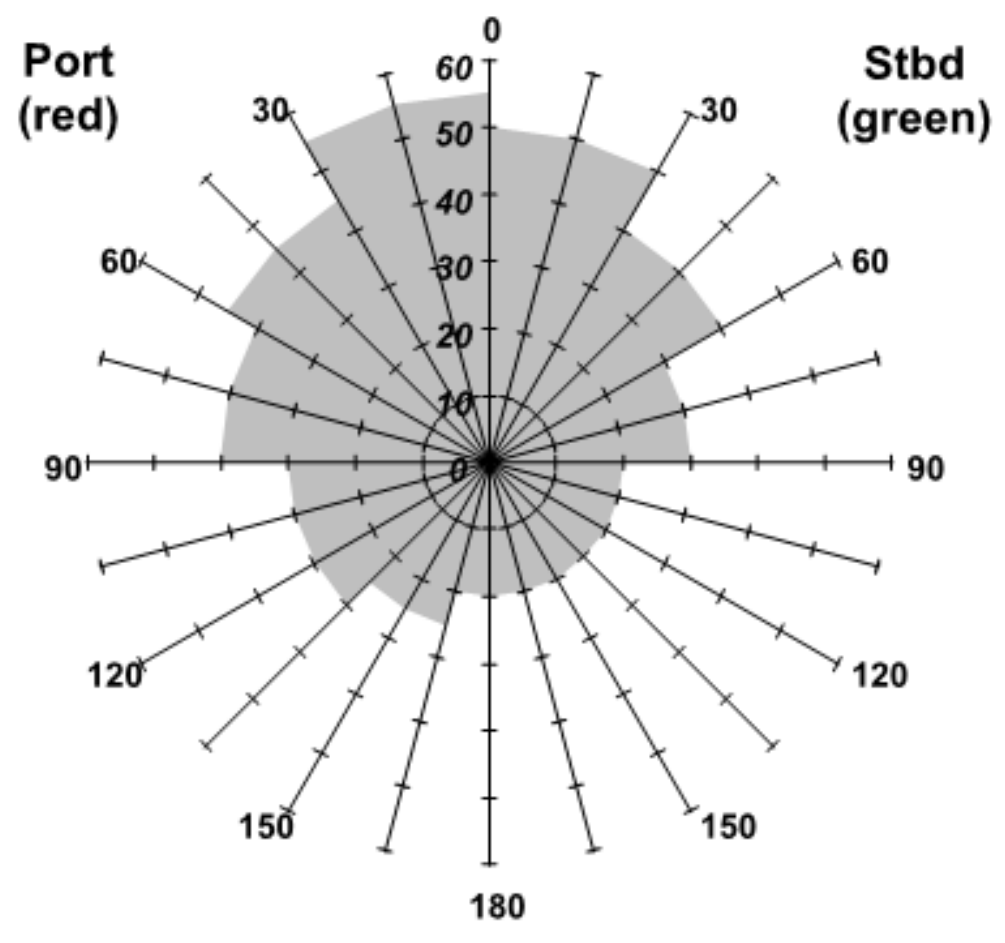

Figure 4-1 Helicopter Relative Wind Operational Envelope Example

For a given wind speed and direction, the operator refers to the published operational limits for that aircraft and ship type to determine whether the approach can be 4-41 
flown or not. These publications are defined for the different ship and aircraft configuration combinations and they are only as accurate as the wind speed and direction observed. If the wind speed or direction changes during the approach, this information is not readily available to the operator. The publications are viewed prior to the approach phase of flight.

For operations where the SHOL is not available, operators perform an incremental approach based on experience. .

When visual of the ship is confirmed and the paddles takes over (ship official guiding aircraft to deck with paddles), the relative wind is re-confirmed from the ship to helicopter.

\subsection{Operational Requirements}

The current airflow assessment procedures requires the operator to know (have ready access to) the following:

- Relative wind azimuth along flight path;

- Relative wind magnitude along flight path;

- True wind (can become important when problems occur); and

- Ship Helicopter Operating Limits publication for the frigate.

Relative wind is the vector sum of the true wind speed and wind direction with the ship speed and ship course relative to the wind. From the listed information the operator will know if the approach is within limits and whether or not the wind will have an influence on the decision as to proceed with the approach. 
The CONOPS proposes the operator is presented with an abstract visualization of the within/outside approach limits.

Visualization of the turbulence is only one (1) of many inputs into the decision making process. For this reason the operator knowledge of wind data is to be maintained.

a. The operator shall be presented with the relative wind azimuth along the flight path.

b. The operator shall be presented with the relative wind magnitude along the flight path.

c. The operator shall be presented with the true wind along the flight path.

\subsection{Critical Location for Turbulence Requirements}

The helicopter landing onto the ship follows the approach path until a predetermined distance in Nautical Miles (NM) from the ship. The helicopter then travels along the length of the port or starboard side of the ship until aligned with the ship. At this point the helicopter is approximately within feet above the deck height (50') and the helicopter then traverses into position over the landing area. Figure 4-2 shows the deck of the ship and the path that the helicopter will take to hover over the landing area on the ship. The operator adjacent to ship is the pilot flying. The pilot flying is determined by the approach path being flown along the port side of the ship the pilot flying is the pilot in the right seat. When the approach is along the starboard side of the ship, the pilot flying is the pilot in the left seat. 
It is along this flight path where turbulence in this area would be of concern to the operators. Helicopter incidents and accidents have occurred as a result of the helicopters being pulled down off the edge of the helideck because of a downdraft off of the helideck of the ship. In addition, turbulence data showed turbulence located off the edges of the helideck of the ship. Depending on the relative wind direction and speed the ship structure itself causes these turbulent airwakes. These turbulent areas are along the approach path of the helicopter and are of interest to the operator for turbulence avoidance determination. Figure 4-3 identifies the area to be assessed for turbulence outside of limits.

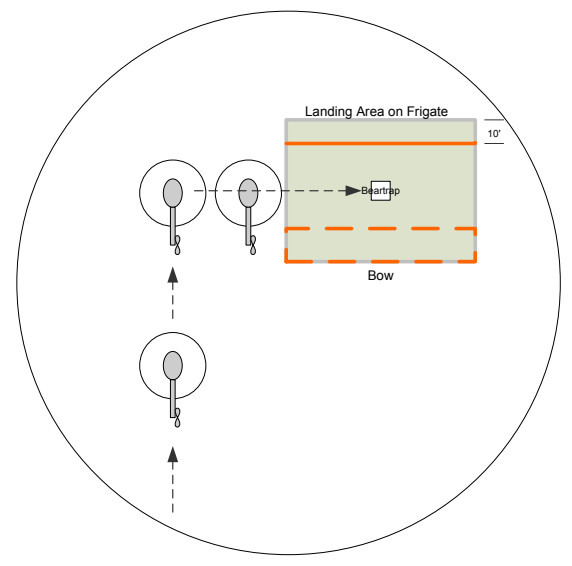

Figure 4-2 Helicopter Approach Path to Ship (Pilot Flying)

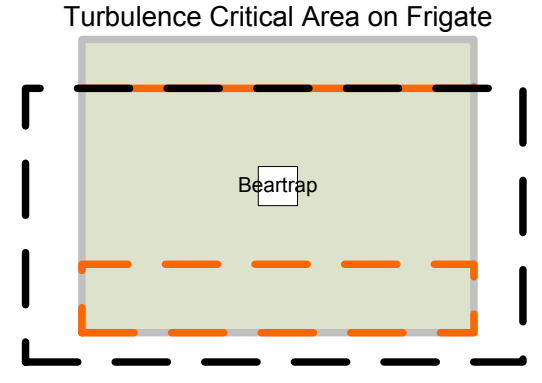

Figure 4-3 Turbulence Critical Area on Frigate

d. The coverage area to display the airflow shall be as per the Figure 4-3. 


\subsection{Turbulence Requirements}

The SHOL defines when airflow that is turbulent and is not suitable for landing. Where the SHOL does not exist, the critical wind azimuth and velocity of the helicopter provided by the manufacturer is used to determine when the airflow is considered to be not suitable for landing. The use of colour to represent warnings, cautions and all clear within the helicopter cockpit is subjected to MIL-STD-411F [48] that dictates compliance to the Human Engineering Design Criteria outlined in the MIL-STD-1472 G [49]. For this application the following design requirements are determined:

e. For wind magnitude and azimuth defined in the SHOL as not suitable for landing, the airflow shall be displayed as a warning (red).

f. For wind magnitude and azimuth defined in the SHOL as cautions, the airflow shall be displayed as a caution (yellow).

g. For wind magnitude and azimuth defined in the SHOL as all clear and to not have an impact on the decision to proceed with the approach, the airflow shall be displayed as an all clear (green).

\subsection{Turbulence Type Requirements}

There are different types of airflow hazards that influence the flight path of an aircraft.

\subsubsection{Microbursts}

Microbursts are downdrafts that are typically hundreds to thousands of feet across. When the downdraft hits the ground, the affected region now becomes in the 
thousands of feet, it is the horizontal vortex that is produced that is the microburst. These are typically associated with thunderstorms. Microbursts can dissipate within five (5) minutes following contact with the ground. Distinguishing the microburst as an airflow hazard is difficult for this reason in that the hazard may have dissipated prior to the aircraft being within the vicinity of the hazard. The operating procedures defined for thunderstorms account for the potential of the existence of microbursts. The simulation for the purpose of this exercise is limited to the input of relative wind only and not considering the other environment influences. For this reason, identifying the airflow hazard as a microburst is not considered.

\subsubsection{Vortices}

Wake vortices can be generated by the ship, other ships and aircraft in the vicinity and the main rotor blade itself can create wake vortices. Honeywell is developing wake vortices visualization systems in preparation for the FAA NextGen ${ }^{4}$ initiative. Identifying wake vortices along the flight path is not considered for this investigation. Inclusion of wake vortices can be considered as a phased approach for the visualization in continuing investigations. Presentation of turbulence and presentation of the wake vortices turbulence type are two (2) separate investigations.

\footnotetext{
${ }^{4}$ FAA NextGen initiative is the optimization of air traffic flow in and around aerodromes by incorporation navigation capability that allows the operators to fly a more controlled flight path resulting in the increase of air traffic capability.
} 


\subsubsection{Low Level Windshear}

Low level windshear is sudden change in wind speed and direction near the surface. The FAA has mandated that all commercial aircraft are equipped with windshear detection and warning systems [5].

Advisory Circular [6] AC No. 20-182 is a FAA guidance document for the forwardlooking windshear turbulence detection and weather hazard indication capability systems. This AC does not cover rotary wing aircraft.

\subsection{High Relative Wind Requirements}

The SHOL defines when airflow that is turbulent and is not suitable for landing. Where the SHOL does not exist, the critical wind azimuth and velocity of the helicopter provided by the manufacturer is used to determine when the airflow is considered to be not suitable.

\subsection{Turbulence Display Requirements Summary}

In summary there are seven (7) requirements to be implemented in the design for the GUI for the hazardous airflow display. Table 4.1 lists these requirements to be addressed in the design. 
Table 4.1: Summary Table of Display of Turbulent Airflow Requirements.

\begin{tabular}{ll}
\hline $\begin{array}{c}\text { Requirement } \\
\text { Type }\end{array}$ & \multicolumn{1}{c}{ Requirement } \\
\hline Operational & $\begin{array}{l}\text { The operator shall be presented with the relative wind azimuth along } \\
\text { the flight path. } \\
\text { The operator shall be presented with the relative wind magnitude } \\
\text { along the flight path. } \\
\text { The operator shall be presented with the true wind along the flight } \\
\text { path. }\end{array}$ \\
Operational & $\begin{array}{l}\text { The coverage area to display the airflow shall be as per the Figure } \\
\text { Derived }\end{array}$ \\
Design & $\begin{array}{l}\text { For wind magnitude and azimuth defined in the SHOL as not } \\
\text { suitable for landing, the airflow shall be displayed as a warning } \\
\text { (red). }\end{array}$ \\
Design & $\begin{array}{l}\text { For wind magnitude and azimuth defined in the SHOL as cautions, } \\
\text { the airflow shall be displayed as a caution (yellow). }\end{array}$ \\
Design & $\begin{array}{l}\text { For wind magnitude and azimuth defined in the SHOL as all clear } \\
\text { and to not have an impact on the decision to proceed with the } \\
\text { approach, the airflow shall be displayed as an all clear (green). }\end{array}$ \\
\hline
\end{tabular}




\section{Design}

This chapter discusses the design concepts and evaluations used to validate the design.

Four (4) design concepts were created and evaluated. The designs were evaluated against the selected design principles and usability heuristics. Although there are many other design principles and usability heuristics that exist, those listed in this chapter were the focus of the design evaluation. Navigation to the turbulence preview screen was not part of the evaluation.

\subsection{Information Visualization}

There are two (2) distinct technologies being investigated in industry today. The first is modelling and simulation and the second is the use of Infrared (IR) technology.

The design evaluated incorporates modelling and simulation. Modelling and simulation in this application is a three dimensional (3D) model of the configured frigate is created and used in the Computational Fluid Dynamics (CFD) simulation that simulates the airflow over the model based on the relative wind speed and relative wind direction. This is then translated into a comprehensible abstract visualization of the data.

The enhanced image of the scene (frigate flight deck/landing area) as viewed through an IR Camera is dynamic relative to the other designs in that the information is 
real time. This technology is known as Enhanced Vision Systems (EVS) and is commonly used on the Heads-Up Display (HUD) in an aircraft. This technology is also used in the lowering of minimas for landings specifically where low visibility is a factor. This investigation utilizes the CFD technology.

\subsubsection{Design A - Aragon}

Design A is based on the work done by Cecilia Aragon who performed her dissertation on the visualization of airflow hazards [1]. Her results found that a red transparent basic shape (e.g. oval) is the preferred visualization for the representation of hazardous airflow data to the operator.

\subsubsection{Design B - Industry Direction}

Design B adopts the industry leaders in Aviation System Integration such as Rockwell Collins and Honeywell. Industry is investigating methods to represent airflow in support of the Federal Aviation Association (FAA) NextGen initiative.

This design utilizes animation airflow overlay atop a Synthetic Vision System (SVS) display. The complexity is less than that of the industry initiatives in order to address the primary goal of interpreting the presented data in the minimal time.

\subsubsection{Design $C$ and $D$ - Traditional Airflow}

Design C and D are variations based on the traditional representation (e.g. Fluid Dynamics) of airflow with the use of velocity vector arrows. 


\subsubsection{Design E - EVS}

This design not only differs in the technology used but also in the display characteristics. The image is presented in grayscale compared to the colour used in the other four (4) designs. The representation of the hazardous airflow is real and not like the abstract representation of the output of the data in the other designs.

This design is of interest because it is real time and there is familiarity with the operators from other applications within the cockpit, primarily for operations where visibility is poor. The 3D modeling and simulation of airflow are limited with respect to the configuration of the model. The complexity of the structures result in a complex output that is relatively slow in generating despite the advances in Central Processing Units (CPU) capability.

This design was not presented as part of the designs (A through D) evaluated in the questionnaire. Within the questionnaire this design was explored for relevant information presented to the operator.

\subsection{Design Principles}

The design principles in focus are those that are to address the type of information required (defined in Chapter 3) for the operator to be able to determine if approach is within operational limits and to know where the areas are of turbulence over the flight deck. 


\subsubsection{Design Principle: Autonomy}

The system status should always keep users informed about what is going on, though appropriate feedback within reasonable time [2].

Status in this application is referring to two (2) items, the first is the operator awareness of the conditions dictating airflow output (ship configuration, the wind speed and wind direction). The second is the status of the airflow itself, in that the operator can determine when the airflow is hazardous turbulence compared to airflow within operating limits.

\subsubsection{Design Principle: Consistency}

The use of being visually inconsistent for display of items when things act differently [2]. Within this application, induced inconsistency is the presentation of turbulent airflow over the landing area that still permits operations. It is necessary for the operator to be able to distinguish between airflow that is turbulent and operations are restricted and airflow that is turbulent and operations are permitted.

Another area of induced inconsistency is the use of the colour red and green. Within the cockpit red indicates caution and green is all clear. These colours are also used to identify the relative wind direction. It is pertinent that the operator is able to distinguish which application is being referred to. 


\subsubsection{Design Principle: Explorable Interfaces}

Considering Fitts's Law in that the time to acquire a target is a function of the distance to and size of the target. The time to acquire multiple targets is the sum of the time to acquire each. Within this application the principle is translated to the presentation of the multiple turbulent areas as opposed to a visual go/no-go indication.

Complex configurations can contribute to multiple turbulent areas, this resulting in an increased time to determine the situation with respect to airflow.

\subsubsection{Design Principle: Metaphors}

The cockpit metaphor is the current glass cockpit concept. The glass cockpit is the presentation of flight instrument information on a display such as a Liquid Crystal Display (LCD) as opposed to the traditional gauges. Maintaining the design within the cockpit metaphor is the display of the turbulent airflow as an easy to read graphical view as opposed to the anemometer gauge depicting wind speed. The design depiction of airflow is chosen to enable the operators to instantly grasp the necessary details of the conceptual model.

\subsection{Usability Heuristics}

\subsubsection{Consistency and Standards}

There should not be a need for the operator to have to determine the application to know the meaning of the word or convention. Within this application the cockpit 
conventions use of colour and size of object, text font are to have the same meaning and remain consistent with the philosophy in the cockpit.

\subsubsection{Recognition Rather Than Recall}

To minimize the operator's workload the operator needs to be able to recognize the design as turbulent airflow and not have to recall the design from memory to know that the symbol used represents airflow.

\subsubsection{Minimalist Design}

The information presented to the operator needs to be relevant at the time of use for the operator. An area to be further investigated is the requirement to present the true wind speed and true wind direction on this display. Although this has been specifically requested by operations this information is presented to the operator on the Primary Flight Displays (PFD). The intent of the display is for the operator to view on a secondary display such as the Electronic Flight Bag (EFB) the representation of hazardous airflow over the flight deck prior to the approach POF.

\subsection{Other}

\subsubsection{Confidence and Perceived Reliability}

It is not unusual to learn that although results can show that design $\mathrm{X}$ is favourable in all characteristics over design $\mathrm{Y}$, design $\mathrm{Y}$ is the favoured design by the users for other reasons such as product marketing, cost or availability to name a few. 
Design A, B, C and D are based on the transformation of a complex CFD output for a given wind condition over a frigate into a comprehensible visualization of the airflow. It encompasses the visualization of abstract data.

Design E (not evaluated) explores the use of an EVS utilizing IR technology image of the turbulent airflow over the landing area.

The intent of this section is to understand if there is a preference for one of the technologies over the other and why.

\subsection{Design Evaluation}

\subsubsection{Methodology}

An evaluation questionnaire was developed. Refer to Appendix A. It consisted of 113 questions and statements distributed into five (5) sections. Section A outlined the instructions for the participants. The participants were to rate their level of agreement with each statement based on the Likert [51] scale of one (1) to five (5) where five (5) is strongly agree and one (1) is strongly disagree. The disagree and strongly disagree responses required the participants to provide a comment as to why.

Section B contained questions on the demographics of the participants. Section C questions addressed the identified requirements. The intent of this section was to confirm the investigation of the current process and the derived requirements as a result.

Section D questions queried the proposed designs (section 4.1) based on the design principles and design heuristics identified in section 4.2 and 4.3 of this paper. 
Section E questions explored the different perspectives available. The Likert scale was chosen because it is a tool that captures the opinions and beliefs of the participants. For this application the opinions and beliefs for the user interface designs proposed. It is necessary to note that the Likert scale used was reverse to the traditional. In that the strongly agree was at the right hand end of the scale whereas the strongly disagree was at the left hand end of the scale. It was learned during the development of the questionnaire that the participants are familiar with both implementations and to remain consistent with the evaluations being performed the reverse scale was used.

Section F consisted of overview summary questions that allowed the participant to state preferences, likes and dislikes and identify areas of concern that were not discussed. See Appendix A for the questionnaire administered.

In order to provide a common starting point for the participants, a ground school was given to the participants prior to administering the Design Evaluation Questionnaire. The ground school consisted of an overview of the current process evaluation; the resulting requirements; proposed designs and their source; and the follow-on next steps. Appendix B (insert hyperlink) contains the presentation slides used for the ground school.

\subsubsection{Participants}

Based on the Nielsen and Landauer model of predicting the number of usability problems found in a heuristic evaluation [3], it was decided a minimum of five (5) evaluators would be used. A total of seven (7) participants contributed. Every participant required helicopter operator experience. The participant's experience profiles are as shown in Table 5.1. 
Table 5.1: Design Evaluation Participant Profiles table.

\begin{tabular}{clcc}
\hline \multirow{2}{*}{ Participant } & \multicolumn{1}{c}{ Experience Type } & $\begin{array}{c}\text { Operating } \\
\text { Hours }\end{array}$ & $\begin{array}{c}\text { Shipboard } \\
\text { Landings }\end{array}$ \\
\hline \hline 1 & Sea King Helicopter Pilot & 4000 & 1100 \\
2 & SAR (Griffin) Helicopter Pilot & 4500 & 10 \\
3 & Sea King Helicopter Pilot & 2500 & 250 \\
4 & Sea King Helicopter Pilot & 5900 & 500 \\
5 & SAR-Griffin Helicopter Test Pilot & 1400 & 0 \\
6 & Helicopter Test Pilot (Sea King) & 3500 & 300 \\
7 & Twin Huey Helicopter Pilot & 4000 & $>500$ \\
\hline
\end{tabular}

\subsubsection{Evaluation Results}

Results of the design evaluation proved to be positive and reinforced the design choices made. The operator interest in the overall concept was not as favourable as hoped. The helicopter sea operators did not support the use of such a tool because they are comfortable with the information that is being provided by the SHOLs. The tool was viewed as a 'nice to have' and would augment the SHOLs but not provide additional capability.

Contrary the SAR helicopter pilots embraced the idea of having an interface providing a hazardous visualization. However, they realize that implementation for the applications that these pilots are subjected to was not feasible. That is creating a model of the landing area that the SAR pilot is subjected to is not predictable in that the destination is not pre-determined and the vegetation is not consistent. When technology 
has developed to the point at which a model of the landing area can be generated in real time based on the viewing of the scene, the operator input of the true wind will yield the presentation of the turbulence visualization.

Surprisingly the preferred design was that of velocity vectors. The operators were able to visualize the hazardous turbulence easier than the other proposed designs that were of a simpler representation. This is in contradiction to the Aragon study that showed the operators preferring the simpler representation and rejecting the more complex representation of airflow. The difference is that in this study the viewing of the hazardous turbulence occurs prior to the approach Phase Of Flight (POF).

For the Aragon study the viewing of the hazardous turbulence occurs during the approach POF and the critical moments of touchdown. The approach and landing POF are high operator workload. One operator stated that there are "some landings that the pilots emerge from the aircraft soaking wet and it is not from the sea spray but from sweat" of landing the aircraft.

\subsubsection{Evaluation Results - Requirements}

The requirements defined are accurate. The evaluation did show that if a Go/NoGo indication was provided on the display, the operator maintains that the relative wind speed and direction are still to be presented to maintain the operator's situational awareness. In addition, the operator feels strongly that the Red/Green orientation used for wind from Starboard or Port be maintained. It was learned that the red/green indication for relative wind is used to determine the go around heading. The LSO 
provides the true wind to the operator during the approach using the red/green reference for port/starboard.

The requirements results identified two (2) areas to be tested. The first is the presentation of true wind. The operators felt it necessary to have the true wind on the display as well. The intent is to have it visible for when conditions occur that require the landing to be aborted and knowledge of the true wind speed and direction is required. The true wind is presented on the Primary Flight Display (PFD) and the Flight Management System (FMS) display.

The display that the turbulence visualization is presented is not utilized during the approach POF and therefore presenting the true wind information on that display will not be viewed when the information is required. This is to be confirmed via testing. The design preference to minimize clutter and avoid confusion by displaying only the relative wind parameters on the EFB display.

The second area to be tested is the identification of the ship type displayed or not. The design evaluation shows that the operators are skeptical and believe that this information is necessary. The original intent was to have the operator select the ship type and enter the relative wind parameters. This will navigate the display to the turbulence visualization screen where the relative wind parameters are displayed. Usability heuristic of consistency and standards within the cockpit would require that operator entered data is always presented to the operator. The testing would be to determine where the ship type is displayed, at the screen where entered or on the turbulence visualization screen. 


\subsubsection{Evaluation Results - Proposed Designs}

One (1) of the primary functions of the designs was to ensure that the operator was able to clearly distinguish the areas of hazardous airflow around the landing area. This did not hold true for some of the proposed designs. The operators found the use of a single arrow depicting the relative wind strength and direction by size and orientation (Appendix A Design C3) and locating the hazardous areas by swirling arrow body (refer to Appendix A Design C) the most challenging for readily depicting the areas of hazardous airflow. The evaluation results showed that it was not clear.

Designs B and B1 confused the operators. The Go/No-go indication presented on the display is based on the SHOL limits. That is, when the relative wind speed and direction were within operational limits the GO indication is displayed (design B1). When the relative wind speed and direction were outside the operational limits the NOGO indication is displayed (design B). The graphical images are the same for both designs. The hazardous turbulence areas shown are located outside the area of concern for landing, in particular the areas adjacent to the hangar door area. The confusion comes from the fact the operator is unable to identify the landing area of concern and it is not clear as to whether the hazardous turbulence identified over the deck is in an area of concern. The transparency of the turbulence overlay presented is $0 \%$ and the operators cannot identify the lines defining the zones over the deck. Changing the transparency of the turbulence overlay image to a value that the operator can distinguish the different turbulence areas by colour and see the zone lines defined underneath. 
With respect to design $\mathrm{C} 2$, the operators were confused when trying to determine the criticality of the turbulence as a result of the use of colours outside the cockpit norm. The use of the blue and green in the flow lines were assumed to be non-turbulent however the swirls indicated it was turbulent. Significance of the colour was unknown. Manipulating the CFD tool to utilize the red, yellow and green colours and their associated ranges is required.

\subsubsection{Evaluation Results - Perspective}

Two (2) different perspectives were presented in the design evaluation. A view from the pilot flying, delta hover position and a top view of the ship's flight deck. The operators unanimously preferred the delta hover position with little concern for turbulence visualization outside the landing area of the ship. There were no specific complaints of the ship deck view however, the preference for the delta hover is based on the fact that the virtual image yields a greater awareness of the ship.

\subsubsection{Evaluation Results - Technology}

Although the EVS design was not evaluated, the questionnaire queried the two (2) different technologies and solicited opinions. Four (4) of the seven (7) participants were undecided, two (2) preferred CFD and one (1) EVS. See Figure 5-1. 


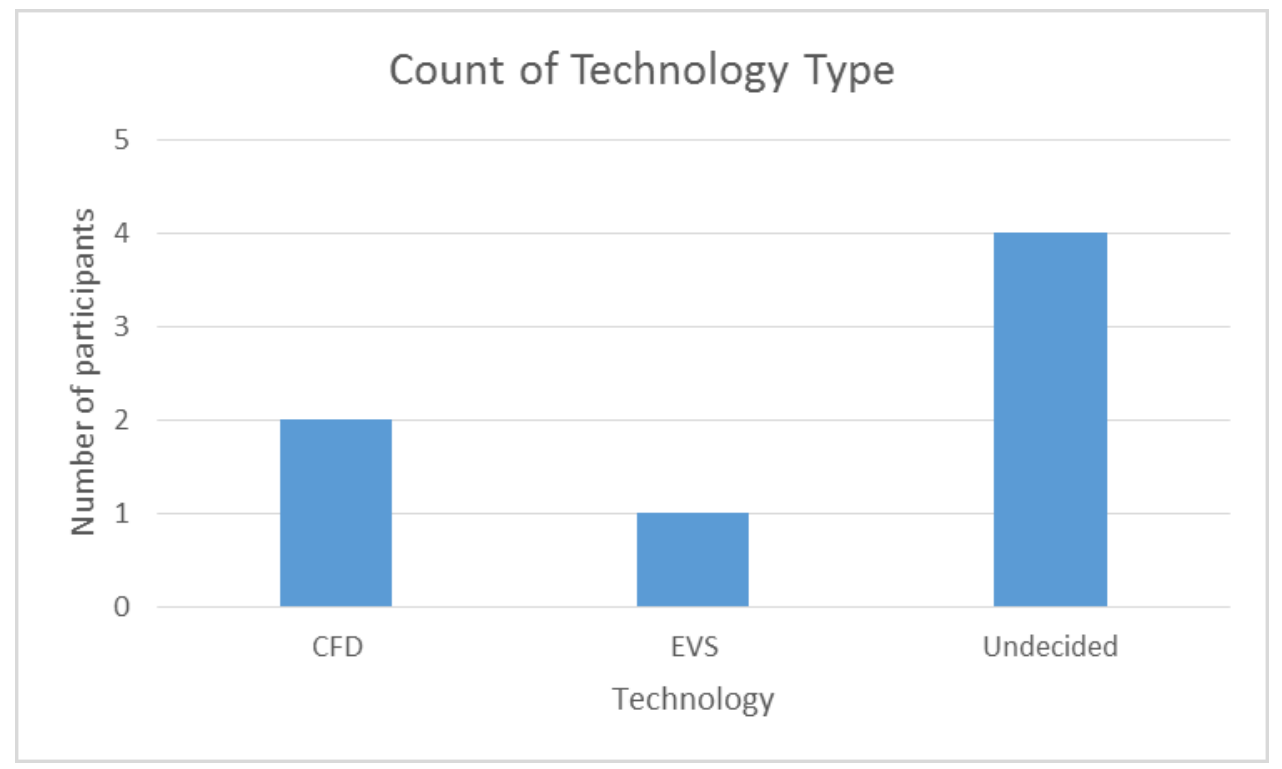

Figure 5-1 Preferred Technology versus Number of Participants

Those that chose CFD preferred this technology because it was deemed that the airflow was easier to visualize. However, one found the display cluttered and the technology limiting by the model available and believed that EVS would allow real time presentation of data and would not be dependent on a model of the structure(s) being available. Most of the participants felt that they lacked in the expertise of the two (2) different technologies and couldn't comment confidently on a preference.

\subsubsection{Selected Design}

The design evaluation questionnaire showed that four (4) of the seven (7) operators preferred the velocity vectors design, two (2) of the seven (7) preferred the simply geometry (Aragon's results) and one (1) undecided. See Figure 5-2. 


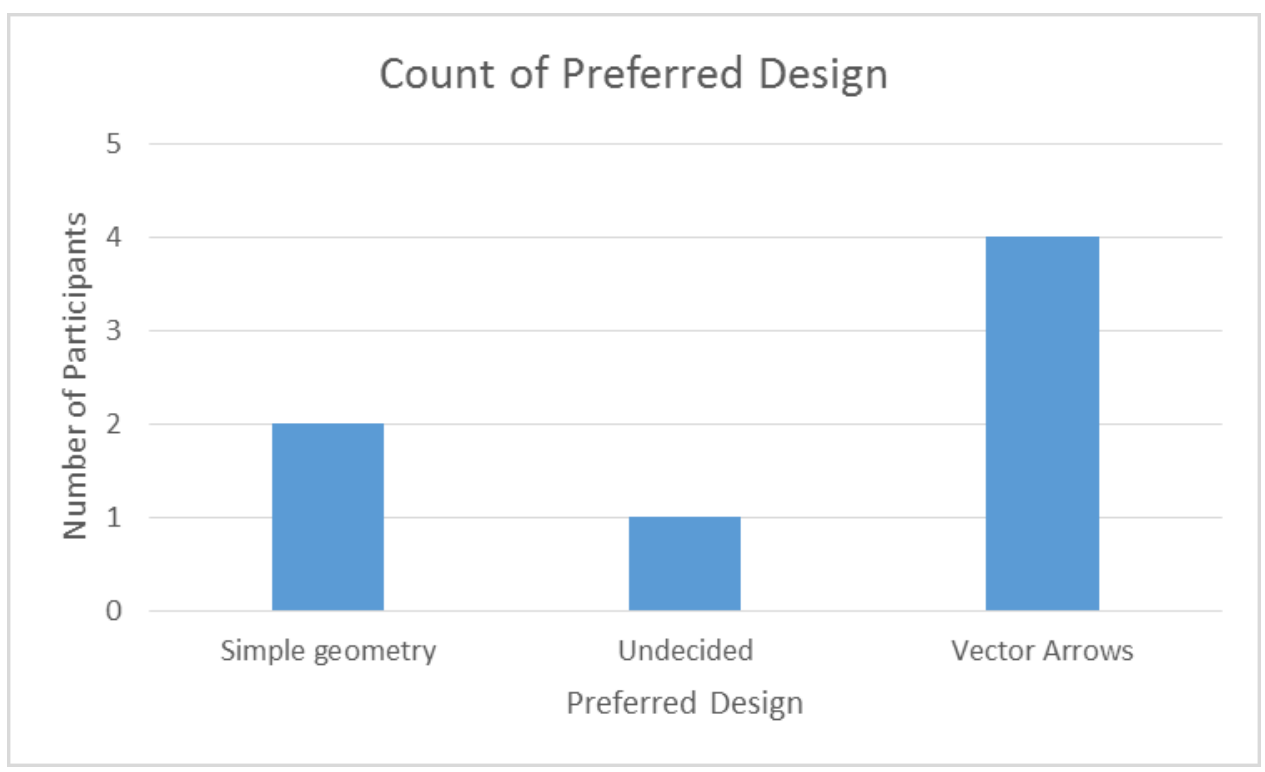

Figure 5-2 Preferred Design versus Number of Participants

The design selected for verification is design $\mathrm{C} 1$. The design shown is a simple oil rig mock-up with a relative wind within the operating limits. This design was developed using the CFD application within the Ansys CFX tool. The operators found that the representation of the airflow was clear, quickly and easily identified compared to the other designs. The challenge as mentioned earlier in this section is to define the airflow so that the colours reflect the traditional cockpit colours of red (warning), yellow (caution) and green.

The simple geometry selected by the two (2) operators preferred this design because it was simple and non-complex. No interpretation required. This design is not selected for testing because the intended use of the turbulence visualization is pre approach POF. There is time to assess the airflow over the landing area and a clearer understanding of what the airflow is doing will result in a more informed decision being 
made. The simple geometry provides less information and would be appropriate for applications where time is not available. The environment that Aragon tested this design was during the approach POF.

The designs depicting industry direction were not selected by any of the operators because all the operators had difficulty in interpreting the images. It was not clear where the hazardous areas were.

\subsubsection{Turbulence Type Differentiation}

One of the considerations during the design stage was whether or not differentiating between the different turbulence types would aid the operator in determining hazardous airflow. Following investigations (reference section 4.5) it was found that knowing the type of turbulence would not benefit the operator. The question was put to the operators to re-confirm the decision to not present the operator with additional information by classifying the type of turbulence over the landing area.

Six (6) of the seven (7) operators indicated that there would be no benefit to them to know the type of turbulence they are subjected to. The general finding was that microburst effects are advised through the weather advisory and the result of the remaining causes are similar and the actions to be taken are similar. The operator that suggested it would be beneficial stated that "knowing the direction of the turbulence would allow avoidance if necessary, as in a Missed Approach Procedure (MAP)." 


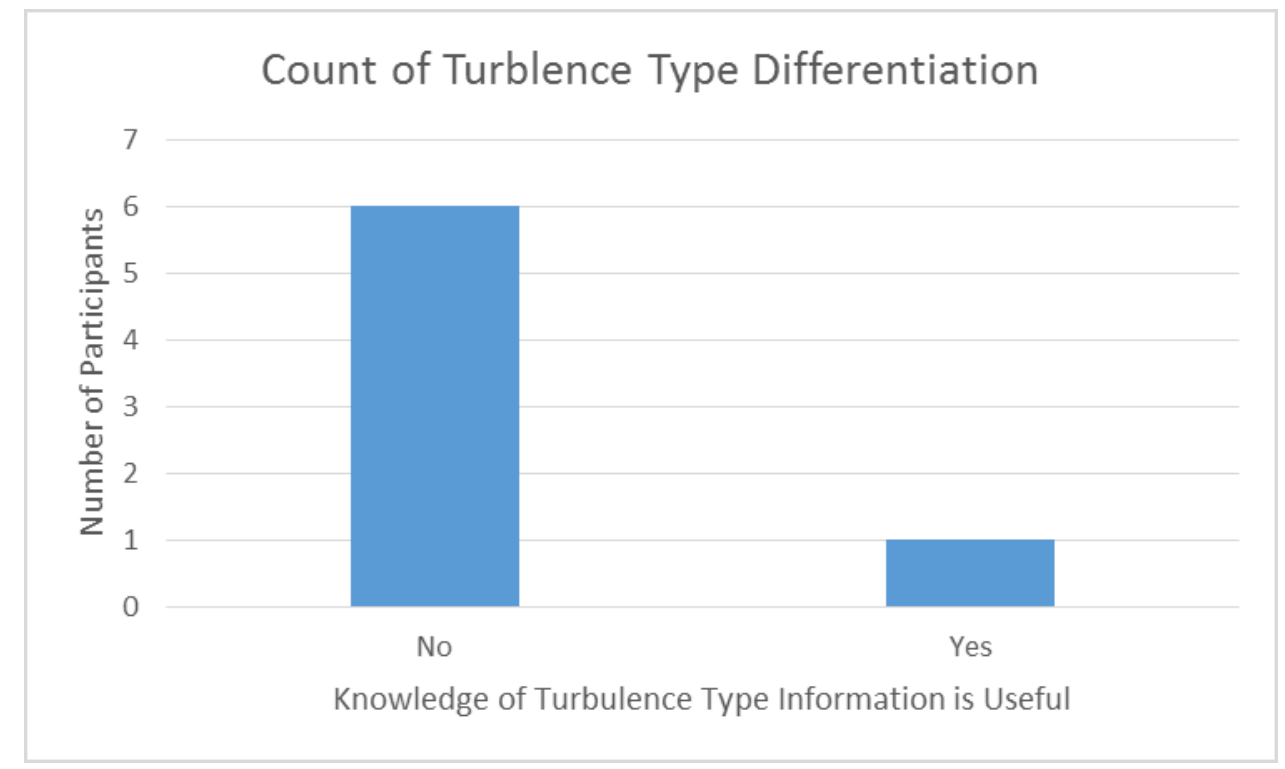

Figure 5-3 Usefulness of Knowledge of Turbulence Type versus Number of Participants

\subsubsection{Useful Information}

All the participants were asked if a SHOL was not available would they use the turbulence visualization displayed? Would it be useful information? Six (6) of the seven (7) participants responded with yes. The understanding is that the presented information would provide a more accurate assessment of turbulence than what the operator would be able to deduce. The operator that had disagreed with the other six (6) stated "I would not land an aircraft where SHOLs were not available." 


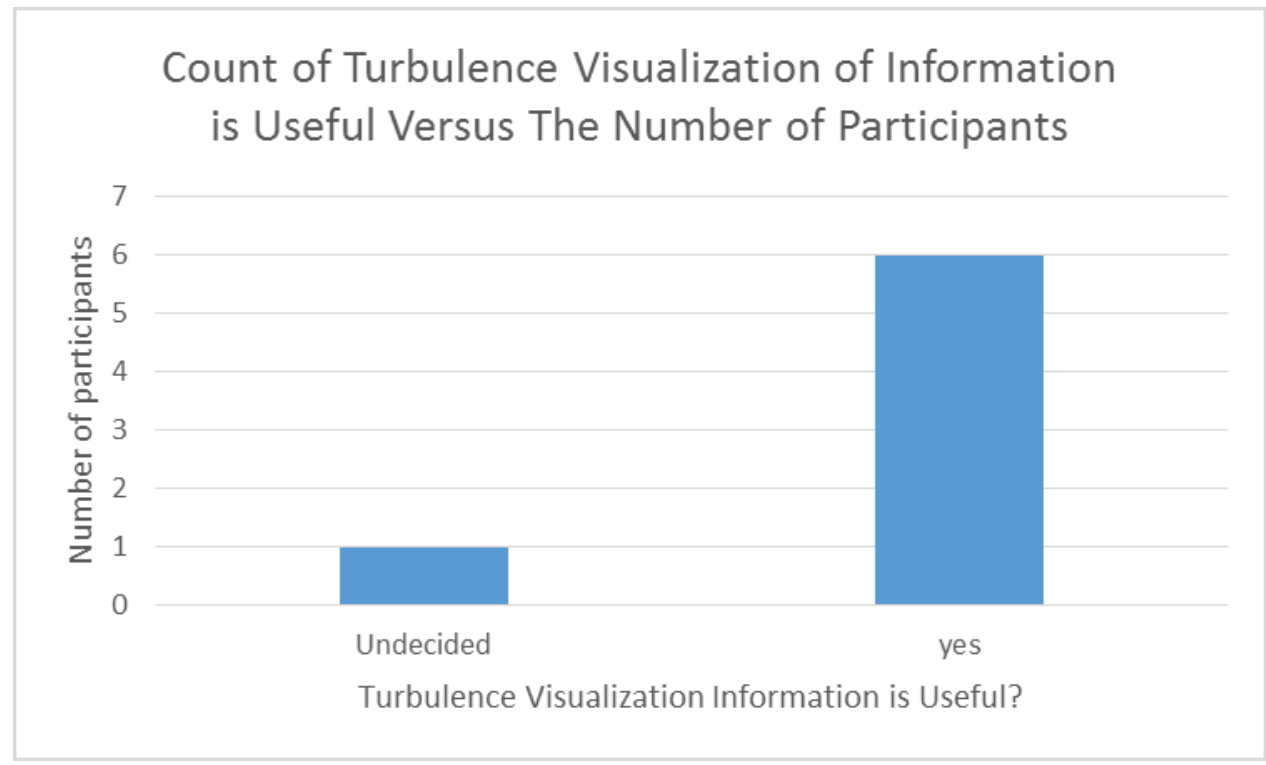

Figure 5-4 Usability of Information versus Number of Participants 


\section{Verification}

This chapter discusses the verification of the design selected from chapter four (4), the velocity vectors. The verification is performed by creating a simulation of the airflow over a 3D model of a ship. The simulation is then loaded onto the $\mathrm{TacView}^{\mathcal{O}}$ to be viewed during pre-approach POF. The 3D dynamic simulation is created at a relative wind used of 55 knots from a direction of 0 green. The development of the turbulence model is detailed in the subsections that follow. For this paper the purpose of simulating the turbulence is to provide a representative presentation of the airflow visually for testing.

\subsection{CFD Turbulence Simulation}

The tool used to create the Computational Fluid Dynamics generated turbulence model for the selected geometry was the ANSYS CFX Academic version 15.0.

\subsubsection{Geometry}

The CPF 3D model (Figure 6-1) involves turbulence of a complexity that is beyond the Reynolds Average Navier-Stokes (RANS) turbulence models. It involves wakes in areas that are shielded by the obstacles that are questionable and assessing these through repeated simulations requires a commitment outside the scope this investigation. 


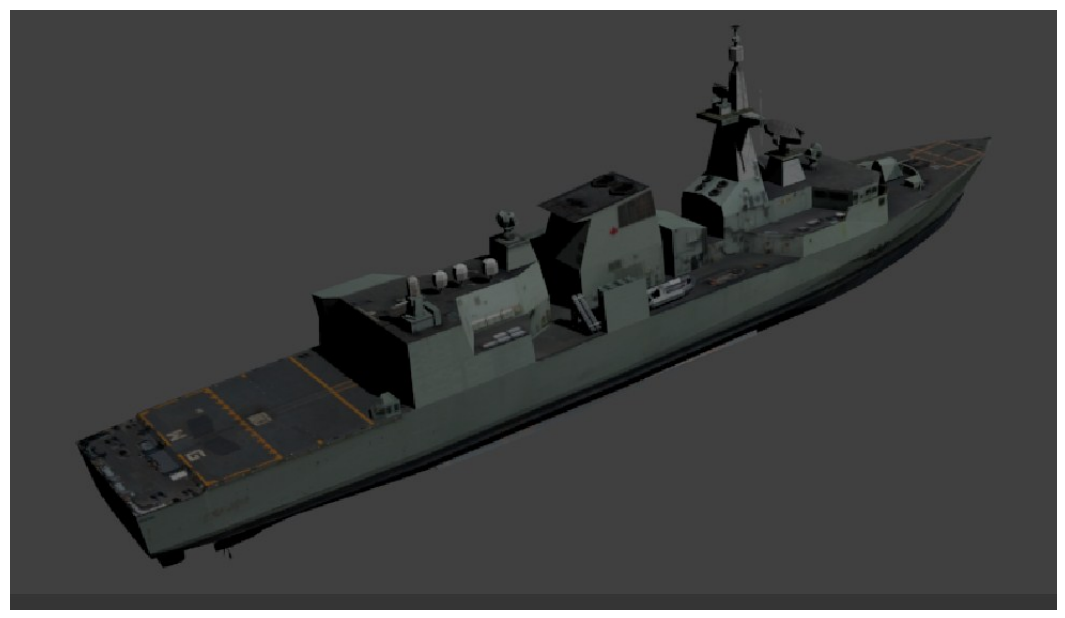

Figure 6-1 3-Dimensional Model of the Canadian Patrol Frigate (CPF) [57]

As a result the simplified model is used (Figure 6-2). The dimensions of the model are similar to the overall dimensions of the CPF. See Table 6.1 for the CPF overall dimensions. 
Table 6.1: CPF Technical Dimensions.

\begin{tabular}{lcc}
\hline \multicolumn{1}{c}{ Dimension } & Units (feet) & Units (metres) \\
\hline \hline Length & 440 & 134 \\
Breadth (includes 10, & 60 & 18 \\
mast) & 54 & 16.5 \\
Depth & & \\
\hline
\end{tabular}

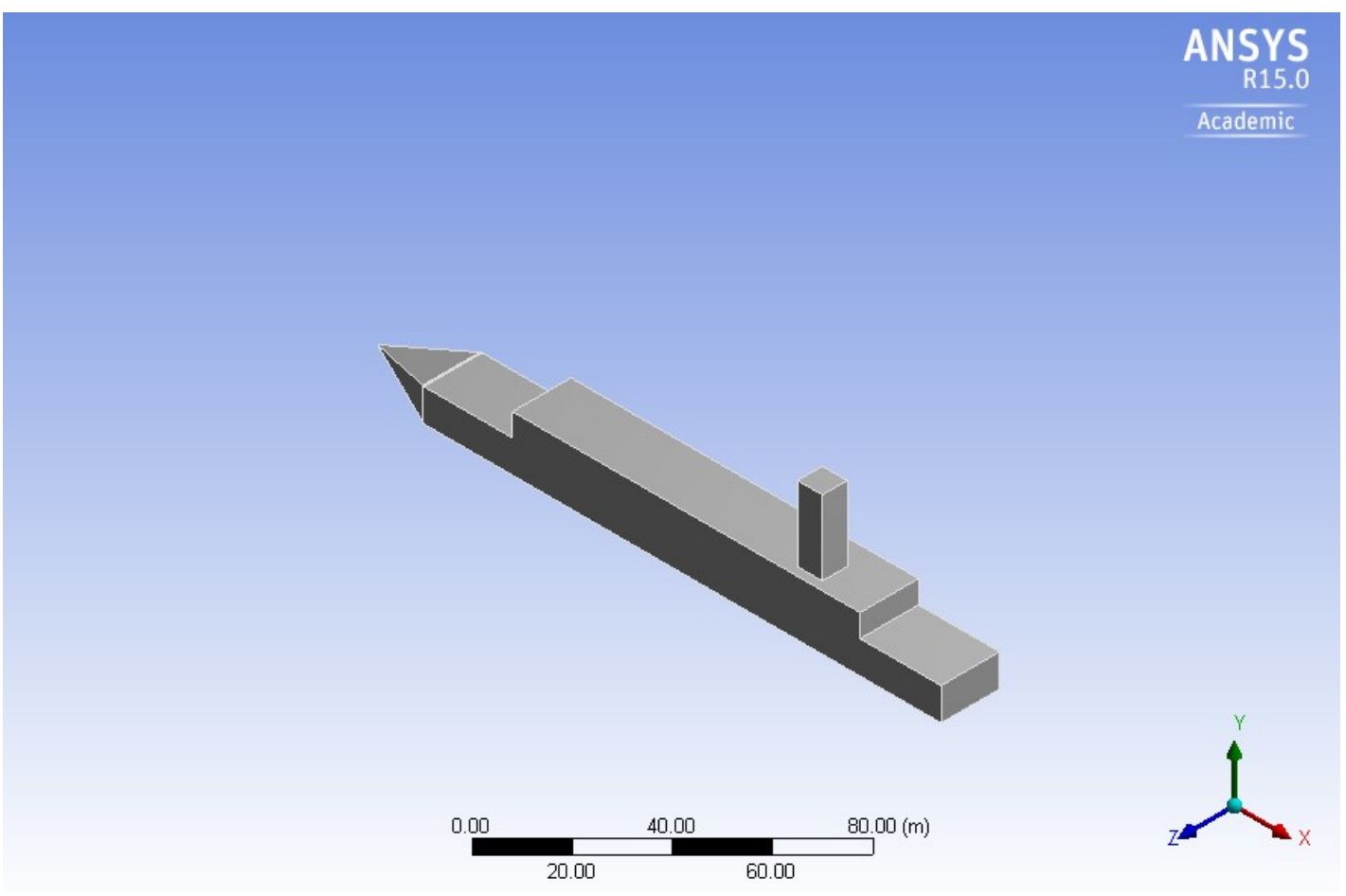

Figure 6-2 Simplified Frigate Shape (SFS2) Geometry 


\subsubsection{Boundary/Initial Conditions}

The turbulence conditions used for the testing of the overall solution is shown in table (Table 6.2). These conditions are typical for operations and are within the GO SHOL established by users for the Sikorsky (S92) helicopter. The ship speed was entered as 0 with a 0 head wind. This allowed the parameters for the wind speed and wind direction to be the relative wind speed and relative wind direction.

Table 6.2: Boundary/Initial Conditions.

\begin{tabular}{lc}
\hline \multicolumn{1}{c}{ Parameter } & Parameter Setting \\
\hline Relative wind Speed & 55 Knots \\
Relative wind direction & $0^{\circ}$ green (port) \\
Temperature & $-5^{\circ} \mathrm{C}$ \\
Ship speed & $0 \mathrm{~km} / \mathrm{hr}$ \\
\hline
\end{tabular}

\subsubsection{Turbulence Model}

The turbulence model used for the reconciling of the turbulence over the SFS2 geometry in the CFX simulation tool is the RANS turbulence Shear Stress Transport (SST) model. The chosen simulation is not subject to any of the weaknesses of other models such as $90^{\circ}$ bends, airfoils and this model assumes an isotropic flow. The SST model performs better near the wall, boundary layers.

In addition to the simplified geometry, the simulation made the following assumptions: 
- Single fluid (air), no considerations for water in the air under the high wind conditions;

- Single fluid (air), no considerations for exhaust gases in the air; and

- The influence of structures in the domain area not considered (e.g. mountain ranges or other ships and aircraft).

\subsubsection{Simulation Mesh}

The statistics for the mesh used on the SFS 11 is shown in Table 6.3

Table 6.3: Table of Mesh Statistics for SFS II 3D Model.

\begin{tabular}{ccc}
\hline Domain & Nodes & Elements \\
\hline \hline Default Domain & 14446 & 78546 \\
\hline
\end{tabular}

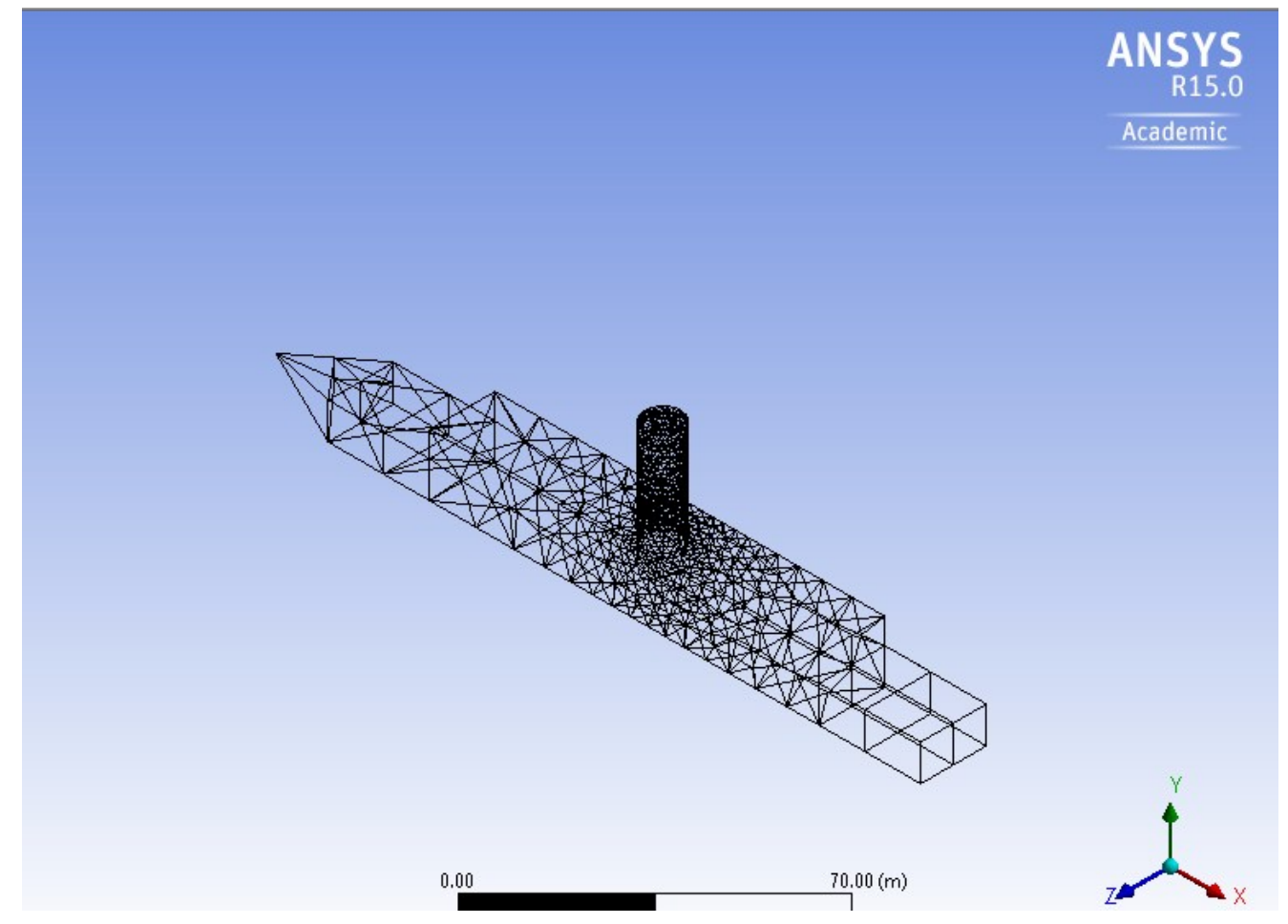

Figure 6-3 Simplified Frigate Shape (SFS2) Mesh 6-71 
Figure 6-3 shows the mesh over the model. The density of the mesh was reduced over the bow and port sections of the ship for clarity in the figure. For the simulation the density in bow and port reflect the density shown for the mast.

The domain area used is ten (10) times the size of the model itself as shown in Figure $5-4$.

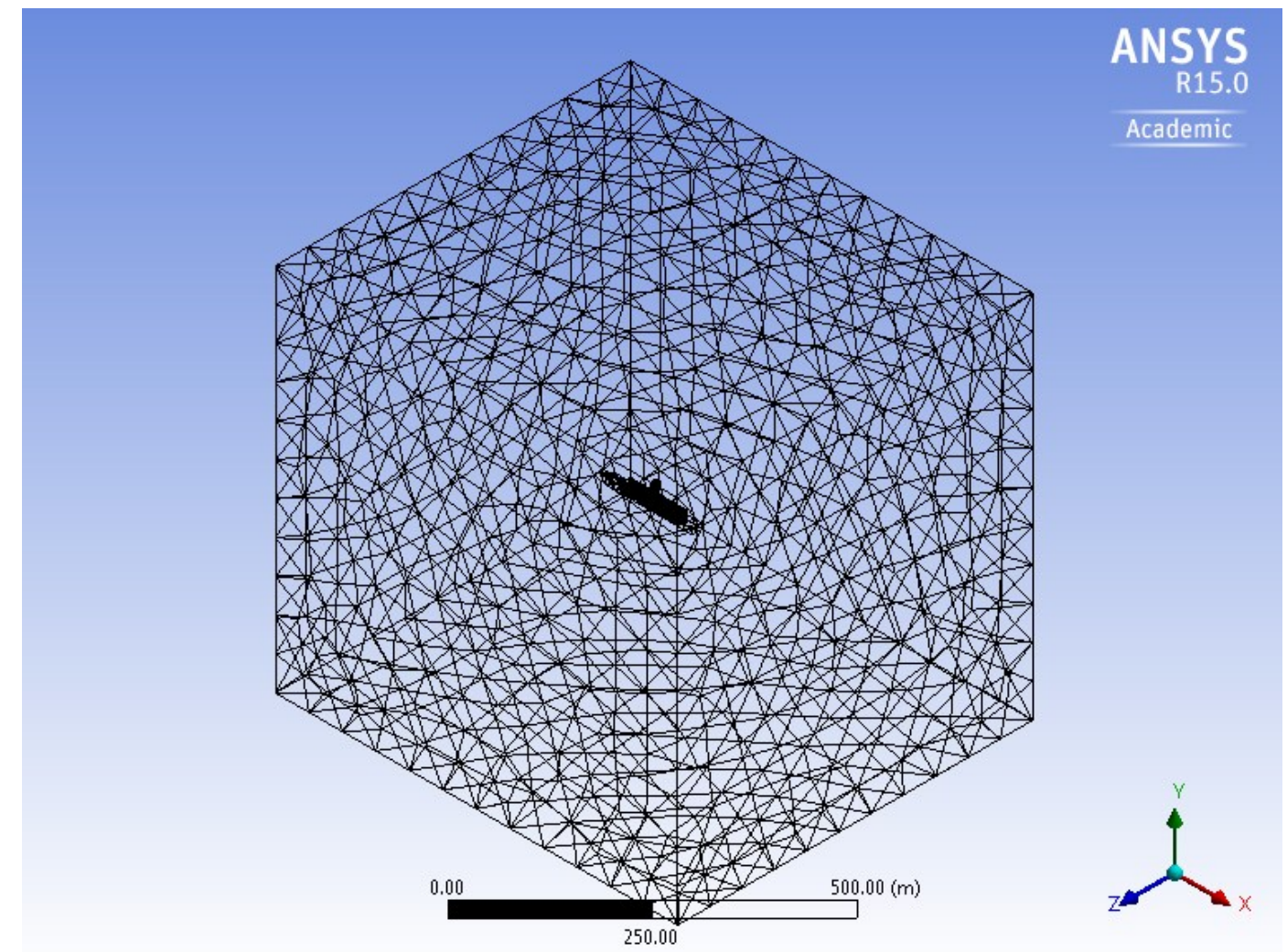

Figure 6-4 Simplified Frigate Shape (SFS2) within Domain Area

Note: The simulation is run on the domain area minus the 3D model. Figure 6-4 shows the ship model within the domain area. The model is laterally centred in the domain area. There is no airflow under the ship. 


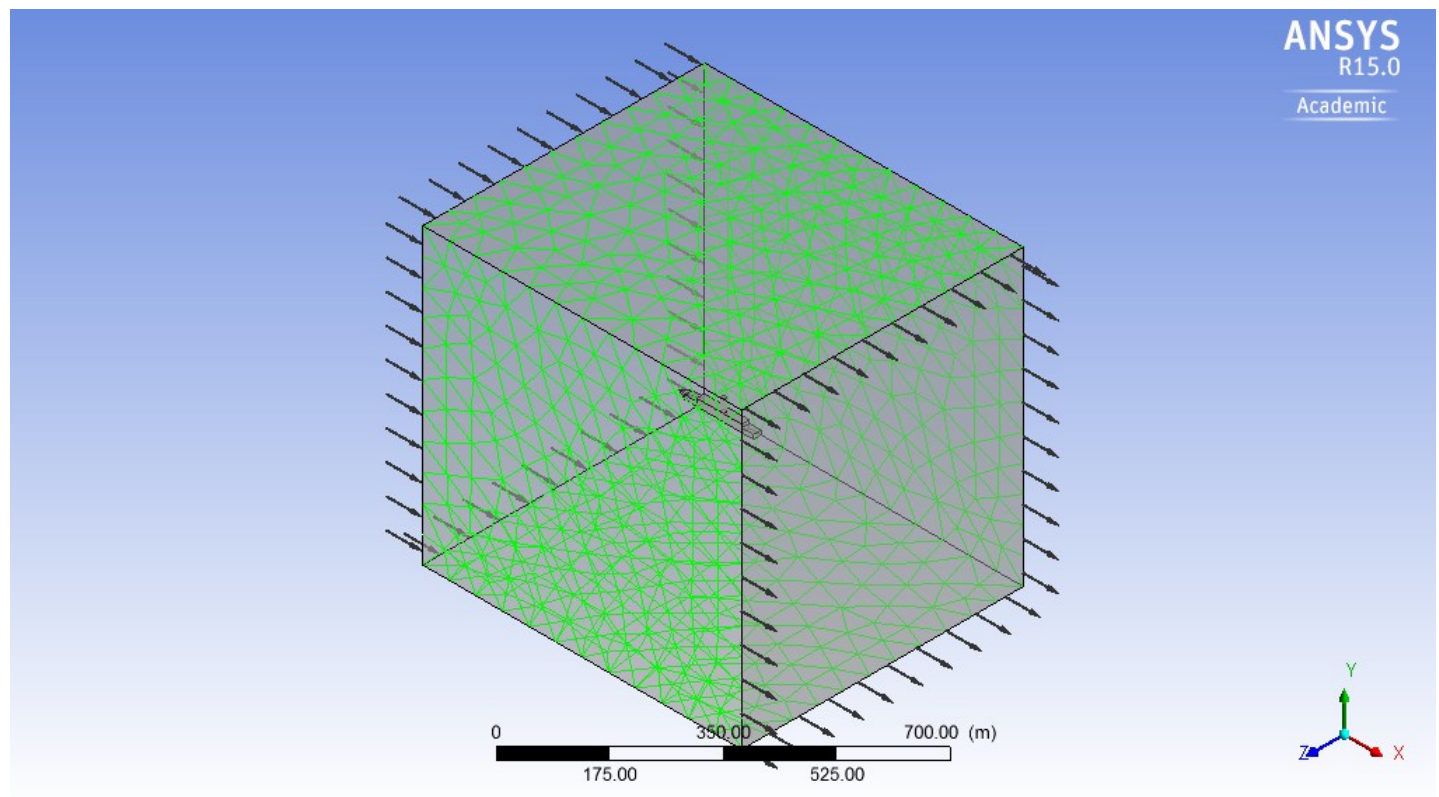

Figure 6-5 Simplified Frigate Shape (SFS2) - Airflow

The air flows through the domain area and the 3D model of the ship is the inner walls of the domain area.

\subsubsection{Turbulence Model Results}

The grid convergence analysis was not performed however a similar 3D model was imported into SolidWorks tool. The two (2) tools produced the same visual results. The simplified model produced comparative results. The turbulence was sensitive to the wind speed. In both cases the simulation was limited by the element quantity. 


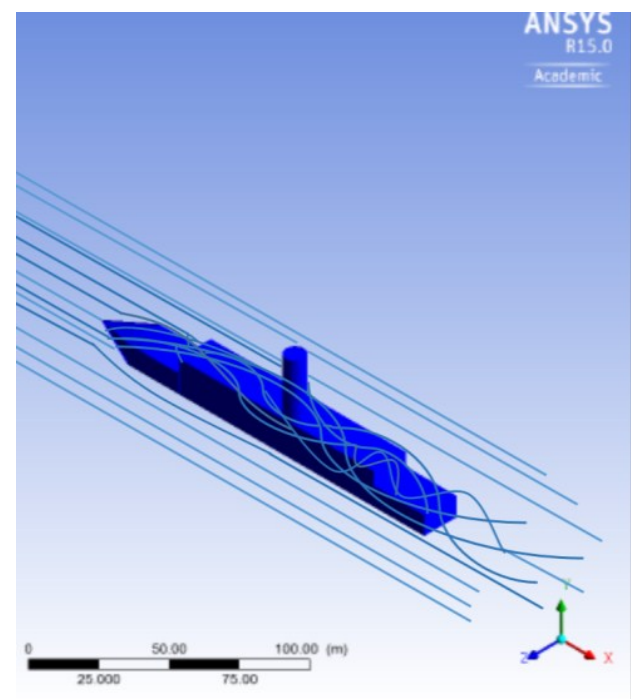

Figure 6-6 Static view of Turbulence Model at $55 \mathrm{KTs}\left(0^{\circ}\right.$ Green) - CFD (ANSYS CFX)

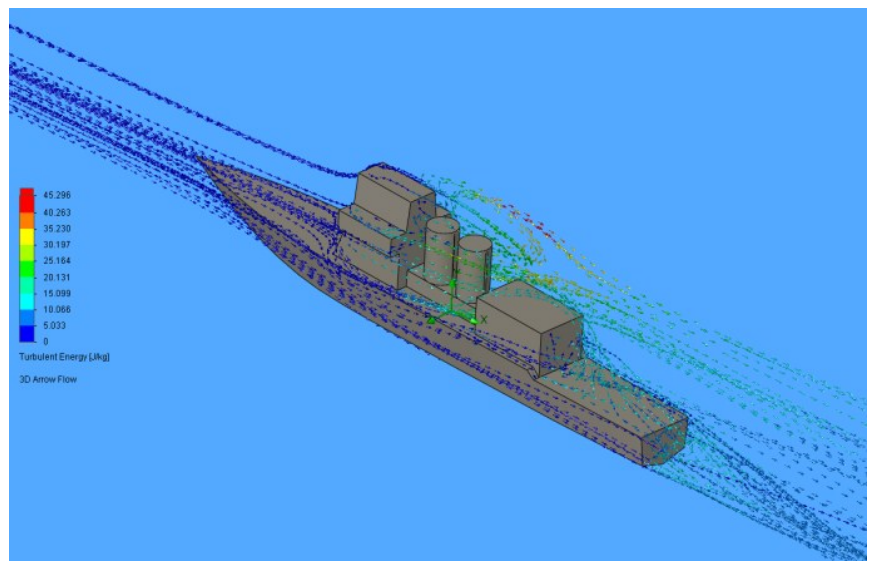

Figure 6-7 Static view of Turbulence Model at $50 \mathrm{KTs}\left(0^{\circ}\right.$ Green $)-$ SolidWorks

Figure 6-6 shows the velocity ribbons produced for the SFS2 using the ANSYS CFX tool. The results were manually modified to reduce the number of visible lines. The limitation of the Academic version of the ANSYS CFX tool is the selection of the colour for the velocity vectors is restricted to the rainbow option. The yellow, red and green variation in colour was manually removed to avoid the confusion of the interpretation of 
the colours. For a complete result the colours would be mapped to the cockpit colours for alerting.

Figure 6-7 shows the results unmodified with the SolidWorks tool. The results utilize vector arrows. 


\subsection{Turbulence Visualization Model Evaluation}

The conceptual user interface as shown in Figure 6-8, is ready for verification. The data presented to the operator incorporates all the requirements resulting from the evaluation (refer to section 4.5.3).

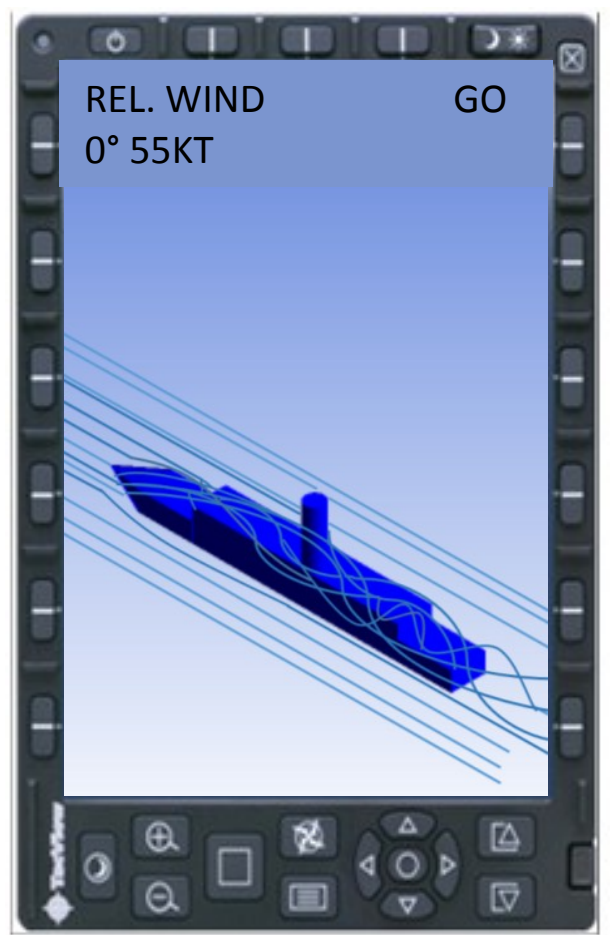

Figure 6-8 Static view of TacView@ Display Presenting Turbulence Information 


\section{Conclusion and Continued Work}

The results show that there would be some benefit from a capability to visualize air turbulence over a landing deck. This is particularly true for applications where the landing deck is unknown such as SAR operations where landing is on a cliff or North American Treaty Organization (NATO) operations where landing is on an ally vessel. In situations where experience is not as extensive (oil rig operations) compared to operations where experience is high (such as tactical missions) and SHOLs are not available, turbulent airflow avoidance and availability would benefit the operator.

Effort is required to further investigate the best way to obtain the information required to present the resulting airflow over the helideck to the operator.

\subsection{Summary}

The CFD simulation as the tool to generate the data required to provide the airflow visualization over the helideck proves to be ineffective today. The detail of the CPF would require over ten (10) million elements for the mesh. A mesh of that complexity would take over a month to run the simulation and would require approximately two (2) dozen processors. The computer required to house these processors results in a large footprint where real estate is already a prime resource and the excess weight would be 
hard to justify because there is no increased capability but improved situational awareness. The capability already exists.

A consideration would be to maintain a database of the simulations as files and the operator can select from the database the configuration of the helideck (i.e. ship type). However, this would not be useable in applications such as the search and rescue operations because the configuration of the model is unknown until the time when the visualization is required. Possible solutions for this application is visualizing the airflow using EVS.

\subsection{Next Steps}

\subsubsection{Test}

\subsubsection{Flight Simulation}

The flight simulation utilizes a ship speed of $24 \mathrm{~km} / \mathrm{hr}$. The turbulence simulation incorporates a ship speed of $0 \mathrm{~km} / \mathrm{hr}$. The relative wind was used in the simulation which is the vector sum of the ship speed and the wind. The true wind for both the flight simulator and the turbulence model simulation is the same, the effect is the same for both simulations.

\subsubsection{Test Environment}

The flight deck is based on the Sikorsky S-92 helicopter. The turbulence model is loaded onto the $\mathrm{TacView}^{\odot}$ (indicate left or right). The $\mathrm{TacView}^{\odot}$ is $\mathrm{CMC}^{-}$Electronics Synthetic Vision System display used for cockpit commercial and military applications. 
The TacView ${ }^{\odot}$ pages that would allow the operator to navigate to the turbulence model by selecting the required input parameters was not considered for this testing. When the flight simulation with the test scenario is being flown by the operators the $\mathrm{TacView}^{\odot}$ is turned on and the operator is presented with the turbulence model as shown in Figure 7-1.

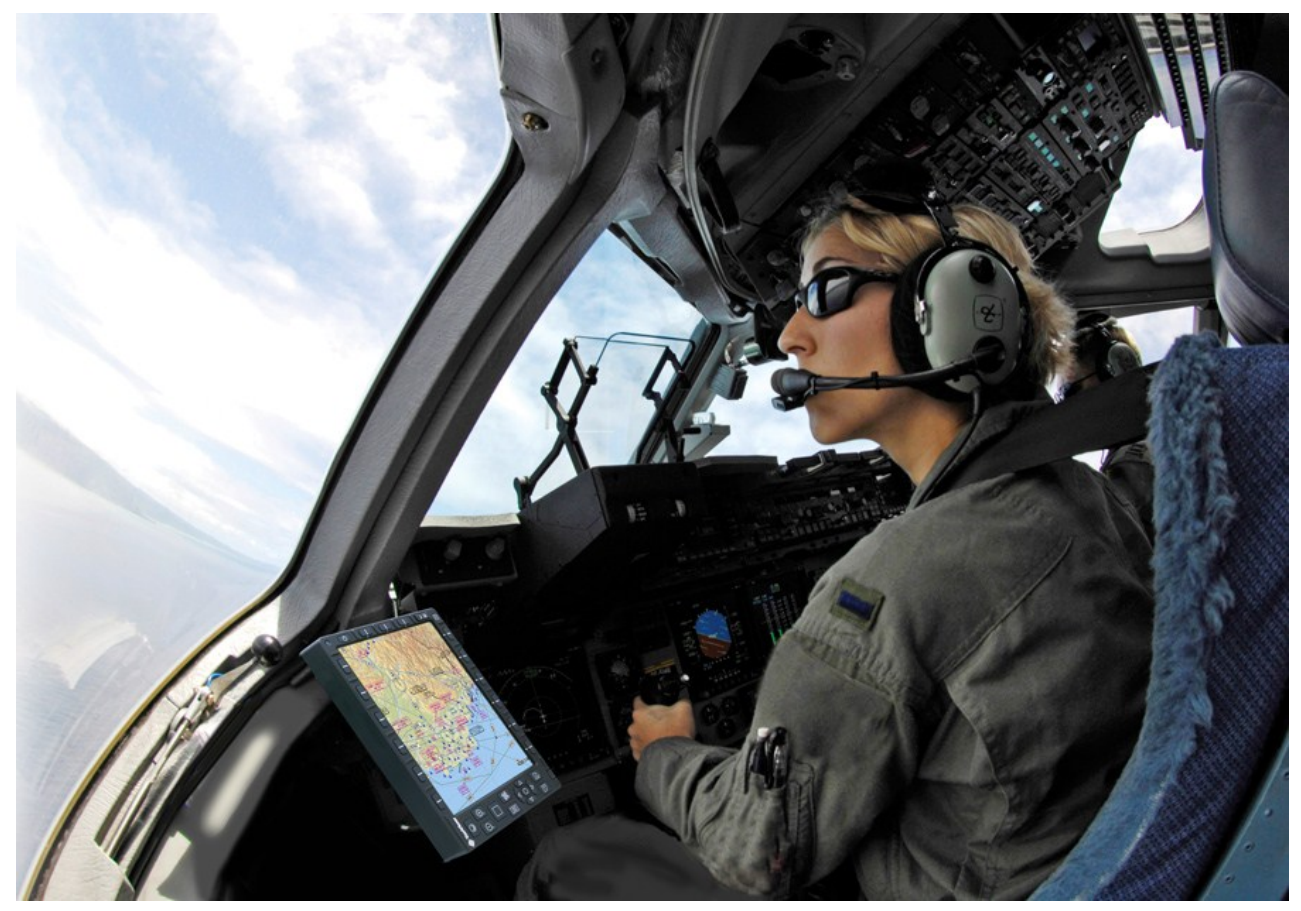

Figure 7-1 TacView $^{\circledR}$ Within Test Environment [17]

\subsubsection{Test Scenario}

Two (2) test scenarios are proposed. Each operator flies both scenarios. Test scenario 1 is an approach to the CPF and the pilot flying is the co-pilot. The approach is uneventful, refer to Figure 4-2 for the approach path.

In test scenario 2 the relative wind causes hazardous turbulence at the edge of the ship where the helicopter traverses to the hover position over the flight deck. The hypothesis 
is that the pilot flying role is transferred to the co-pilot for the approach to occur on the starboard side. This decision is made to avoid the hazardous turbulent airflow shown.

\subsubsection{Evaluate Performance}

Situational awareness is defined as an understanding of what is happening around you and how this information will influence your actions and future events [18]. An operator's knowledge of hazardous turbulent airflow in the approach path of the helicopter results in the operator avoiding the hazardous airflow when feasible. Quantitative data is obtained through having the operator fly test scenario one (1) with the flight path unobstructed with hazardous turbulence. The operator is then exposed to fly test scenario two (2). Test scenario two (2) has hazardous turbulence in the approach path. The decision by the operator is to change the pilot flying to avoid the hazardous airflow. The intent is not to measure the operator's performance but to evaluate what information is enhancing their performance.

The questionnaire during and following the flying of the test augments the measuring situational awareness with confirmation from the operators.

\subsection{Continued Work}

\subsubsection{Challenges}

Although industry has made significant progress with technology and the innovations demonstrated with its uses in our everyday life admirable. Of the two (2) 
technologies explored within this study, both show limitations that require addressing prior to a feasible implementation. The CFD simulations are based on a fixed geometry. The complexity of the geometry of a real frigate requires months for the development of the model. This is true because everything needs to be resolved in the model. Once the model is resolved the running of the simulation requires a lot of computer processing power that cannot be accommodated for on the aircraft (weight and space) as well as it takes days to run the simulation. As a potential solution a database of geometries could be retained on the aircraft, however the limitation still exists for the ability to change the configuration of the geometry if required.

EVS also proved to have its limitations within this application. Further investigation is required to determine if low range sensors can interpret the airflow over a flight deck and render an associated image that is of use to the operator. The image from EVS does not yield quantitative or qualitative information that would provide the detail required to assess the intensity of the airflow. A possible solution to address this is to place an overlay on the EVS image highlighting areas of concern.

\subsubsection{Benefits}

EVS as a technology for consideration had several benefits over CFD. Comments from the SAR operators was that a real time system would facilitate the ability to be able to use the system within the SAR environment where the configuration of the landing area and destinations are not known prior to the operation. 
Oil rig operations would benefit from a system that allowed the oil rig flight operators visibility on the airflow over the flight deck. Their Standard Operating Procedures (SOP) are not developed to the extent that the military is with their SHOLs and therefore errs on the side of safety. The use of a turbulence airflow system would allow the increase of their flight operating limits. This would be particularly useful in the oil rig region of Newfoundland where weather conditions affecting visibility are considered constant.

Flight trials are a standard process within the military for development of Ship Helicopter Operational Procedures (SHOPS) and SHOLS. It is a subjective assessment of determining operating limits based on a quantitative input. As a cost reduction incentive, flight trials can be used for verification method for validating the model as opposed to the extensive exercise of determining the model itself. 


\section{References}

[1] Aragon, C., Berkeley University, California, Improving Aviation Safety with Information Visualization: Airflow Hazard Display for Helicopter Pilots, 2004

[2] Nielsen Norman Group, Article, 10 Usability Heuristics for user Interface Design, http://www.nngroup.com/articles/ten-usability-heuristics/

[3] Nielsen Norman Group, Article, How to conduct a Heuristic Evaluation, http://www.nngroup.com/articles/how-to-conduct-a-heuristic-evaluation/

[4] Colwell, J. L., Defence Research and Development Canada (DRDC) Technical Memo TM 2004-003, Flight Deck Motion System (FDMS): Operating Concepts and System Description by DRDC, 2004

[5] NASA, Article, Making the Skies Safe from Winshear, http://www.nasa.gov/centers/langley/news/factsheets/Windshear.html1992

[6] FAA, Advisory Circular Airworthiness Approval for Aircraft Weather Radar Systems, AC No. 20-182, June 2014

[7] FAA, Advisory Circular Preventing Injuries caused by Turbulence, AC 120-88A 12b and 12c., January 2006

[8] FAA, Advisory Circular, Thunderstorms, AC 00-24C, February 2013

[9] FAA, Advisory Circular, Pilot Windshear Guide, AC 00-54, November 2088

[10] Kaaria, C. H. Paper, Investigating the Impact of Ship Superstructure Aerodynamics on Maritime Helicopter Operations, University of Liverpool (School of Engineering), August 2012

[11] Gawron, Valarie J., CRC Press Taylor and Francis Group, Human Performance, Workload, and Situational Awareness Measures Handbook. 2008. 
[12] Syms, G. F., Aerodynamics laboratory, Institute for Aerospace Research, National Research Council Canada, Simulation of simplified-frigate airwakes using a latticeBoltzmann method. July 23, 2007.

[13] FAA, Technical Standard Order TSO-C63d, Airborne Weather Radar Equipment, 2012

[14] Flight Safety Foundation, Flight Safety Digest, Killers in Aviation: FSF Task Force Presents Facts About Approach-and-landing and Controlled-flight-into-terrain Accidents. Final Report, version 2, 1999. http://flightsafety.org/fsd/fsd_nov-feb99.pdf

[15] Colwell, J. L., Defence Research and Development Canada, Technical Memo TM 2004003, Flight Deck Motion System (FDMS) Operating Concepts and System Description. 2004.

[16] Stone, Brian F., Superintendent Maritime Search and Rescue Canadian Coast Guard Newfoundland and Labrador Region, Presentation, "High Risk, High Rewqard" Search and Rescus and the Oil and Gas Industry off Canada's East Coast - A Sarscene Presentation

[17] CMC Electronics, TacView Portable Mission Display, accessed through http://www.esterline.com/avionicssystems/en-

us/productsservices/aviation/displaysvi

[18] Rogers, Sharp, Preece, Textbook, Interaction Design beyond human-computer interaction. 2011 Wiley

[19] C\&PS Flight Technical Services, Honeywell Presentation, Vision Systems Overview EVS EFVS SVS CVS, January 2013

[20] Honeywell FMS Quarterly Update and Newsletter, Understanding Windshear Detection Systems, January 2011

[21] Pruyn, Peter W, Greenberg Donald P, Paper, Exploring 3D Computer Graphics in Cockpit Avionics, Cornell University, May 1993

[22] John Burt Associates Limited, Offshore Helideck Design Guidelines, BOMEL Limited HSE Health and Safety Executive Publication 
[23] Civil Aviation Authority, CAP-437, Standards for Offshore Helicopter Landing Areas, accessed

https://www.caa.co.uk/application.aspx?catid=33\&pagetype=65\&appid=11\&mode $=$ detai $\underline{1 \& \mathrm{id}=523}$

[24] Valner J., Leighton S. J., Paper, Validation of EGNOS Helicopter Approach Procedures to North Sea Oil Platforms, The Journal of navigation - Issue 62, pages 189-201, 2009

[25] International Civil Aviation Organization, ICAO Annex 14, Volume 11, Aerodrome Standards

[26] Civil Aviation Authority, CAA Paper 99004, Research on Offshore Helideck Environmental Issues, 2000

[27] International Association of Oil and Gas Producers, Report No. 434-2, Risk Assessment Data Directory-Blowout Frequencies, March 2010

[28] BOMEL Ltd. For Health and Safety Executive, Offshore Technology Report 2000/131, Bird Guano Accumulations and Their Effect on Offshore Helicopter Operations, 2000

[29] Fulton, William W., Lappos Nicholas, Paper, WAAS Rotorcraft Infrastructure Development and Public Use Next Generation National Airspace Integration, Department of Transportation, FAA, Bell helicopters, Third Edition

[30] Department of Transportation FAA, Handbook, United States Standard for Terminal Instrument Procedures (TERPS), Third Edition

[31] NAV Canada, Aeronautical Publication, Canada Air pilot Instrument Procedures General pages (CAP-GEN) AIP Canada (ICAO Part 3 - Aerodromes AD), 27 August 2009

[32] Transport Canada Civil Aviation, Staff Instruction, Review and Approval of Air Operator Submitted Helicopter Offshore Approach Procedures, 2009-10-01

[33] U.S. Department of Transportation FAA, Advisory Circular AC No. 90-80B, Approval of Offshore Standard Approach Procedures, Airborne Radar Approaches, and Helicopter En Route Descent Areas, 4/12/99 
[34] TCCA, Commercial Air Service Standards, Part V11, section 704, Commuter Operations, 2009/12/01

[35] TCCA, Commercial Air Service Standards, Part V11, section 724, Commuter Operations - Helicopters, 2008/12/30

[36] Field, Andy, Text, Discovering Statistics Using SPSS, Third Edition, Sage Publications, 2009

[37] Clausing, Donald J., Text, Aviator's Guide to Navigation, Third Edition, McGraw-Hill, 1997

[38] Shneiderman, Ben, Paper, Direct manipulation for Comprehensible, Predictable and Controllable user Interfaces, 1997

[39] Shneiderman, Ben, Paper, We can design better user interfaces: A review of humancomputer interaction styles, 1988

[40] Aragon, Cecilia R., Long Kurtis R., Paper, Airflow Hazard Visualization for Helicopter Pilots: Flight Simulation Study Results, 2005

[41] Aragon, Cecilia R., Paper, Usability Evaluation of a Flight-Deck Airflow Hazard Visualization System

[42] Sorensen, Chris, Macleans Magazine article, Cockpit Crisis, September 5, 2011, page 5661 inclusive.

[43] Nyk1, Scott et al, Paper, A Flight Tested Wake Turbulence Aware Altimeter, Presented at the Conference Advances In Visual Computing $-7^{\text {th }}$ International Symposium, September 2011.

[44] Honeywell Aerospace, Primus Weather Radars, https://aerospace.honeywell.com/ /media/Brochures/BizAvPlatforms/Primus\%20880\%2 0660\%20440\%20Weather\%20Radars.ashx

[45] Rockwell Collins, WXR-2100 MultiScan ThreatTrackTM Weather Radar, https://www.rockwellcollins.com/Data/Products/Radar_and_Surveillance/Weather_Radar /WXR-2100_Weather_Radar_System.aspx 
[46] FLIR, Technical Note, Visualization of Air Flows with an Infrared Camera:

Presentation of a Simple Technique and Examples of Data Analysis, 2011

[47] DRCD, DRDC Technology Supports Safer and Smoothr Landings for the Royal Canadian Navy, http://www.drdc-rddc.gc.ca/en/dynamic-article.page?doc=drdctechnology-supports-safer-and-smoother-landings-at-sea-for-the-royal-canadian$\underline{\text { navy/i2 } \mathrm{kahg} 7 \mathrm{t}}$

[48] Department of Defense Design Criteria Standard, Aircrew Station Alerting Systems, MILSTD-411F, 10 March 1997

[49] Department of Defense Design Criteria Standard, Human Engineering Design Criteria for Military Systems, Equipment and Facilities, MIL-STD-1472F, 23 August 1999

[50] Librapix Image Library. Oil Rig photos 2799, http://www.oilrigphotos.com/picture/number2799.asp, 2011

[51] Likert, Rensis, Archives of Psychology 140, "A Technique for the Measurement of Attitudes", pages 1-55, 1932.

[52] Aircraft Crashes Record Office Geneva, Switzerland, www.baaa-acro.com

[53] Transport Canada Staff Instruction SI 700-003 Issue 01, section 4.2 (e)(ii) for offshore approach procedures.

[54] Energy-Pedia News, article dated 21Jul2009, titled UK: BP North Sea Production Output Could Drop 9\% This Year.

[55] Aeronautical Information manual/ Federal Aviation Regulations 2007

[56] GPS World Magazine, April 2010

[57] Kyle_Nelson30@hotmail.com 


\section{Appendix A - Turbulence Visualization Evaluation}

Design Principles and Usability Heuristics Evaluation 
Esterline CMC Electronics

Design Principles

and Usability

Heuristics

Evaluation for

Defence Industrial

Research Program

(DIRP)

Turbulence Visualization Evaluation

Diane Hould 
Turbulence Visualization Evaluation

\section{A. Design Principles and Usability Heuristic Evaluation Instructions}

Helicopters are sensitive to airflow hazards near oil rigs, vessels and ships. Hazards manifest in the form of vortices, downdrafts, low level wind shear, microbursts and turbulence as a result of structures and vegetation in the vicinity. These airflow hazards can make helicopter landing challenging.

Canadian helicopter to ship operating procedures develop a go/no-go indication in the form of a Shipborne Helicopter Operating Procedures (SHOPS) publication based on the relative wind direction and magnitude, the ship and helicopter limits and configuration.

The intent is to present a turbulence model based on the ship configuration, helicopter configuration and the relative wind (magnitude and direction) to the operator that will identify the areas of turbulence over the flight deck that will aid operators with the landing. This is to be displayed on the Electronic Flight Bag (EFB) in the cockpit. The simulated image shows expected turbulence based on the physical structure of the platform, its orientation, and the selected relative wind parameters.

The operator is to view the airflow visualization over the landing area prior to the approach phase of flight (POF).

This questionnaire is to assist in the evaluation of the proposed airflow visualization designs against the requirements, design principles and usability heuristics. 
Turbulence Visualization Evaluation

\section{B. Part I Demographics}

Please provide answers to the following demographic questions.

Name:

Current occupation:

Date of last flight:

Approximate number of shipboard landings:

Current Aircraft

Type:

Total number of hours on type:

Total number of hours on type performing ship/aircraft operations:

Previous Aircraft

Type:

Total number of flight hours on all previous types:

Total number of hours on all previous types performing ship/aircraft operations:

Previous Aircraft

Type:

Total number of flight hours on all previous types:

Total number of hours on all previous types performing ship/aircraft operations: 
Turbulence Visualization Evaluation

\section{Part II - Information Requirements}

On the following pages you will be presented with a series of statements addressing the information required for a helicopter operator to make an approach and landing over the landing area of a frigate. Please rate your level of agreement with all of the statements related to each design.

If you respond with Strongly Disagree or Disagree to any of the statements, please provide the reason in the appropriate comment section. 
Turbulence Visualization Evaluation

\section{C.1. Information Required / Relative Wind - Speed Component}

\begin{tabular}{|c|c|c|c|c|c|c|c|}
\hline \multicolumn{8}{|c|}{ Information Required - Relative Wind Speed } \\
\hline & Statement & $\begin{array}{l}\text { Strongly } \\
\text { Disagree }\end{array}$ & Disagree & $\begin{array}{l}\text { Border } \\
\text {-line }\end{array}$ & Agree & $\begin{array}{l}\text { Strongly } \\
\text { Agree }\end{array}$ & Comment \\
\hline C.1.1 & $\begin{array}{l}\text { To make a helicopter approach to a } \\
\text { frigate, I need to know the speed of the } \\
\text { relative wind. }\end{array}$ & & & & & & \\
\hline C. 1.2 & $\begin{array}{l}\text { Two and a half }(2.5) \text { knots }(\mathrm{KT}) \text { for a } \\
\text { resolution of the speed of the relative } \\
\text { wind is satisfactory. }\end{array}$ & & & & & & \\
\hline C.1.3 & $\begin{array}{l}\text { I want the speed of the relative wind } \\
\text { displayed numerically (e.g. } 10 \mathrm{KTS} \text { ) }\end{array}$ & & & & & & \\
\hline C.1.4 & $\begin{array}{l}\text { I want the speed of the relative wind } \\
\text { displayed graphically. }\end{array}$ & & & & & & \\
\hline C. 1.5 & $\begin{array}{l}\text { If a GO/NO-GO indication is provided } \\
\text { to indicate whether or not to proceed } \\
\text { with an approach, I do NOT need the } \\
\text { speed of the relative wind displayed. }\end{array}$ & & & & & & \\
\hline
\end{tabular}


Turbulence Visualization Evaluation

\section{C.2. Information Required / Relative Wind - Azimuth}

\begin{tabular}{|c|c|c|c|c|c|c|c|}
\hline \multicolumn{8}{|c|}{ Information Required - Relative Wind Azimuth } \\
\hline & Statement & $\begin{array}{l}\text { Strongly } \\
\text { Disagree }\end{array}$ & Disagree & $\begin{array}{l}\text { Border } \\
\text {-line }\end{array}$ & Agree & $\begin{array}{l}\text { Strongly } \\
\text { Agree }\end{array}$ & Comment \\
\hline C.2.1 & $\begin{array}{l}\text { To make a helicopter approach to a } \\
\text { frigate, I need to know the direction of } \\
\text { the relative wind (azimuth). }\end{array}$ & & & & & & \\
\hline C.2.2 & $\begin{array}{l}\text { I want the direction of the relative wind } \\
\text { to include the red/green Port/Starboard } \\
\text { side indication. }\end{array}$ & & & & & & \\
\hline C.2.3 & $\begin{array}{l}\text { I don't care if the direction of the } \\
\text { relative wind includes the red/green side } \\
\text { indication. }\end{array}$ & & & & & & \\
\hline C.2.4 & $\begin{array}{l}\text { Five }(5) \text { degrees }\left({ }^{\circ}\right) \text { for a resolution of } \\
\text { the direction of the relative wind is } \\
\text { satisfactory. }\end{array}$ & & & & & & \\
\hline C. 2.5 & $\begin{array}{l}\text { I want the direction of the relative wind } \\
\text { displayed numerically }\left(\text { e.g. } 15^{\circ}\right)\end{array}$ & & & & & & \\
\hline C.2.6 & $\begin{array}{l}\text { I want the direction of the relative wind } \\
\text { displayed graphically (e.g. arrow). }\end{array}$ & & & & & & \\
\hline C.2.7 & $\begin{array}{l}\text { If a GO / NO-GO indication is provided } \\
\text { to indicate whether or not to proceed } \\
\text { with an approach, I do NOT need the } \\
\text { direction of the relative wind displayed. }\end{array}$ & & & & & & \\
\hline
\end{tabular}


Turbulence Visualization Evaluation

\section{C.3. Information Required / SHOPS}

\begin{tabular}{|c|c|c|c|c|c|c|c|}
\hline \multicolumn{8}{|c|}{ Information Required - SHOPS } \\
\hline & Statement & $\begin{array}{l}\text { Strongly } \\
\text { Disagree }\end{array}$ & Disagree & Border & Agree & Strongly & Comment \\
\hline $\begin{array}{ll}\text { C.3.1 } \\
\end{array}$ & $\begin{array}{l}\text { To make a helicopter approach to a } \\
\text { ship, I need to know the ship type. }\end{array}$ & & & & & & \\
\hline C.3.2 & $\begin{array}{l}\text { If the relative wind is within the } \\
\text { operational limits of the SHOPS, I will } \\
\text { proceed with the approach (helicopter to } \\
\text { ship). }\end{array}$ & & & & & & \\
\hline C.3.3 & $\begin{array}{l}\text { I have proceeded with an approach that } \\
\text { is within the operational limits defined } \\
\text { in the associated SHOPS and was } \\
\text { subjected to turbulence that required the } \\
\text { ship to alter course (change the relative } \\
\text { wind) to allow the landing to occur. }\end{array}$ & & & & & & \\
\hline C.3.4 & $\begin{array}{l}\text { I want the ship type shown on the } \\
\text { display with the airflow visualization. }\end{array}$ & & & & & & \\
\hline C.3.5 & $\begin{array}{l}\text { If a GO / NO-GO indication is provided } \\
\text { to indicate whether or not to proceed } \\
\text { with an approach, I do NOT need the } \\
\text { ship type displayed. }\end{array}$ & & & & & & \\
\hline
\end{tabular}


Turbulence Visualization Evaluation

\section{C.4. Information Required / True Wind}

\begin{tabular}{|c|c|c|c|c|c|c|c|}
\hline \multicolumn{8}{|c|}{ Information Required - SHOPS } \\
\hline & Statement & $\begin{array}{l}\text { Strongly } \\
\text { Disagree }\end{array}$ & Disagree & $\begin{array}{l}\text { Border } \\
\text {-line }\end{array}$ & Agree & $\begin{array}{l}\text { Strongly } \\
\text { Aoree }\end{array}$ & Comment \\
\hline C.3.1 & $\begin{array}{l}\text { To make a GO / NO-GO decision for a } \\
\text { helicopter approach to a frigate, I need } \\
\text { to know the direction of the True wind } \\
\text { (azimuth). }\end{array}$ & & & & & & \\
\hline C.3.2 & $\begin{array}{l}\text { To make a GO / NO-GO decision for a } \\
\text { helicopter approach to a frigate, I do } \\
\text { need to know the speed of the True } \\
\text { wind (speed/strength). }\end{array}$ & & & & & & \\
\hline C.3.3 & $\begin{array}{l}\text { I want the speed of the true wind } \\
\text { displayed numerically (e.g. } 10 \mathrm{KTS} \text { ). }\end{array}$ & & & & & & \\
\hline C.3.4 & $\begin{array}{l}\text { I want the speed of the true wind } \\
\text { displayed graphically. }\end{array}$ & & & & & & \\
\hline C.3.5 & $\begin{array}{l}\text { If a GO/NO-GO indication is provided, } \\
\text { I do need the speed of the true wind } \\
\text { displayed. }\end{array}$ & & & & & & \\
\hline C.3.6 & $\begin{array}{l}\text { If a } \mathrm{GO} / \mathrm{NO}-\mathrm{GO} \text { indication is provided, } \\
\text { I do need the direction of the true wind } \\
\text { displayed. }\end{array}$ & & & & & & \\
\hline C.3.7 & $\begin{array}{l}\text { I want the true wind to be displayed on } \\
\text { the display showing the airflow over the } \\
\text { ship deck. }\end{array}$ & & & & & & \\
\hline
\end{tabular}


Turbulence Visualization Evaluation

\section{D.Part III - Design}

On the following pages you will be presented with a design visualizing turbulence on a frigate followed by a series of statements. Please rate your level of agreement with all of the statements related to each design.

If you respond with Strongly Disagree or Disagree to any of the statements, please provide the reason in the appropriate comment section. 


\section{D.1. Design A (Red areas indicating hazardous airflow)}

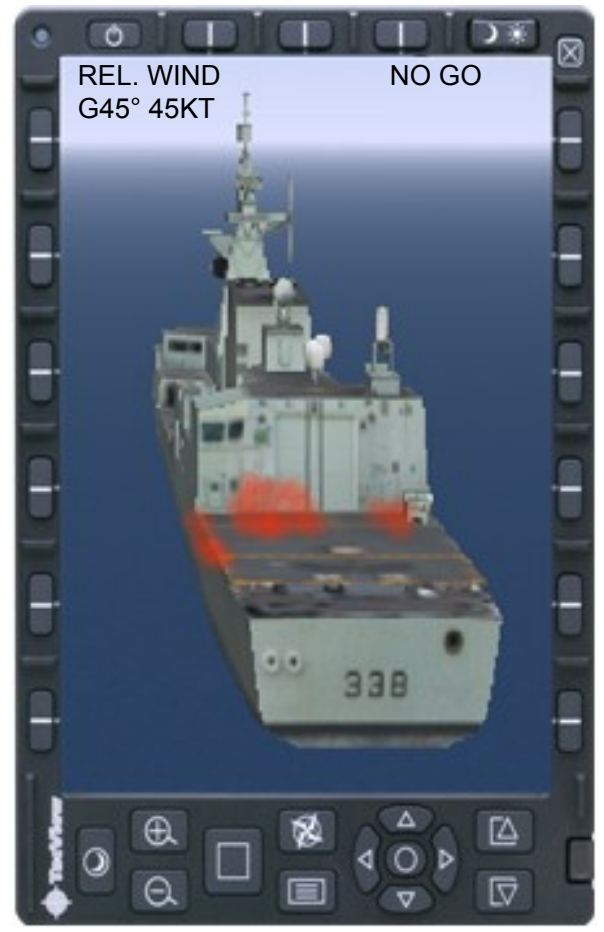

Figure D-1: Design A

\begin{tabular}{|c|c|c|c|c|c|c|c|}
\hline \multicolumn{8}{|c|}{ Design A } \\
\hline & Statement & $\begin{array}{l}\text { Strongly } \\
\text { Disagree }\end{array}$ & $\begin{array}{l}\text { Disagre } \\
\mathrm{e}\end{array}$ & $\begin{array}{l}\text { Borde } \\
\text { r-line }\end{array}$ & Agree & $\begin{array}{l}\text { Strongly } \\
\text { Agree }\end{array}$ & Comment \\
\hline D.1.1 & $\begin{array}{l}\text { The red blobs are a good representation of } \\
\text { hazardous airflow. }(4.2 .1,4.2 .2)^{5}\end{array}$ & & & & & & \\
\hline D.1.2 & $\begin{array}{l}\text { It is clear that there are three (3) distinct } \\
\text { areas of hazardous airflow. (4.2.1 and 4.3.1) }\end{array}$ & & & & & & \\
\hline D.1.3 & $\begin{array}{l}\text { It is clear that the red blobs are based on the } \\
\text { relative wind parameters displayed. }(4.2 .1)\end{array}$ & & & & & & \\
\hline D.1.4 & $\begin{array}{l}\text { I have a clear graphical indication of NOT } \\
\text { to proceed with the approach. }(4.2 .3)\end{array}$ & & & & & & \\
\hline D.1.5 & $\begin{array}{l}\text { It is clear that where there are no red blobs } \\
\text { there is NO hazardous airflow. }\end{array}$ & & & & & & \\
\hline D.1.6 & $\begin{array}{l}\text { The relative wind speed presented helps with } \\
\text { the GO/NO-GO decision. }(4.3 .3)\end{array}$ & & & & & & \\
\hline D.1.7 & $\begin{array}{l}\text { The relative wind direction helps with the } \\
\text { GO / NO-GO decision. (3.3.3) }\end{array}$ & & & & & & \\
\hline D.1.8 & $\begin{array}{l}\text { It is clear, the NO-GO presented indicates } \\
\text { not to proceed with approach. }\end{array}$ & & & & & & \\
\hline D.1.9 & $\begin{array}{l}\text { I do NOT need the ship identifier displayed } \\
\text { on this screen. }\end{array}$ & & & & & & \\
\hline
\end{tabular}

\footnotetext{
${ }^{5}$ These section references are for evaluation purpose only. They refer to the sections in the thesis write-up that discuss the design principle or heuristic usability principle. As a participant, they are to be ignored.
} 
Turbulence Visualization Evaluation

\section{D.2. Design A1}

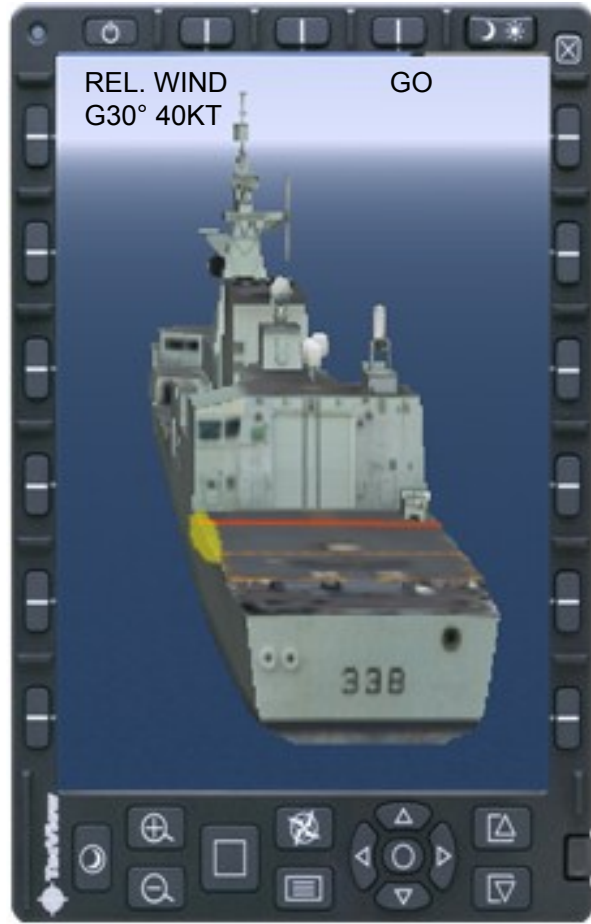

Figure D-2: Design A1

\begin{tabular}{|c|c|c|c|c|c|c|c|}
\hline \multicolumn{8}{|c|}{ Design A1 } \\
\hline & Statement & Strongly & Disagree & Border & Agree & Strongly & Comment \\
\hline D.2.1 & $\begin{array}{l}\text { It is clear that the yellow blob represents } \\
\text { airflow that requires caution. }(3.2 .1,3.2 .2)\end{array}$ & & & & & & \\
\hline $\mathrm{D} 2.2$ & $\begin{array}{l}\text { It is clear that airflow over deck is within } \\
\text { helicopter/ship operating limits. }\end{array}$ & & & & & & \\
\hline D.2.3 & $\begin{array}{l}\text { It is clear that there is NO hazardous } \\
\text { airflow detected. (3.2.1 and 3.3.1) }\end{array}$ & & & & & & \\
\hline D.2.4 & $\begin{array}{l}\text { It is clear that there is one (1) distinct area } \\
\text { of airflow that requires caution. (4.2.1 and } \\
4.3 .1)\end{array}$ & & & & & & \\
\hline D.2.5 & $\begin{array}{l}\text { The yellow blob is a good representation } \\
\text { of airflow that requires caution. (4.2.1, } \\
4.2 .2)\end{array}$ & & & & & & \\
\hline D.2.6 & $\begin{array}{l}\text { Knowledge of airflow that requires caution } \\
\text { will aid in the landing. }\end{array}$ & & & & & & \\
\hline D.2.7 & $\begin{array}{l}\text { I have a clear graphical indication of to } \\
\text { proceed with the approach. }(4.2 .3)\end{array}$ & & & & & & \\
\hline D.2.8 & $\begin{array}{l}\text { The relative wind speed presented helps } \\
\text { with the GO /NO-GO decision. }(4.3 .3)\end{array}$ & & & & & & \\
\hline D.2.9 & $\begin{array}{l}\text { The relative wind direction helps with the } \\
\text { GO / NO-GO decision. (3.3.3) }\end{array}$ & & & & & & \\
\hline D.2.10 & $\begin{array}{l}\text { It is clear that the GO presented indicates } \\
\text { to proceed with the approach. }\end{array}$ & & & & & & \\
\hline
\end{tabular}


Turbulence Visualization Evaluation

\section{D.3. Design A2}

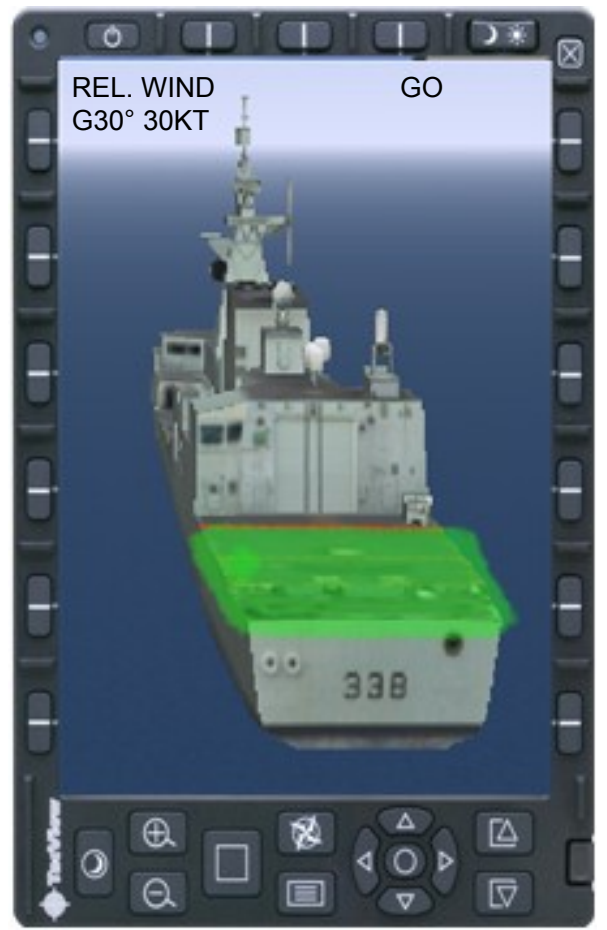

Figure D-3: Design A2

\begin{tabular}{|c|c|c|c|c|c|c|c|}
\hline \multicolumn{8}{|c|}{ Design A2 } \\
\hline \multicolumn{2}{|r|}{ Statement } & Strongly & Disagree & Border & Agree & Strongly & Comment \\
\hline $\begin{array}{c}\text { D.3. } \\
1\end{array}$ & $\begin{array}{l}\text { It is clear that the green mass represents } \\
\text { non-turbulent airflow. }(3.2 .1,3.2 .2)\end{array}$ & & & & & & \\
\hline $\begin{array}{c}\text { D.3. } \\
2\end{array}$ & $\begin{array}{l}\text { It is clear that airflow over deck is within } \\
\text { helicopter/ship operating limits. }\end{array}$ & & & & & & \\
\hline $\begin{array}{c}\text { D. } 3 . \\
3\end{array}$ & $\begin{array}{l}\text { It is clear that there is NO hazardous } \\
\text { airflow detected. (3.2.1 and 3.3.1) }\end{array}$ & & & & & & \\
\hline $\begin{array}{c}\text { D.3. } \\
4\end{array}$ & $\begin{array}{l}\text { It is clear that the non-turbulent airflow } \\
\text { extends beyond the deck surface. ( } 4.2 .1 \text { and } \\
\text { 4.3.1) }\end{array}$ & & & & & & \\
\hline $\begin{array}{c}\text { D.3. } \\
5\end{array}$ & $\begin{array}{l}\text { The green mass is a good representation of } \\
\text { non-turbulent airflow. }(4.2 .1,4.2 .2)\end{array}$ & & & & & & \\
\hline $\begin{array}{c}\text { D.3. } \\
6\end{array}$ & $\begin{array}{l}\text { Knowledge of non-turbulent airflow will } \\
\text { aid in the landing. }\end{array}$ & & & & & & \\
\hline $\begin{array}{c}\text { D.3. } \\
7\end{array}$ & $\begin{array}{l}\text { I have a clear graphical indication of to } \\
\text { proceed with the approach. }(4.2 .3)\end{array}$ & & & & & & \\
\hline $\begin{array}{c}\text { D. } 3 . \\
8\end{array}$ & $\begin{array}{l}\text { The GO presented indicates to proceed with } \\
\text { approach. }\end{array}$ & & & & & & \\
\hline
\end{tabular}


Turbulence Visualization Evaluation

\section{D.4. Design B}

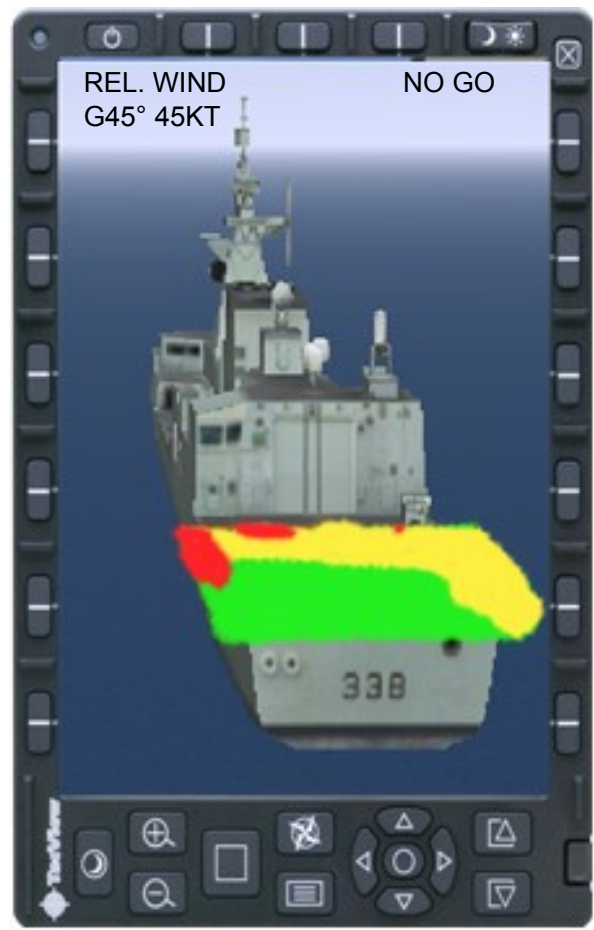

Figure D-4: Design B

\begin{tabular}{|c|c|c|c|c|c|c|c|}
\hline \multicolumn{8}{|c|}{ Design B } \\
\hline & Statement & Strongly & Disagree & Border & Agree & Strongly & Comment \\
\hline D.4.1 & $\begin{array}{l}\text { It is clear the red areas indicate hazardous } \\
\text { airflow. }\end{array}$ & & & & & & \\
\hline $\begin{array}{l}\text { D.4.2 } \\
\end{array}$ & $\begin{array}{l}\text { It is clear the yellow areas are areas that } \\
\text { require caution. Caution implying will } \\
\text { cause difficulty in landing but not beyond } \\
\text { limits. }\end{array}$ & & & & & & \\
\hline $\begin{array}{l}\text { D.4.3 } \\
\end{array}$ & $\begin{array}{l}\text { It is clear that the green areas represent } \\
\text { non-turbulent flow. }\end{array}$ & & & & & & \\
\hline D.4.4 & $\begin{array}{l}\text { Knowledge of the location of the different } \\
\text { airflow intensities will aid in the landing. }\end{array}$ & & & & & & \\
\hline D.4.5 & $\begin{array}{l}\text { It is clear that the NO-GO presented } \\
\text { indicates NOT to proceed with approach. }\end{array}$ & & & & & & \\
\hline D.4.6 & $\begin{array}{l}\text { The graphical image matches the NO-GO } \\
\text { presented. }\end{array}$ & & & & & & \\
\hline $\begin{array}{l}\text { D.4.7 } \\
\end{array}$ & $\begin{array}{l}\text { The relative wind speed presented helps } \\
\text { with the GO /NO-GO decision. }(4.3 .3)\end{array}$ & & & & & & \\
\hline $\begin{array}{l}\text { D. } 4.8 \\
\end{array}$ & $\begin{array}{l}\text { The relative wind direction helps with the } \\
\text { GO / NO-GO decision. (3.3.3) }\end{array}$ & & & & & & \\
\hline
\end{tabular}


Turbulence Visualization Evaluation

\section{D.5. Design B1}

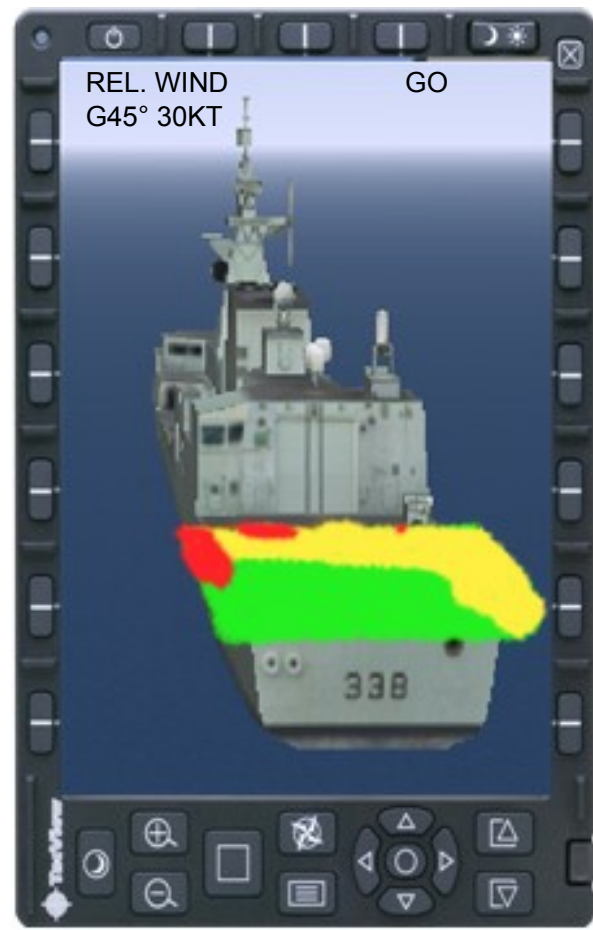

Figure D-5: Design B1

\begin{tabular}{|c|c|c|c|c|c|c|c|}
\hline \multicolumn{8}{|c|}{ Design B1 } \\
\hline & Statement & Strongly & Disagree & Border & Agree & Strongly & Comment \\
\hline D.5.1 & $\begin{array}{l}\text { It is clear the red areas indicate hazardous } \\
\text { airflow. Beyond the capabilities of the } \\
\text { aircraft. }\end{array}$ & & & & & & \\
\hline D.5.2 & $\begin{array}{l}\text { It is clear the yellow areas are areas that } \\
\text { require caution. }\end{array}$ & & & & & & \\
\hline D.5.3 & $\begin{array}{l}\text { It is clear that the green areas represent } \\
\text { non-turbulent flow. }\end{array}$ & & & & & & \\
\hline D.5.4 & $\begin{array}{l}\text { Knowledge of the location of the different } \\
\text { airflow intensities will aid in the landing. }\end{array}$ & & & & & & \\
\hline D.5.5 & $\begin{array}{l}\text { I have a clear graphical indication of to } \\
\text { proceed with the approach. }(4.2 .3)\end{array}$ & & & & & & \\
\hline D.5.6 & $\begin{array}{l}\text { It is clear that the GO presented indicates } \\
\text { to proceed with approach. }\end{array}$ & & & & & & \\
\hline D.5.7 & $\begin{array}{l}\text { The graphical image matches the GO } \\
\text { presented. }\end{array}$ & & & & & & \\
\hline $\begin{array}{l}\text { D.5.8 } \\
\end{array}$ & $\begin{array}{l}\text { The relative wind speed presented helps } \\
\text { with the GO /NO-GO decision. (4.3.3) }\end{array}$ & & & & & & \\
\hline D.5.9 & $\begin{array}{l}\text { The relative wind direction helps with the } \\
\text { GO / NO-GO decision. (3.3.3) }\end{array}$ & & & & & & \\
\hline
\end{tabular}


Turbulence Visualization Evaluation

\section{D.6. Design B2}

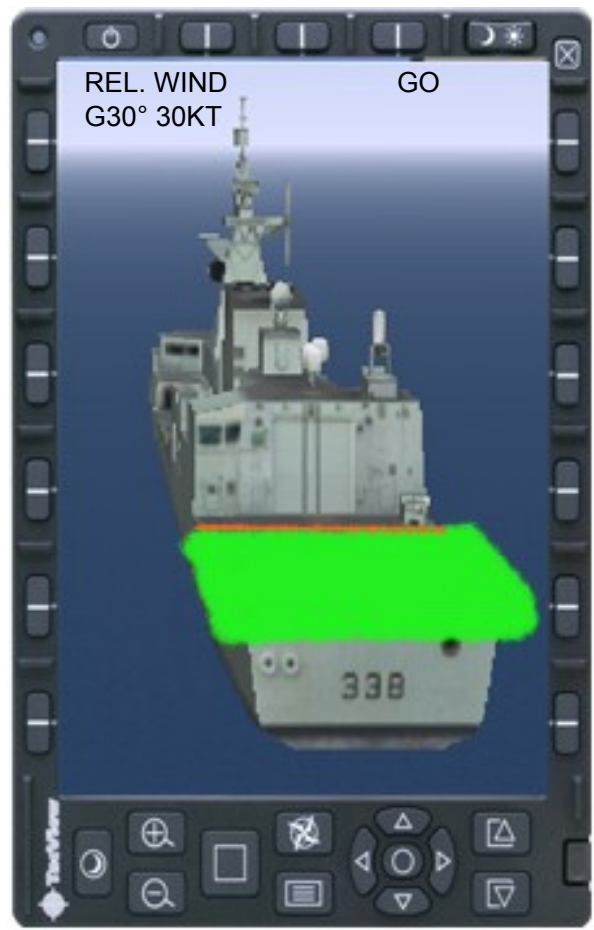

Figure D-6: Design B2

\begin{tabular}{|c|c|c|c|c|c|c|c|}
\hline \multicolumn{8}{|c|}{ Design B2 } \\
\hline & Statement & Strongly & Disagree & Border & Agree & Strongly & Comment \\
\hline D.6.1 & $\begin{array}{l}\text { It is clear that the green mass overlay } \\
\text { represents non-turbulent airflow. (3.2.1, } \\
3.2 .2)\end{array}$ & & & & & & \\
\hline D.6.2 & $\begin{array}{l}\text { It is clear that airflow over deck is within } \\
\text { helicopter/ship operating limits. }\end{array}$ & & & & & & \\
\hline $\begin{array}{l}\text { D.6.3 } \\
\end{array}$ & $\begin{array}{l}\text { It is clear that there is NO hazardous } \\
\text { airflow detected. (3.2.1 and 3.3.1) }\end{array}$ & & & & & & \\
\hline D.6.4 & $\begin{array}{l}\text { It is clear that the non-turbulent airflow } \\
\text { extends beyond the deck surface. }(4.2 .1 \\
\text { and 4.3.1) }\end{array}$ & & & & & & \\
\hline D.6.5 & $\begin{array}{l}\text { The green mass is a good representation } \\
\text { of non-turbulent airflow. }(4.2 .1,4.2 .2)\end{array}$ & & & & & & \\
\hline D.6.6 & $\begin{array}{l}\text { Knowledge of non-turbulent airflow will } \\
\text { aid in the landing. }\end{array}$ & & & & & & \\
\hline $\begin{array}{l}\text { D.6.7 } \\
\end{array}$ & $\begin{array}{l}\text { I have a clear graphical indication of to } \\
\text { proceed with the approach. }(4.2 .3)\end{array}$ & & & & & & \\
\hline \begin{tabular}{|l|} 
D.6.8 \\
\end{tabular} & $\begin{array}{l}\text { It is clear that the GO presented indicates } \\
\text { to proceed with approach. }\end{array}$ & & & & & & \\
\hline
\end{tabular}


Turbulence Visualization Evaluation

D.7. Design C (Red velocity vectors indicating hazardous airflow area and direction)

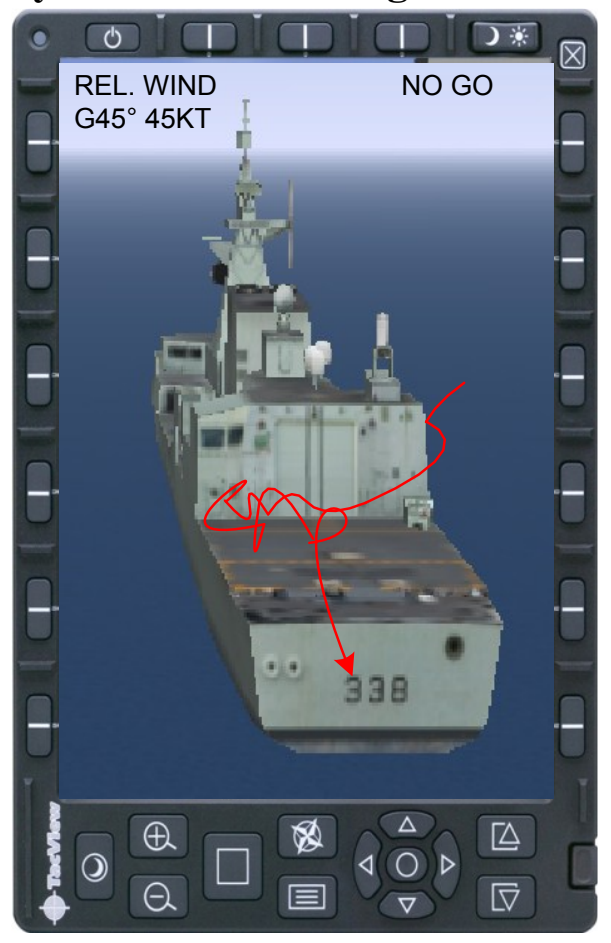

Figure D-7: Design C

\begin{tabular}{|c|c|c|c|c|c|c|c|}
\hline \multicolumn{8}{|c|}{ Design $\mathrm{C}$} \\
\hline & Statement & $\begin{array}{l}\text { Strongly } \\
\text { Disagree }\end{array}$ & Disagree & $\begin{array}{l}\text { Border } \\
\text {-line }\end{array}$ & Agree & $\begin{array}{l}\text { Strongly } \\
\text { Agree }\end{array}$ & Comment \\
\hline D.7.1 & $\begin{array}{l}\text { The red arrows are a good representation } \\
\text { of hazardous airflow. }(4.2 .1,4.2 .2)\end{array}$ & & & & & & \\
\hline D.7.2 & $\begin{array}{l}\text { It is clear where the hazardous airflow is } \\
\text { located. }(4.2 .1 \text { and } 4.3 .1)\end{array}$ & & & & & & \\
\hline $\begin{array}{l}\text { D.7.3 } \\
\end{array}$ & $\begin{array}{l}\text { It is clear that the red arrow is based on the } \\
\text { relative wind parameters displayed. } \\
(4.2 .1)\end{array}$ & & & & & & \\
\hline D.7.4 & $\begin{array}{l}\text { I have a clear graphical indication of NOT } \\
\text { to proceed with the approach. }(4.2 .3)\end{array}$ & & & & & & \\
\hline D.7.5 & $\begin{array}{l}\text { It is clear where there is NO hazardous } \\
\text { airflow. }\end{array}$ & & & & & & \\
\hline D.7.6 & $\begin{array}{l}\text { The relative wind speed presented helps } \\
\text { with the GO /NO-GO decision. (4.3.3) }\end{array}$ & & & & & & \\
\hline D.7.7 & $\begin{array}{l}\text { The relative wind direction helps with the } \\
\text { GO / NO-GO decision. (3.3.3) }\end{array}$ & & & & & & \\
\hline D.7.8 & $\begin{array}{l}\text { It is clear the direction of the relative wind } \\
\text { is indicated by the fletching end of the } \\
\text { arrow. }\end{array}$ & & & & & & \\
\hline $\begin{array}{l}\text { D.7.9 } \\
\end{array}$ & $\begin{array}{l}\text { The NO-GO presented indicates not to } \\
\text { proceed with approach. }\end{array}$ & & & & & & \\
\hline$\overline{D .7 .10}$ & $\begin{array}{l}\text { I do NOT need the ship identifier } \\
\text { displayed on this screen. }\end{array}$ & & & & & & \\
\hline D.7.11 & $\begin{array}{l}\text { I do NOT need the aircraft identifier } \\
\text { displayed on this screen. }\end{array}$ & & & & & & \\
\hline
\end{tabular}


Turbulence Visualization Evaluation

\section{D.8. Design C1 (Velocity vectors of airflow over simplified oil rig)}

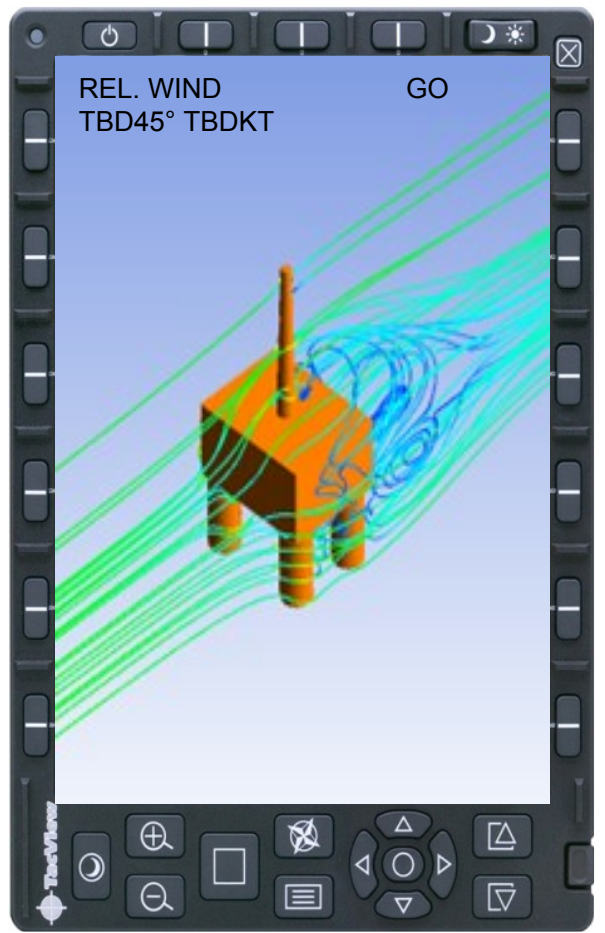

Figure D-8: Design C1

\begin{tabular}{|c|c|c|c|c|c|c|c|}
\hline \multicolumn{8}{|c|}{ Design C1 } \\
\hline & Statement & $\begin{array}{l}\text { Strongly } \\
\text { Disagree }\end{array}$ & Disagree & $\begin{array}{l}\text { Border } \\
\text {-line }\end{array}$ & Agree & $\begin{array}{l}\text { Strongly } \\
\text { Agree }\end{array}$ & Comment \\
\hline D.8.1 & $\begin{array}{l}\text { It is clear that the lines shown represent } \\
\text { the airflow. }(4.2 .1,4.2 .2)\end{array}$ & & & & & & \\
\hline D.8.2 & $\begin{array}{l}\text { I can identify where the areas of } \\
\text { hazardous airflow is. }(4.2 .1 \text { and } 4.3 .1)\end{array}$ & & & & & & \\
\hline D.8.3 & $\begin{array}{l}\text { I can identify where the areas of non- } \\
\text { turbulent airflow is. }\end{array}$ & & & & & & \\
\hline D.8.4 & $\begin{array}{l}\text { The visual representation of the airflow } \\
\text { shown will aid in the landing. }\end{array}$ & & & & & & \\
\hline D.8.5 & $\begin{array}{l}\text { It is clear that the green in the flow lines } \\
\text { indicates the flow is non-turbulent. }\end{array}$ & & & & & & \\
\hline D.8.6 & $\begin{array}{l}\text { It is clear that the blue in the flow lines } \\
\text { indicates the flow is non-turbulent. }\end{array}$ & & & & & & \\
\hline D.8.7 & $\begin{array}{l}\text { It is clear the colour of the indicator } \\
\text { shows the intensity of the airflow. }\end{array}$ & & & & & & \\
\hline D.8.8 & $\begin{array}{l}\text { It is clear graphically of the areas to } \\
\text { avoid. }\end{array}$ & & & & & & \\
\hline D.8.9 & $\begin{array}{l}\text { Knowledge of the turbulent areas over the } \\
\text { landing surface will aid in the landing. }\end{array}$ & & & & & & \\
\hline
\end{tabular}


Turbulence Visualization Evaluation

\section{D.9. Design C2}

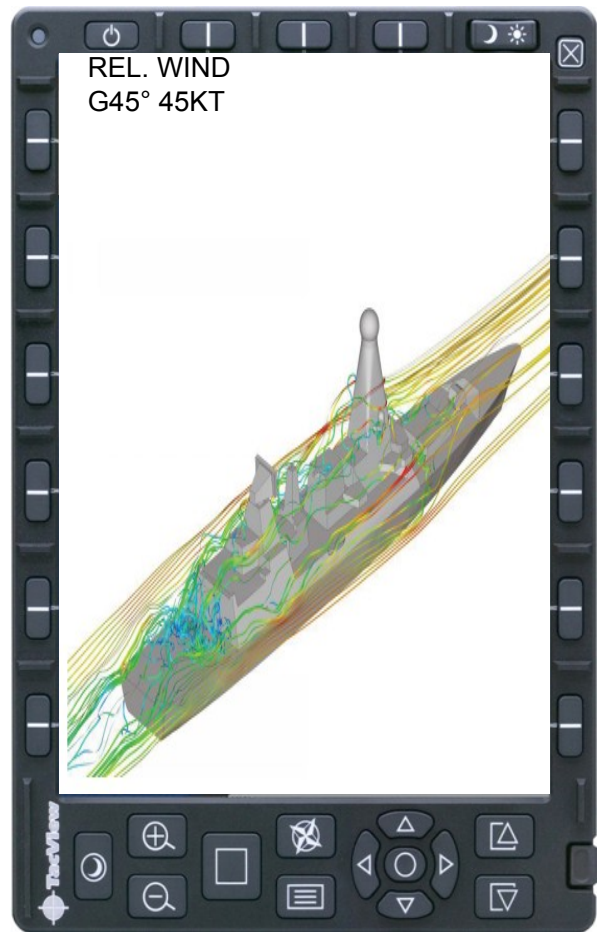

Figure D-9: Design C2

\begin{tabular}{|c|c|c|c|c|c|c|c|}
\hline \multicolumn{8}{|c|}{ Design C2 } \\
\hline & Statement & Strongly & Disagree & Border & Agree & Strongly & Comment \\
\hline D.9.1 & $\begin{array}{l}\text { It is clear that the lines shown represent } \\
\text { the airflow. }(4.2 .1,4.2 .2)\end{array}$ & & & & & & \\
\hline D.9.2 & $\begin{array}{l}\text { I can identify where the areas of } \\
\text { hazardous airflow is. }(4.2 .1 \text { and } 4.3 .1)\end{array}$ & & & & & & \\
\hline D.9.3 & $\begin{array}{l}\text { I can identify where the areas of non- } \\
\text { turbulent airflow is. }\end{array}$ & & & & & & \\
\hline D.9.4 & $\begin{array}{l}\text { The visual representation of the airflow } \\
\text { shown will aid in the landing. }\end{array}$ & & & & & & \\
\hline D.9.5 & $\begin{array}{l}\text { It is clear that the green in the flow lines } \\
\text { indicates the flow is non-turbulent. }\end{array}$ & & & & & & \\
\hline D.9.6 & $\begin{array}{l}\text { It is clear that the blue in the flow lines } \\
\text { indicates the flow is non-turbulent. }\end{array}$ & & & & & & \\
\hline D.9.7 & $\begin{array}{l}\text { It is clear the colour of the indicator } \\
\text { shows the intensity of the airflow. }\end{array}$ & & & & & & \\
\hline D.9.8 & $\begin{array}{l}\text { It is clear graphically of the areas to } \\
\text { avoid. }\end{array}$ & & & & & & \\
\hline D.9.9 & $\begin{array}{l}\text { Knowledge of the turbulent areas over the } \\
\text { landing surface will aid in the landing. }\end{array}$ & & & & & & \\
\hline
\end{tabular}


Turbulence Visualization Evaluation

\section{D.10. Design C3}

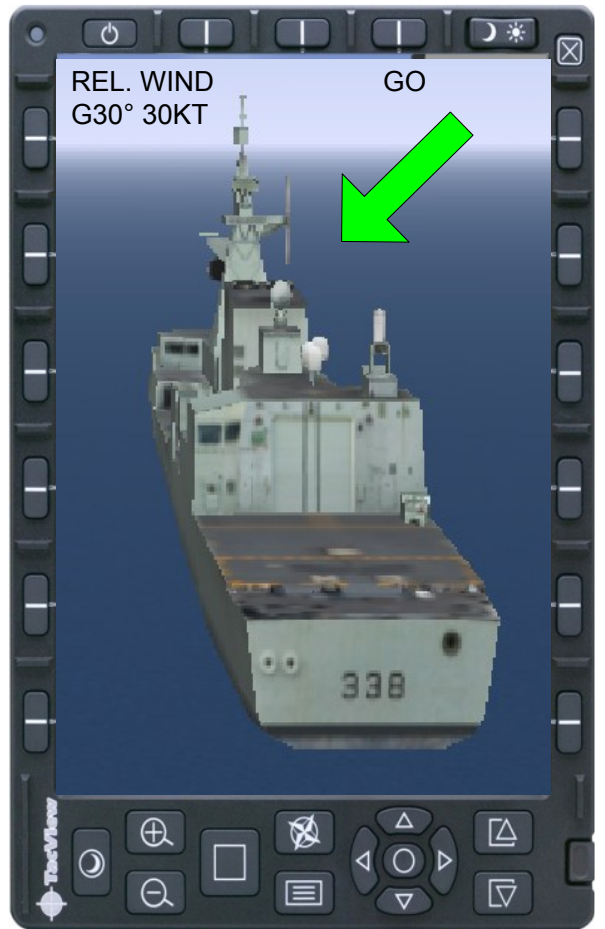

Figure D-10: Design C3

\begin{tabular}{|c|c|c|c|c|c|c|c|}
\hline \multicolumn{8}{|c|}{ Design C3 } \\
\hline & Statement & Strongly & Disagree & Border & Agree & Strongly & Comment \\
\hline D.10.1 & $\begin{array}{l}\text { It is clear graphically that airflow is } \\
\text { within helicopter to ship operating limits. } \\
(3.2 .1,3.2 .2)\end{array}$ & & & & & & \\
\hline D.10.2 & $\begin{array}{l}\text { It is clear that there is NO hazardous } \\
\text { airflow detected over the ship deck. (3.2.1 } \\
\text { and 3.3.1) }\end{array}$ & & & & & & \\
\hline D. 10.3 & $\begin{array}{l}\text { It is clear, the green arrow indicates the } \\
\text { direction of the relative wind. }(3.2 .2)\end{array}$ & & & & & & \\
\hline D.10.4 & $\begin{array}{l}\text { It is clear, the green arrow indicates the } \\
\text { relative wind is within operating limits. }\end{array}$ & & & & & & \\
\hline
\end{tabular}


Turbulence Visualization Evaluation

\section{D.11. Design D (Other e.g. Hazard Types)}

\begin{tabular}{|c|c|c|c|c|c|c|c|}
\hline \multicolumn{8}{|c|}{ Design D } \\
\hline & Statement & $\begin{array}{l}\text { Strongly } \\
\text { Disagree }\end{array}$ & Disagree & $\begin{array}{l}\text { Border } \\
\text {-line }\end{array}$ & Agree & $\begin{array}{l}\text { Strongly } \\
\text { Agree }\end{array}$ & Comment \\
\hline D.11.1 & $\begin{array}{l}\text { Knowledge of the airflow hazard type } \\
\text { (e.g. vortices, wind shear, downdraft or } \\
\text { turbulence) will NOT aid in the landing. } \\
\text { (Qualitative). }\end{array}$ & & & & & & \\
\hline D.11.2 & $\begin{array}{l}\text { Knowledge of airflow hazard intensity } \\
\text { (i.e. detailed greater than the warnings } \\
\text { (yellow) or danger (red)) will not aid in } \\
\text { the landing. (Quantitative). }\end{array}$ & & & & & & \\
\hline D.11.3 & $\begin{array}{l}\text { I like the airflow hazards displayed as } \\
\text { static indicators. }\end{array}$ & & & & & & \\
\hline D.11.4 & $\begin{array}{l}\text { I am interested in learning more about the } \\
\text { airflow hazards presented as dynamic } \\
\text { indicators. }\end{array}$ & & & & & & \\
\hline
\end{tabular}




\section{E. Part IV - Perspective}

On the following pages you will be presented with two (2) different perspectives for viewing the ship's landing area. The first one is the ship as seen from the pilot flying cockpit window. The intent is to have a dynamic scene as the distance between the ship and helicopter decreases, up to the delta hover position. The second perspective is a static view of the landing area of the flight deck.

Please rate your level of agreement with all of the statements related to both perspectives. If you respond with Strongly Disagree or Disagree to any of the statements, please provide the reason in the appropriate comment section. 
Turbulence Visualization Evaluation

\section{E.1. Virtual E1}

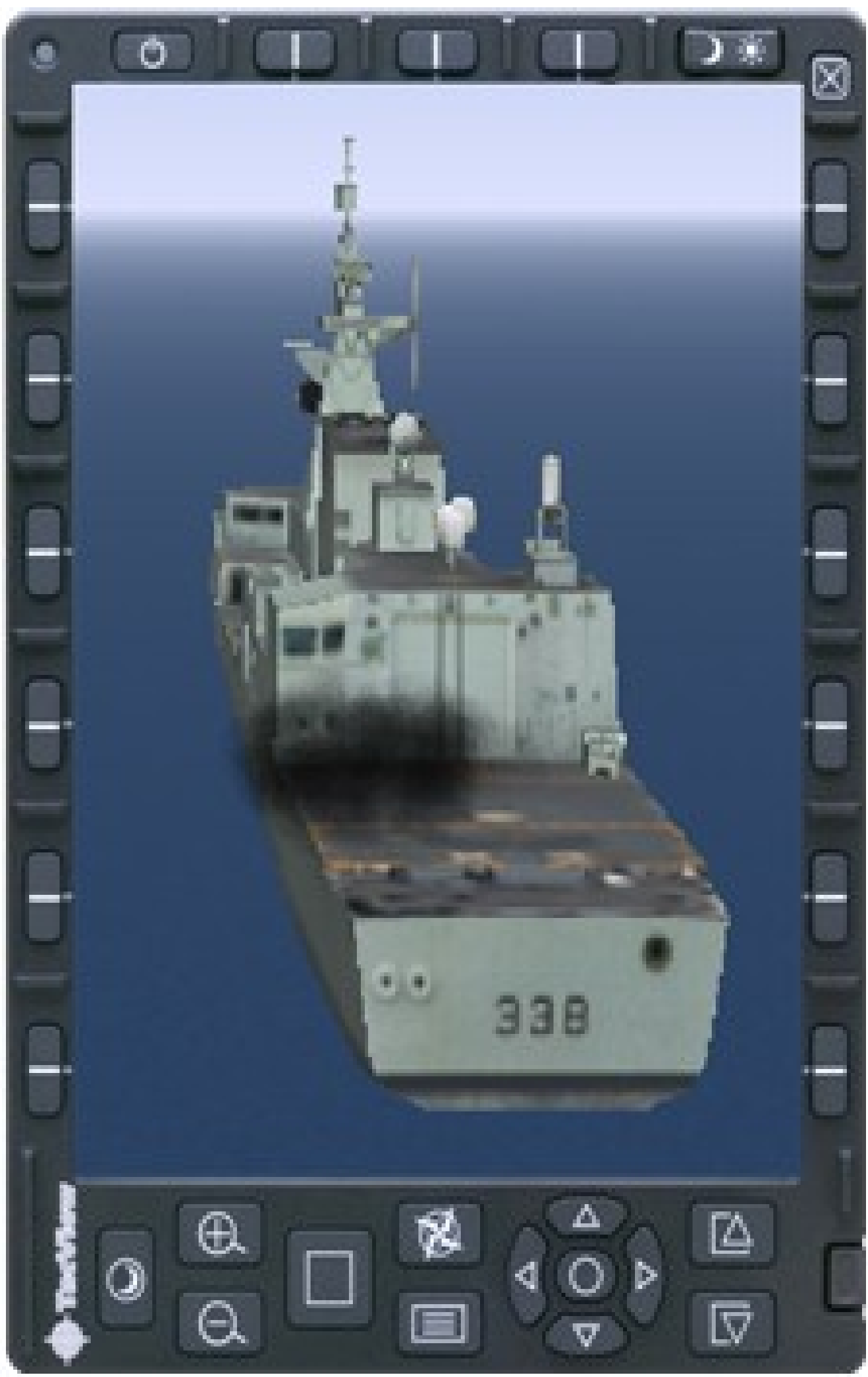

Figure E-1: Design E1 (actual size) 


\section{Turbulence Visualization Evaluation}

\begin{tabular}{|c|c|c|c|c|c|c|c|}
\hline \multicolumn{8}{|c|}{ Design E1 } \\
\hline & Statement & Strongly & Disagree & Border & Agree & Strongly & Comment \\
\hline E.1.1 & $\begin{array}{l}\text { I like the view of the ship from the delta } \\
\text { hover perspective. }\end{array}$ & & & & & & \\
\hline E.1.2 & $\begin{array}{l}\text { I like the view of the ship from the } \\
\text { operator flying seat. }\end{array}$ & & & & & & \\
\hline E.1.3 & $\begin{array}{l}\text { The size of the ship in the display is the } \\
\text { correct size. }\end{array}$ & & & & & & \\
\hline E.1.4 & $\begin{array}{l}\text { I can identify areas of turbulent airflow } \\
\text { on the ships landing surface. }\end{array}$ & & & & & & \\
\hline E.1.5 & $\begin{array}{l}\text { I can identify non-turbulent airflow areas } \\
\text { on the ships landing area. }\end{array}$ & & & & & & \\
\hline E.1.6 & $\begin{array}{l}\text { Knowledge of the areas of turbulent } \\
\text { airflow over the deck will aid in the } \\
\text { landing. }\end{array}$ & & & & & & \\
\hline E.1.7 & $\begin{array}{l}\text { I would like to see more of the scene in } \\
\text { the display. }\end{array}$ & & & & & & \\
\hline E.1.8 & $\begin{array}{l}\text { Knowledge of airflow turbulence from } \\
\text { ships and other aircraft in the scene will } \\
\text { aid in the landing. }\end{array}$ & & & & & & \\
\hline E.1.9 & $\begin{array}{l}\text { I would like to be able to rotate the ship } \\
\text { to view the airflow turbulence. }\end{array}$ & & & & & & \\
\hline E.1.10 & $\begin{array}{l}\text { Knowledge of the airflow turbulence } \\
\text { surrounding the whole ship will aid in the } \\
\text { landing. }\end{array}$ & & & & & & \\
\hline
\end{tabular}


Turbulence Visualization Evaluation

\section{E.2. Deck View E2}

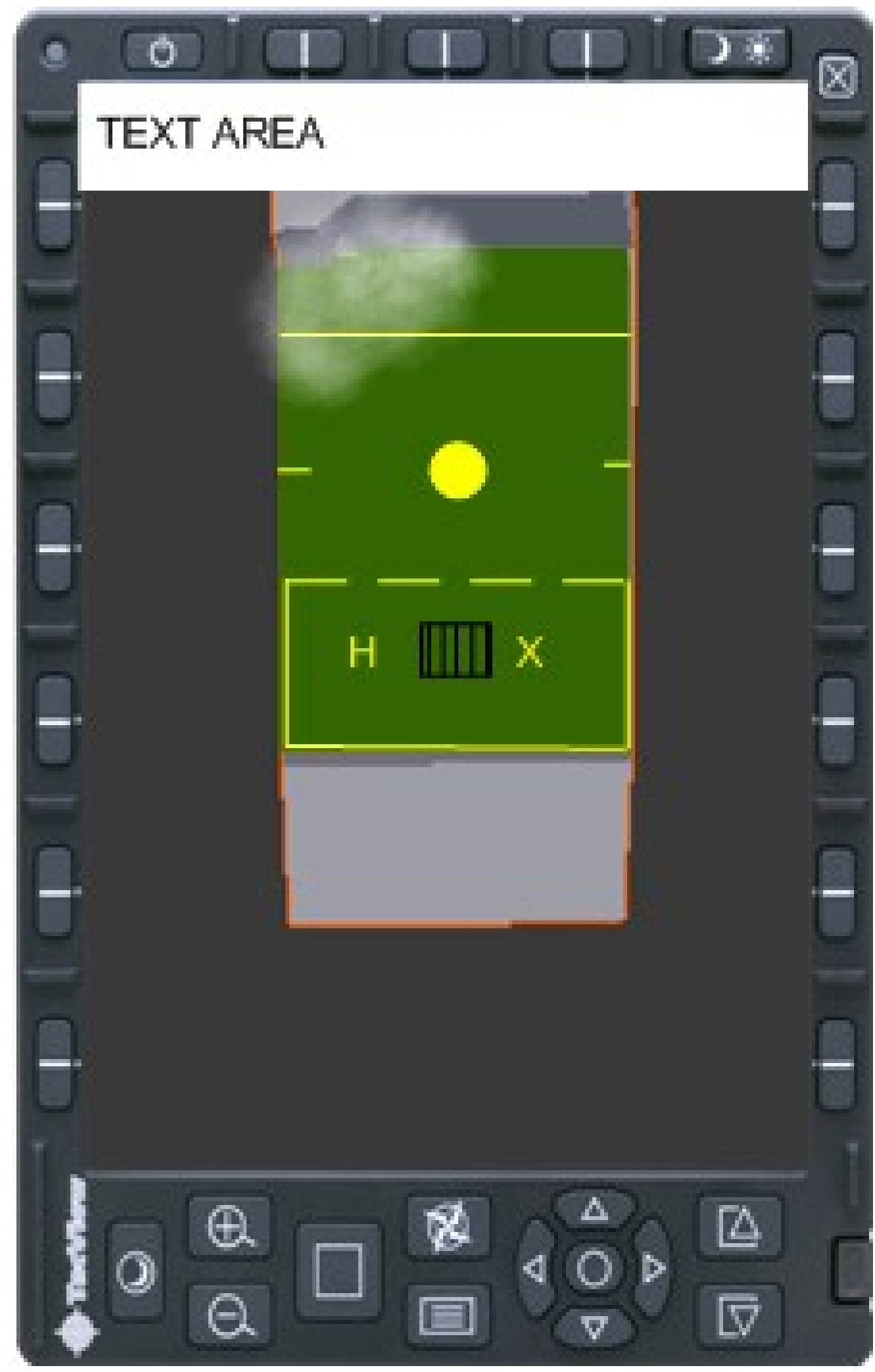

Figure E-2: Design E2 (actual size) 
Turbulence Visualization Evaluation

\begin{tabular}{|c|c|c|c|c|c|c|c|}
\hline \multicolumn{8}{|c|}{ Perspective E2 } \\
\hline & Statement & Strongly & Disagree & Border & Agree & Strongly & Comment \\
\hline E.2.1 & $\begin{array}{l}\text { It is clear that the display shows the landing } \\
\text { area of the ship. }\end{array}$ & & & & & & \\
\hline E.2.2 & $\begin{array}{l}\text { It is clear that the landing area of the ship } \\
\text { shown is the top view. }\end{array}$ & & & & & & \\
\hline E.2.3 & $\begin{array}{l}\text { I can identify the area of turbulent airflow } \\
\text { on the ships landing surface. }\end{array}$ & & & & & & \\
\hline E.2.4 & $\begin{array}{l}\text { I can identify non-turbulent airflow areas } \\
\text { on the ships landing area. }\end{array}$ & & & & & & \\
\hline E.2.5 & $\begin{array}{l}\text { Knowledge of the areas of turbulent airflow } \\
\text { over the deck will aid in the landing. }\end{array}$ & & & & & & \\
\hline E.2.6 & $\begin{array}{l}\text { I would like to see more of the scene in the } \\
\text { display. }\end{array}$ & & & & & & \\
\hline E.2.7 & $\begin{array}{l}\text { Knowledge of airflow turbulence from } \\
\text { other ship and aircraft airwakes in the scene } \\
\text { will aid in the landing. }\end{array}$ & & & & & & \\
\hline
\end{tabular}


Turbulence Visualization Evaluation

\section{F. Part V - General}

1. In comparison of all the graphical designs presented displaying turbulent airflow, which design do you prefer? State why.

2. One technology was presented, Computational Fluid Dynamics. Enhanced Vision System (EVS) is being explored as an alternative solution. Do you have a preference for one technology over the other? State why.

3. There are different causes of airflow turbulence with different results. The ones causing concern for helicopter to ship operations are primarily microbursts, downdrafts, vortices and the airflow turbulence as a result of structures and vegetation. Would differentiating between the different types assist in assessing airflow turbulence over the ship's flight deck? State why.

4. If a published (e.g. SHOPS) wind envelope was not available (e.g. foreign ship, offshore Civilian operations, landing behind a hangar ashore in strong winds, etc.) could such a display assist in assessing airflow turbulence over and around obstacles? Please include in your response why. 


\section{Turbulence Visualization Evaluation}

5. Please provide any other comments that are relevant to the designs.

6. Did anything get missed? 


\section{G. Part VI - Art Critics}

Although the design has not been finalized, we do love the art critic in everyone. Please provide any cosmetic comments or preferences in this section. All comments on choice of colour, line thickness etc. are welcome here.

We would also like to hear from you on any comments or questions that you may have in this area as well. For example, ...

\section{Comments}

The density of the swirls showing the turbulent areas in figure TBD is too dense and becomes distracting. The colour for design B is extremely loud and is distracting for a high workload POF, pre-approach is fine.

\section{Questions}

How is the ship type selected?

I prefer the EVS technology, is there a way to incorporate the GO / NO-GO criteria into the image as an overlay?

What is the criteria to determine when turbulent airflow is outside operational limits? 

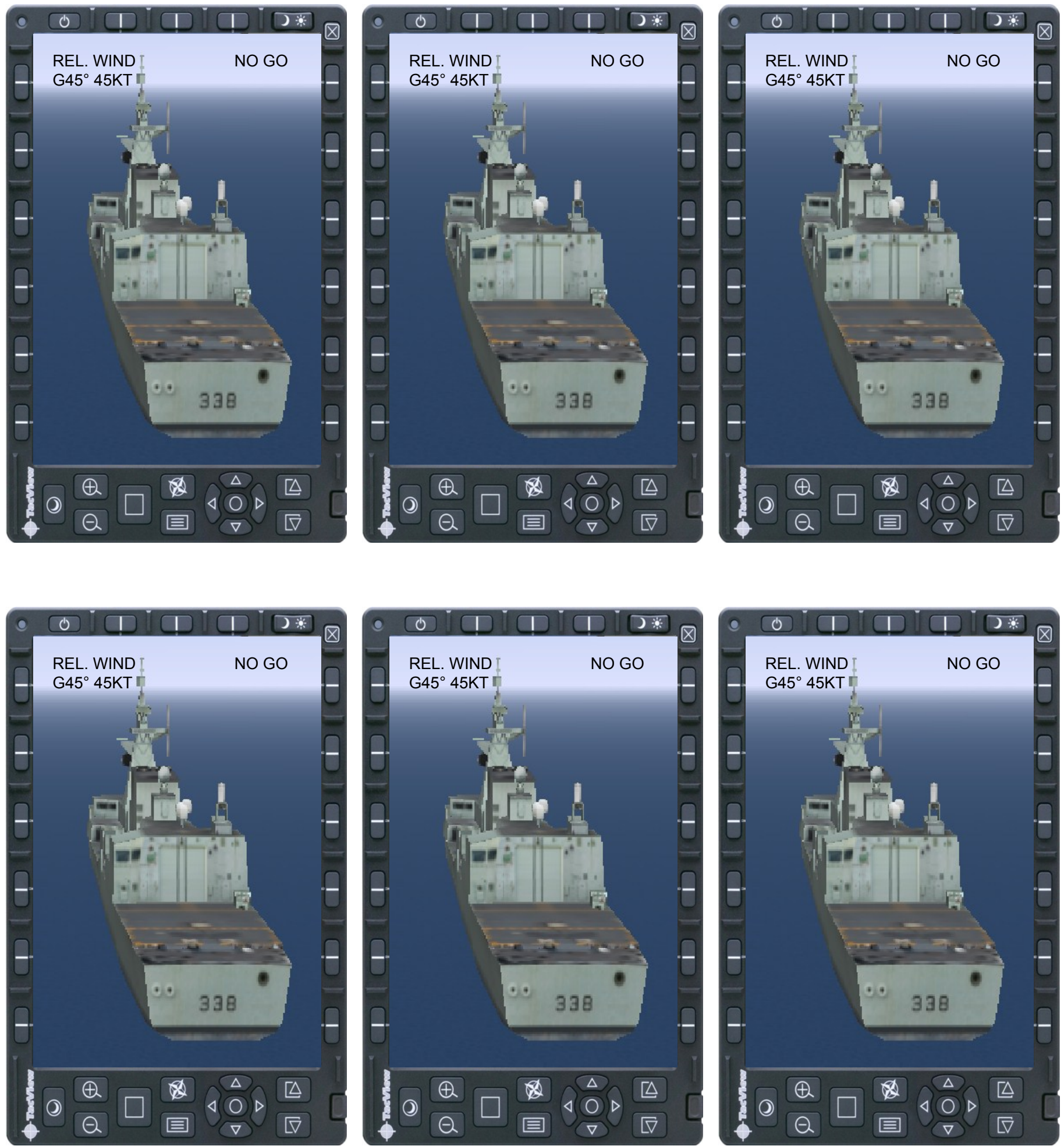
Appendix B - Ground School Flight Deck Turbulence Visualization

\author{
Ground School Presentation
}

Flight Deck Turbulence Visualization - Overview

\author{
For the
}

Design Principles and Usability Heuristics Evaluation for Defence

Industrial Research Program (DIRP) 


\section{Esterlinç}

\section{Flight Deck Turbulence Visualization - Overview}

Preliminary

- Week of March 2015

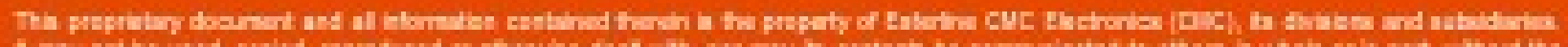

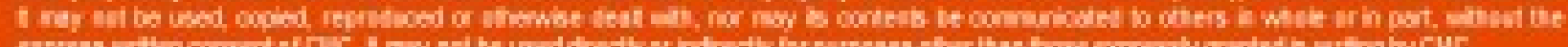

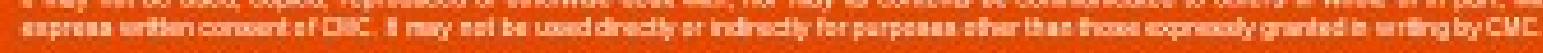




\section{Introduction}

The intent is to develop an airflow visualization for an operator to view prior to the approach POF:

- Current process;

- Resulting requirements;

- Proposed Designs; followed by

- Next steps. 


\section{Current Process}

Scope is limited to the Canadian helicopter to ship operating procedures:

- Relative wind (magnitude and azimuth) over flight path transmitted from ship to helicopter prior to approach POF;

- Shipborne Helicopter Operating Procedures (SHOPS) publication reviewed prior to approach POF;

- Landing area scanned for visual cues of air turbulence when within visual;

- Relative wind re-affirmed from ship to helicopter when paddles take over landing. 


\section{Resulting Requirements}

- Relative wind azimuth along flight path;

- Relative wind magnitude along flight path;

- True wind; and

- GO / NO-GO indication (SHOPS). 


\section{Proposed Designs}

The following is a brief outline of the following proposed turbulence visualization designs:

- Aragon variation;

- Rockwell Collins turbulence / Honeywell airwake visualization;

- Vector arrows;

- IR EVS. 
Esterline

Frigate

Halifax Class

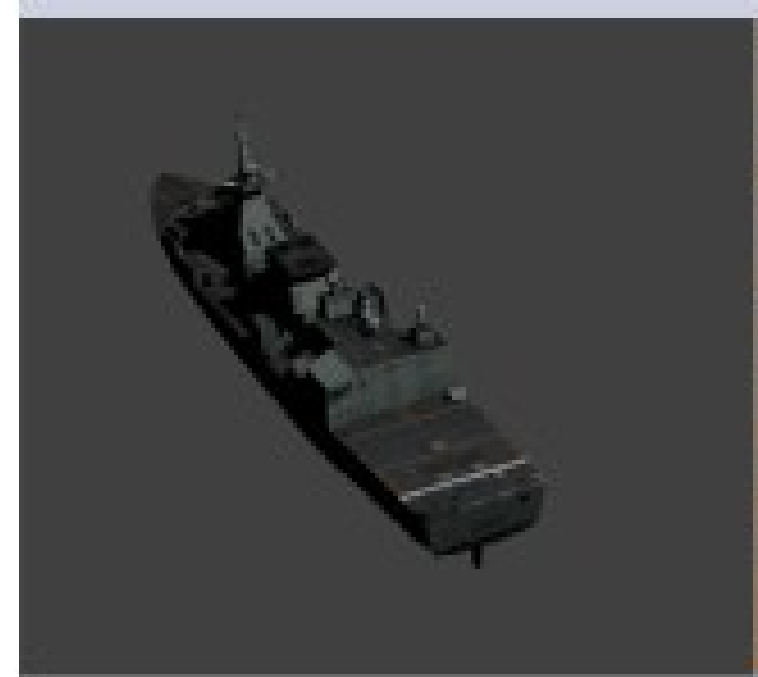

SFS2

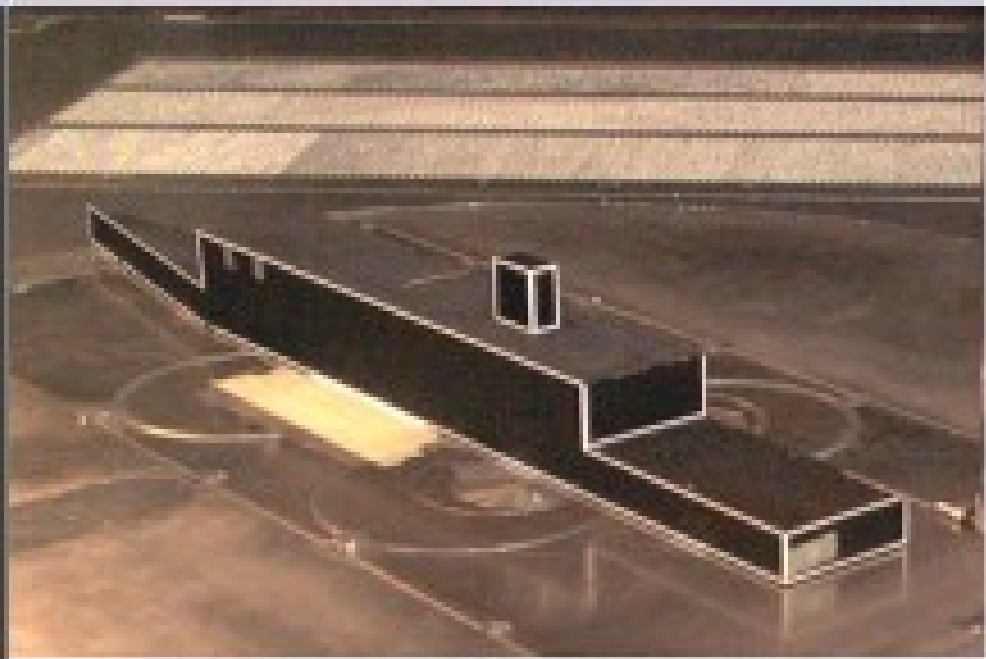




\section{Esterlined /CMC Electronics}

\section{Frigate}

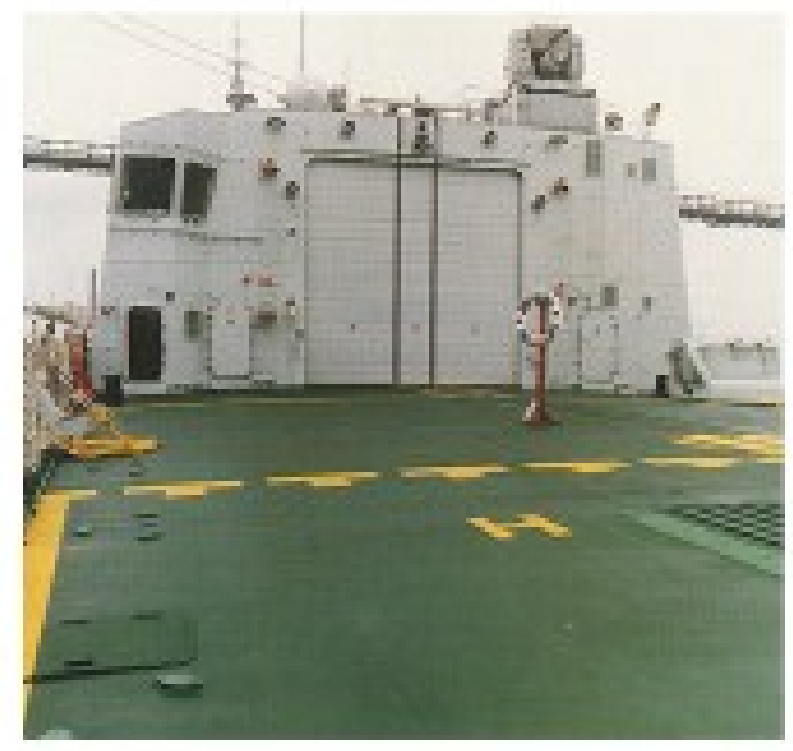

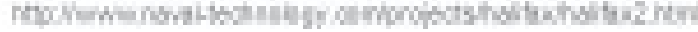

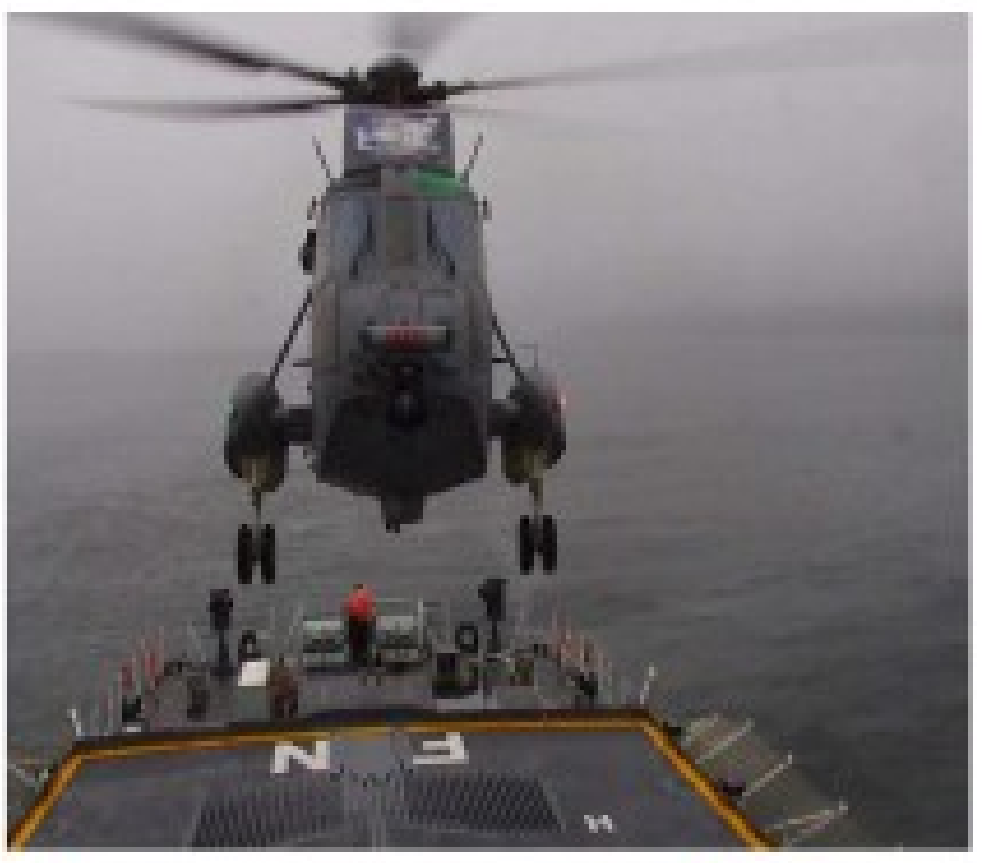

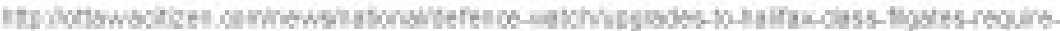

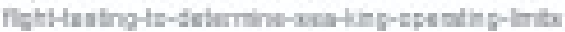




\section{Aragon}

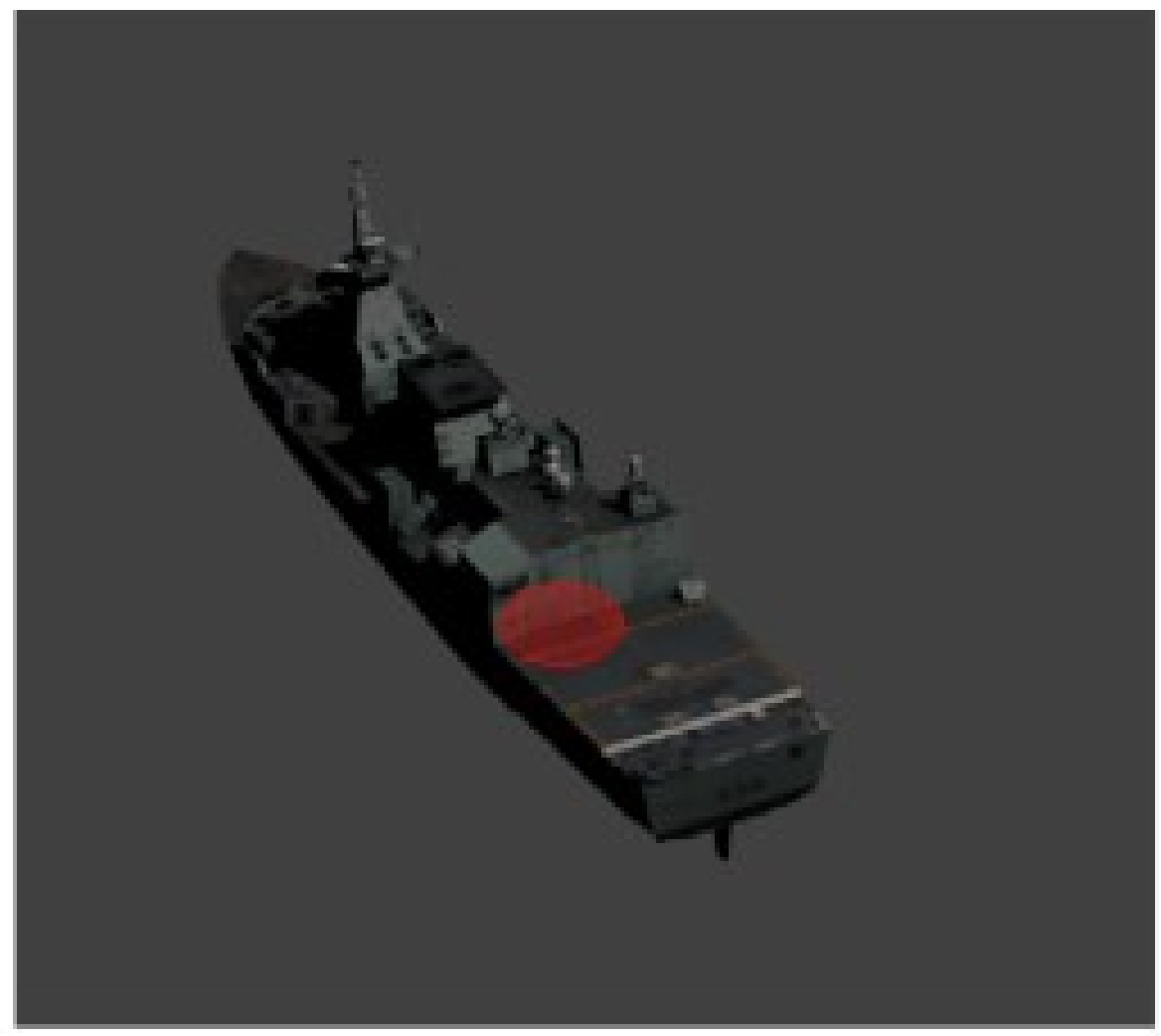




\section{Industry Direction}

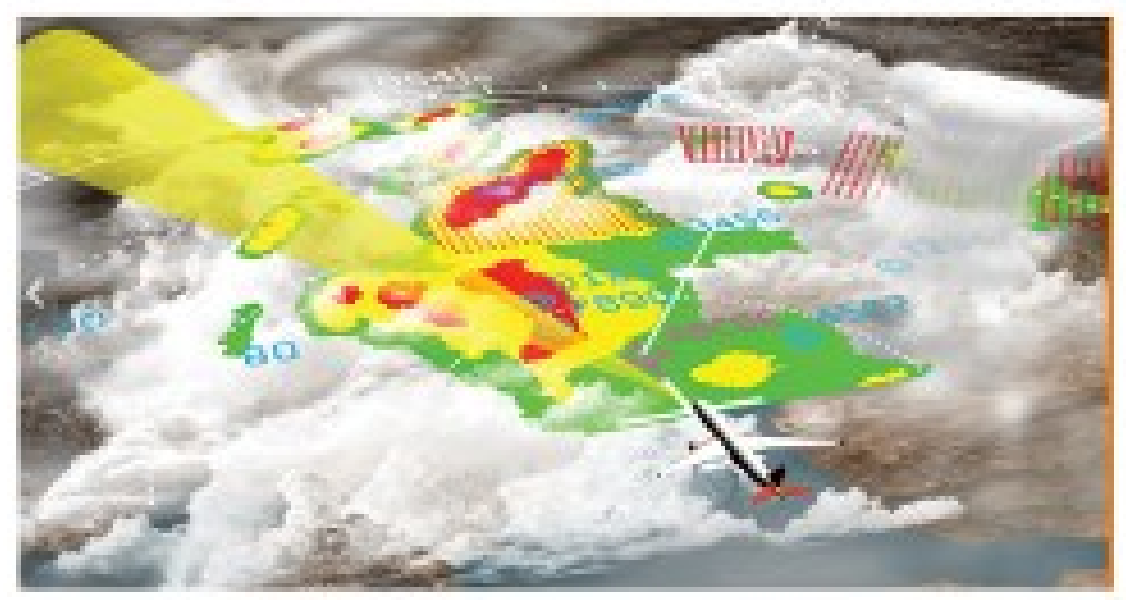

Rockwell Collins

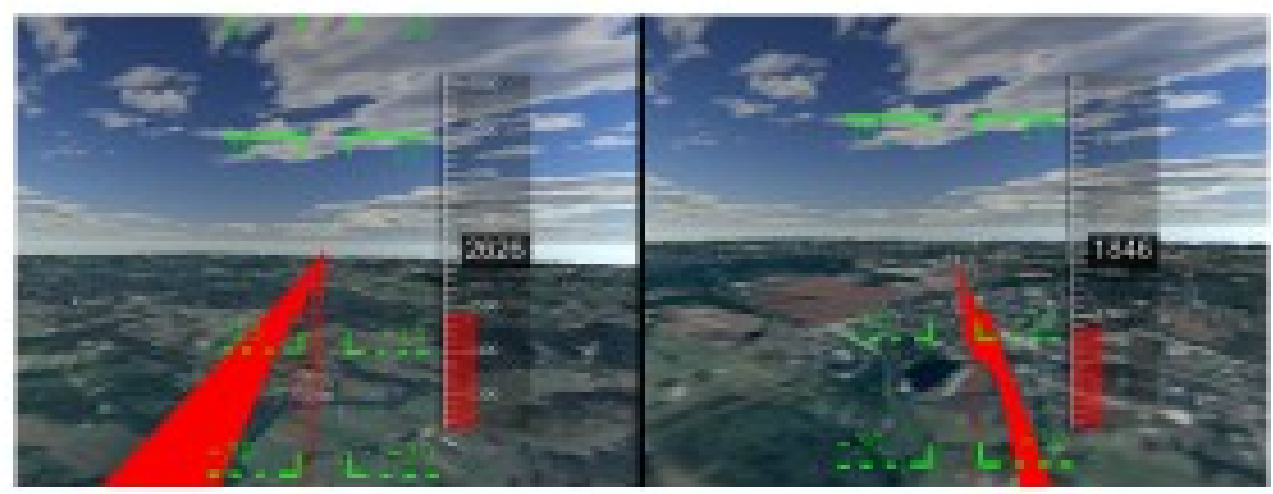

Honeywell 


\section{Velocity Vectors}
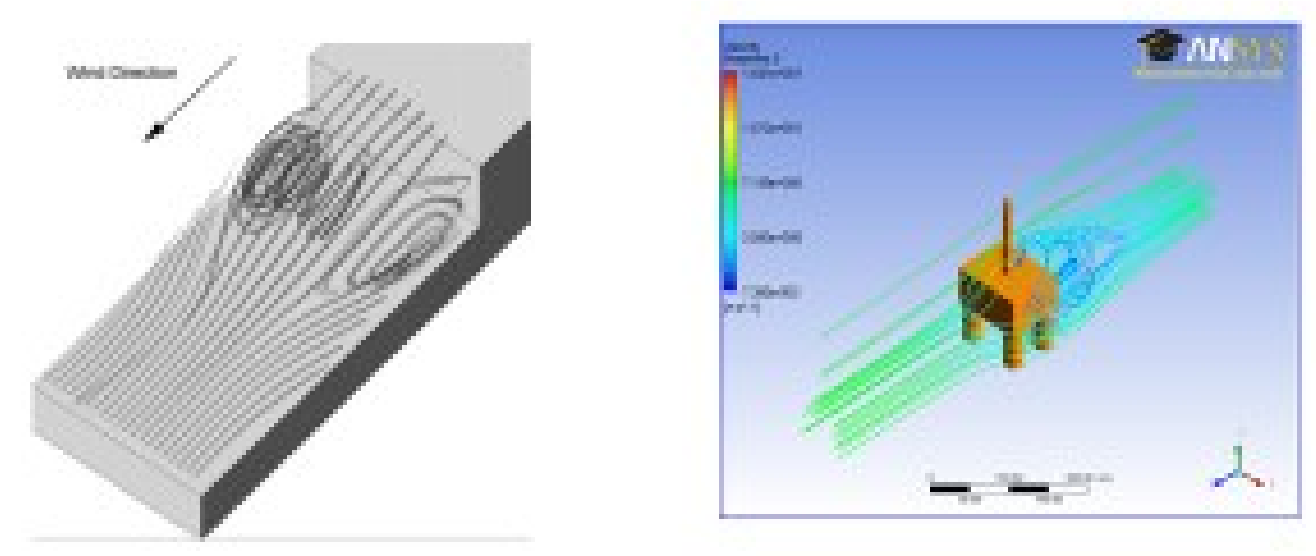


\section{EVS Imaging}

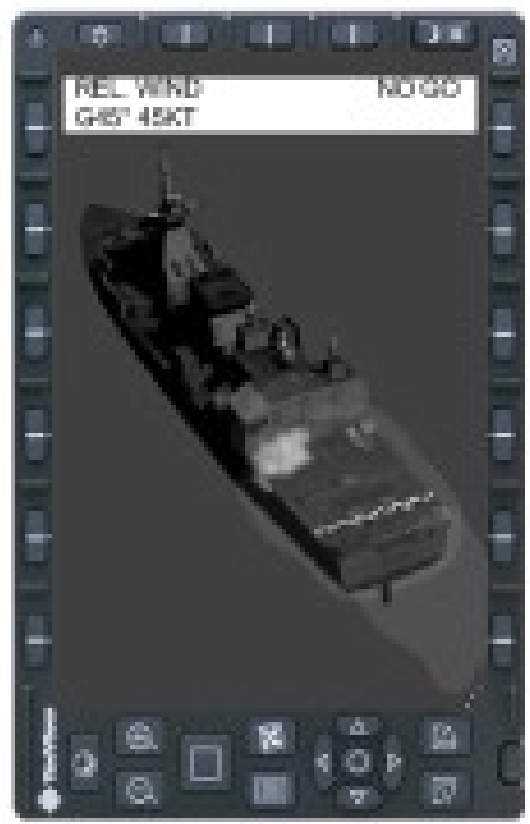




\section{Perspectives}
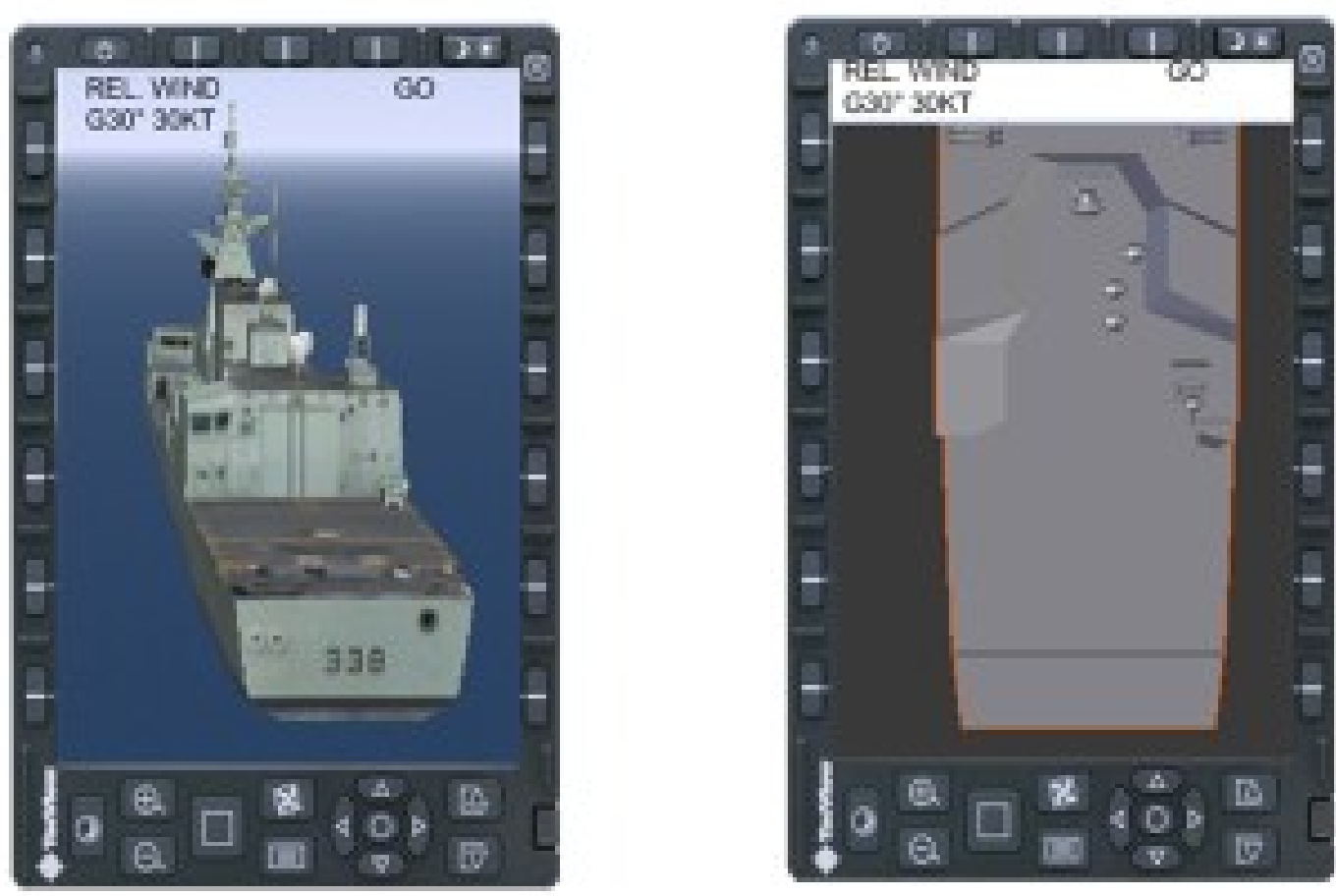


\section{Technology}

- CFD

- Massive computer power creates the complex visualization and the human cognitive limitations limit the timely comprehension to retrieve data.

- Fixed in that changes to configuration requires changes to the model

- Costly, requires modelling and simulation

- EVS

- Technically feasible although not significantly being investigated in industry.

- Costly (large NRE)

- Real time data

- Operator familliarity with EVS images 
Esterlined icMC Electronics

\section{Design Principles and Usability Heuristics}

\section{Evaluation}

- Design Principles

- Autonomy

- Consistency

- Explorable Interfaces

- Metaphors

- Usability Heuristics

- Consistency and Standards

- Recognition rather than recall

- Aesthetics and Minimalist Design

- Other

\section{- Confidence and Perceived Reliability}




\section{Next Steps}

- March 9, 2015 - Design Evaluation

- April/May - Testing (simulation) 


\section{Back-up Slides}




\section{Velocity Vectors - Design 3}
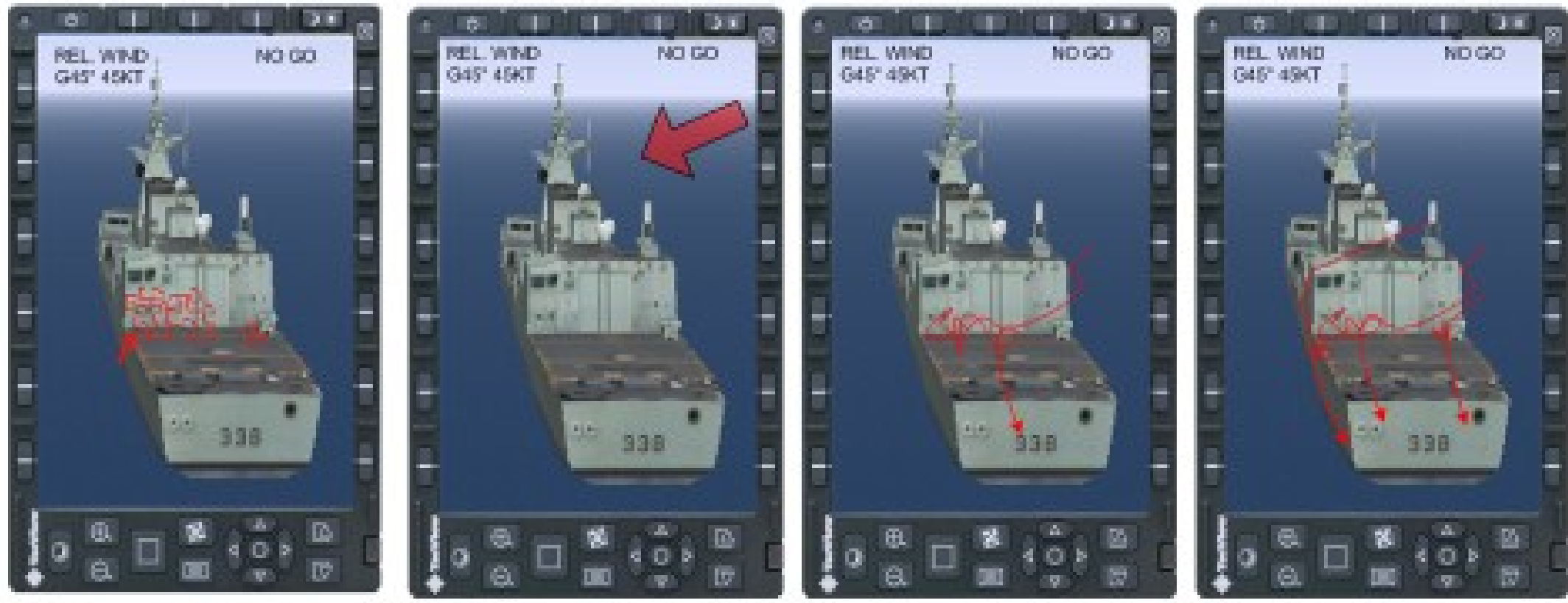


\section{Aragon - Design 1}
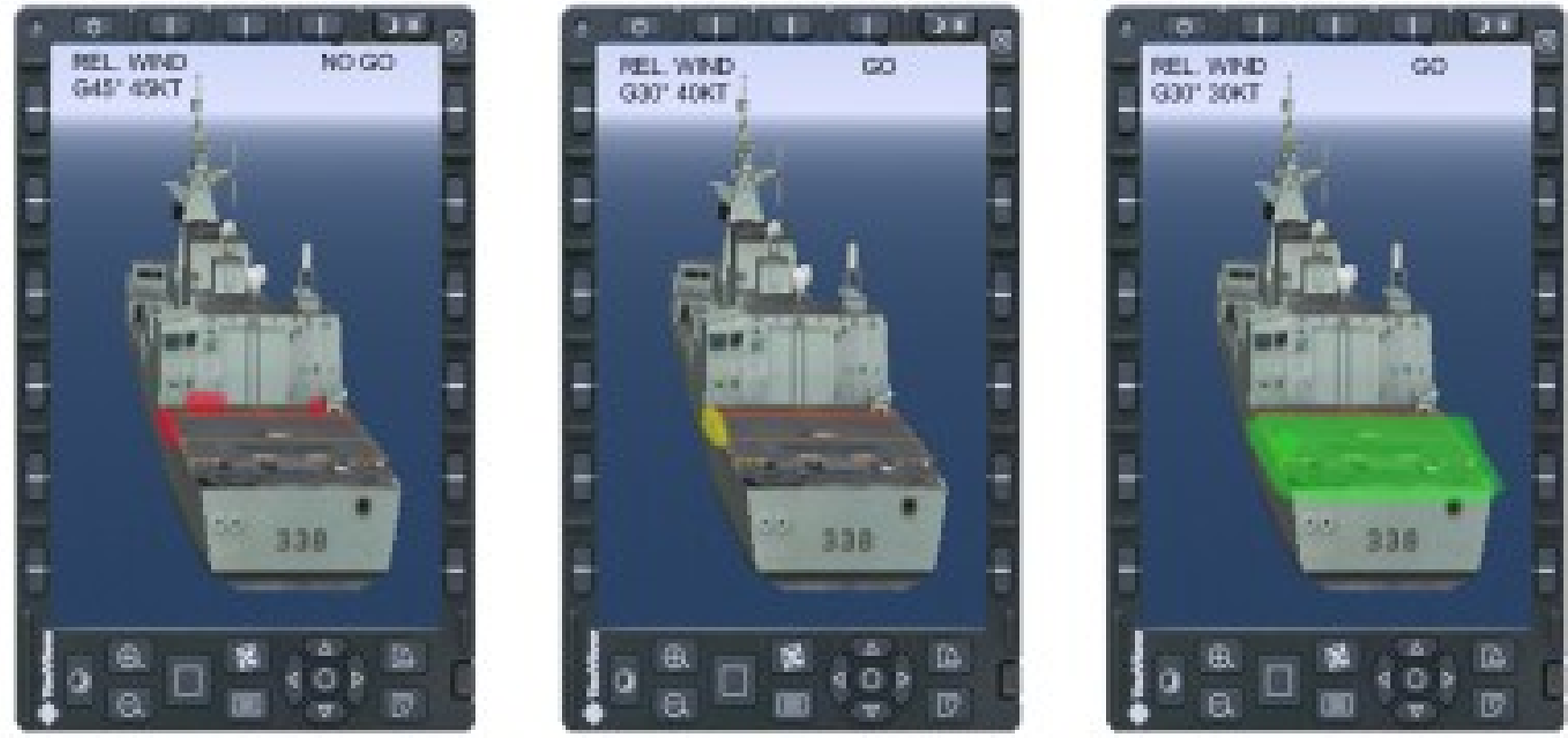
